Cochrane Database of Systematic Reviews

\title{
Antibiotics and antiseptics for surgical wounds healing by secondary intention (Review)
}

Norman G, Dumville JC, Mohapatra DP, Owens GL, Crosbie EJ

Norman G, Dumville JC, Mohapatra DP, Owens GL, Crosbie EJ.

Antibiotics and antiseptics for surgical wounds healing by secondary intention.

Cochrane Database of Systematic Reviews 2016, Issue 3. Art. No.: CD011712.

DOI: 10.1002/14651858.CD011712.pub2.

www.cochranelibrary.com 
TABLE OF CONTENTS

ABSTRACT

PLAIN LANGUAGE SUMMARY

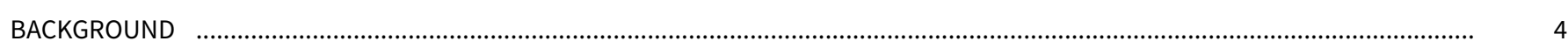

OBJECTIVES

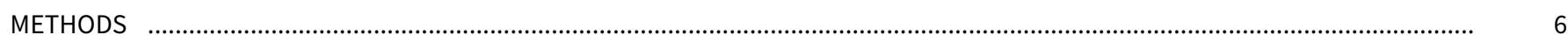

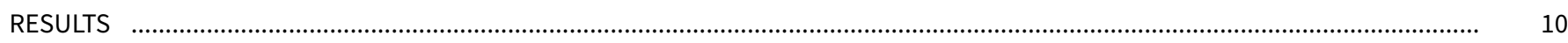

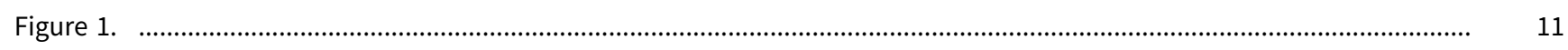

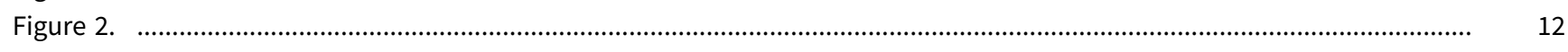

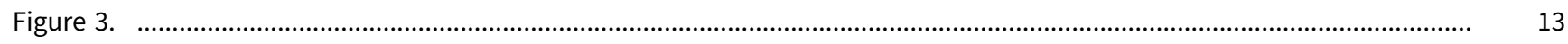

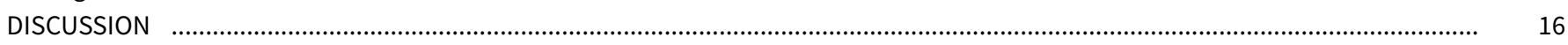

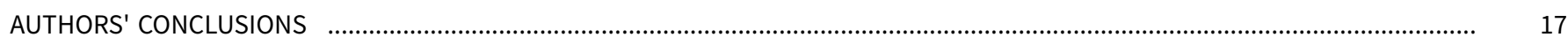

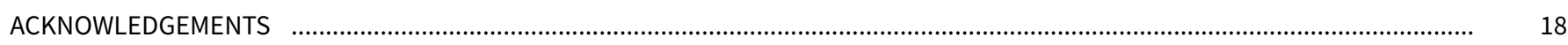

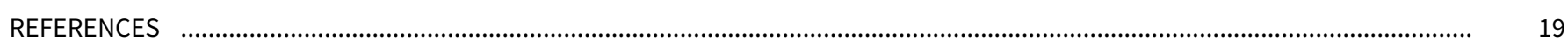

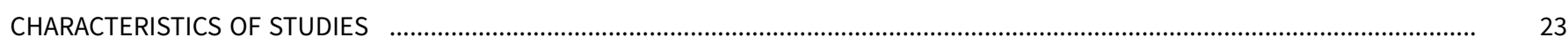

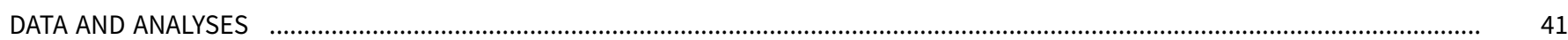

Analysis 1.1. Comparison 1: Polyvidone iodine-impregnated mesh compared with alginate mesh, Outcome 1: Proportion of 42 wounds healed

Analysis 1.2. Comparison 1: Polyvidone iodine-impregnated mesh compared with alginate mesh, Outcome 2: Wound infection

Analysis 1.3. Comparison 1: Polyvidone iodine-impregnated mesh compared with alginate mesh, Outcome 3: Mean number of dressing changes

Analysis 2.1. Comparison 2: Zinc oxide mesh compared with placebo, Outcome 1: Wound infection (based on presence of smell)

Analysis 2.2. Comparison 2: Zinc oxide mesh compared with placebo, Outcome 2: Participants prescribed antibiotics ............

Analysis 3.1. Comparison 3: Sucralfate compared with petrolatum, Outcome 1: Proportion of wounds healed ........................

Analysis 3.2. Comparison 3: Sucralfate compared with petrolatum, Outcome 2: Pain score (10-point VAS scale) .......................

Analysis 4.1. Comparison 4: Trimethoprim-sulfamethoxazole compared with placebo, Outcome 1: Adverse events (attributed to medication)

Analysis 4.2. Comparison 4: Trimethoprim-sulfamethoxazole compared with placebo, Outcome 2: Wound recurrence ............

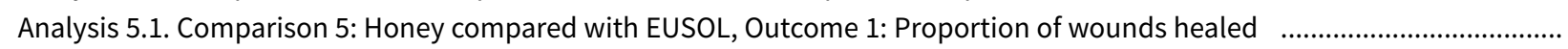

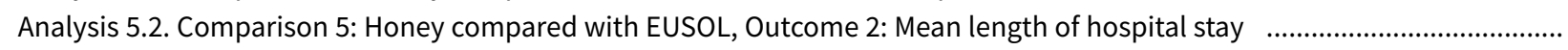

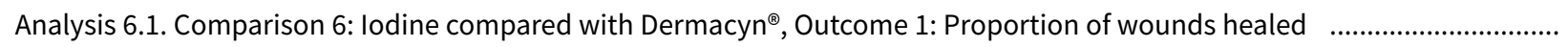

Analysis 7.1. Comparison 7: Triclosan compared with sodium hypochlorite, Outcome 1: Time to wound healing ....................

Analysis 7.2. Comparison 7: Triclosan compared with sodium hypochlorite, Outcome 2: Adverse events (bleeding/secretions) .

Analysis 7.3. Comparison 7: Triclosan compared with sodium hypochlorite, Outcome 3: Pain

ADDITIONAL TABLES

APPENDICES

WHAT'S NEW

HISTORY

CONTRIBUTIONS OF AUTHORS

DECLARATIONS OF INTEREST

SOURCES OF SUPPORT

DIFFERENCES BETWEEN PROTOCOL AND REVIEW

INDEX TERMS 
[Intervention Review]

\title{
Antibiotics and antiseptics for surgical wounds healing by secondary intention
}

\author{
Gill Norman¹, Jo C Dumville¹, Devi Prasad Mohapatra², Gemma L Owens³ ${ }^{3}$ Emma J Crosbie 4
}

1Division of Nursing, Midwifery and Social Work, School of Health Sciences, Faculty of Biology, Medicine and Health, University of Manchester, Manchester Academic Health Science Centre, Manchester, UK. 2Plastic Surgery, Jawaharlal Institute of Postgraduate Medical Education and Research (JIPMER), Puducherry, India. ${ }^{3}$ Institute of Cancer Sciences, University of Manchester, Manchester, UK. ${ }^{4}$ Division of Cancer Sciences, Faculty of Biology, Medicine and Health, The University of Manchester, Manchester, UK

Contact: Gill Norman, gill.norman@manchester.ac.uk.

Editorial group: Cochrane Wounds Group.

Publication status and date: Edited (no change to conclusions), published in Issue 4, 2022.

Citation: Norman G, Dumville JC, Mohapatra DP, Owens GL, Crosbie EJ.Antibiotics and antiseptics for surgical wounds healing by secondary intention. Cochrane Database of Systematic Reviews 2016, Issue 3. Art. No.: CD011712. DOI: 10.1002/14651858.CD011712.pub2.

Copyright @ 2022 The Cochrane Collaboration. Published by John Wiley \& Sons, Ltd.

Editorial note: $21 / 4 / 22$ Minor amendment made to Table 1 - Study outcomes.

\section{A B S T R A C T}

\section{Background}

Following surgery, incisions are usually closed by fixing the edges together with sutures (stitches), staples, adhesives (glue) or clips. This process helps the cut edges heal together and is called 'healing by primary intention'. However, a minority of surgical wounds are not closed in this way. Where the risk of infection is high or there has been significant loss of tissue, wounds may be left open to heal by the growth of new tissue rather than by primary closure; this is known as 'healing by secondary intention'. There is a risk of infection in open wounds, which may impact on wound healing, and antiseptic or antibiotic treatments may be used with the aim of preventing or treating such infections. This review is one of a suite of Cochrane reviews investigating the evidence on antiseptics and antibiotics in different types of wounds. It aims to present current evidence related to the use of antiseptics and antibiotics for surgical wounds healing by secondary intention (SWHSI).

\section{Objectives}

To assess the effects of systemic and topical antibiotics, and topical antiseptics for the treatment of surgical wounds healing by secondary intention.

\section{Search methods}

In November 2015 we searched: The Cochrane Wounds Specialised Register; The Cochrane Central Register of Controlled Trials (CENTRAL) (The Cochrane Library); Ovid MEDLINE; Ovid MEDLINE (In-Process \& Other Non-Indexed Citations); Ovid EMBASE and EBSCO CINAHL. We also searched three clinical trials registries and the references of included studies and relevant systematic reviews. There were no restrictions with respect to language, date of publication or study setting.

\section{Selection criteria}

Randomised controlled trials which enrolled adults with a surgical wound healing by secondary intention and assessed treatment with an antiseptic or antibiotic treatment. Studies enrolling people with skin graft donor sites were not included, neither were studies of wounds with a non-surgical origin which had subsequently undergone sharp or surgical debridement or other surgical treatments or wounds within the oral or aural cavities. 


\section{Data collection and analysis}

Two review authors independently performed study selection, risk of bias assessment and data extraction.

\section{Main results}

Eleven studies with a total of 886 participants were included in the review. These evaluated a range of comparisons in a range of surgical wounds healing by secondary intention. In general studies were small and some did not present data or analyses that could be easily interpreted or related to clinical outcomes. These factors reduced the quality of the evidence.

Two comparisons compared different iodine preparations with no antiseptic treatment and found no clear evidence of effects for these treatments. The outcome data available were limited and what evidence there was low quality.

One study compared a zinc oxide mesh dressing with a plain mesh dressing. There was no clear evidence of a difference in time to wound healing between groups. There was some evidence of a difference in measures used to assess wound infection (wound with foul smell and number of participants prescribed antibiotics) which favoured the zinc oxide group. This was low quality evidence.

One study reported that sucralfate cream increased the likelihood of healing open wounds following haemorrhoidectomy compared to a petrolatum cream (RR: $1.50,95 \% \mathrm{Cl} 1.13$ to 1.99) over a three week period. This evidence was graded as being of moderate quality. The study also reported lower wound pain scores in the sucralfate group.

There was a reduction in time to healing of open wounds following haemorrhoidectomy when treated with Triclosan post-operatively compared with a standard sodium hypochlorite solution (mean difference -1.70 days, $95 \% \mathrm{Cl}-3.41$ to 0.01 ). This was classed as low quality evidence.

There was moderate quality evidence that more open wounds resulting from excision of pyomyositis abscesses healed when treated with a honey-soaked gauze compared with a EUSOL-soaked gauze over three weeks' follow-up (RR: 1.58, 95\% $\mathrm{Cl} 1.03$ to 2.42 ). There was also some evidence of a reduction in the mean length of hospital stay in the honey group. Evidence was taken from one small study that only had 43 participants.

There was moderate quality evidence that more Dermacym ${ }^{\circledR}$-treated post-operative foot wounds in people with diabetes healed compared to those treated with iodine (RR $0.61,95 \% \mathrm{Cl} 0.40$ to 0.93 ). Again estimates came from one small study with 40 participants.

\section{Authors' conclusions}

There is no robust evidence on the relative effectiveness of any antiseptic/antibiotic/anti-bacterial preparation evaluated to date for use on SWHSI. Where some evidence for possible treatment effects was reported, it stemmed from single studies with small participant numbers and was classed as moderate or low quality evidence. This means it is likely or very likely that further research will have an important impact on our confidence in the estimate of effect, and may change this estimate.

\section{PLAIN LANGUAGE SUMMARY}

\section{Antibiotics and antiseptics for surgical wounds healing by secondary intention}

\section{What are surgical wounds healing by secondary intention?}

These are surgical wounds which are left open to heal through the growth of new tissue, rather than being closed in the usual way with stitches or other methods which bring the wound edges together. This is usually done when there is a high risk of infection or a large amount of tissue has been lost from the wound. Wounds which are often treated in this way include chronic wounds in the cleft between the buttocks (pilonidal sinuses) and some types of abscesses.

\section{Why use antibiotics and antiseptics to treat surgical wounds healing by secondary intention?}

One reason for allowing a wound to heal by secondary intention after surgery is that the risk of infection in that wound is thought to be high. If a wound has already become infected, then antibiotics or antiseptics are used to kill or slow the growth of the micro-organisms causing the infection and prevent it from getting worse or spreading. This may also help the wound to heal. Even where wounds are not clearly infected, they usually have populations of micro-organisms present. It is thought that they may heal better if these populations are reduced by antibacterial agents. However, the relationship between infection and micro-organism populations in wounds and wound healing is not very clear.

\section{What we found}

In November 2015 we searched for as many studies as possible that both had a randomised controlled design and looked at the use of an antibiotic or antiseptic in participants with surgical wounds healing by secondary intention. We found 11 studies which included a total of 886 participants.These all looked at different comparisons. Several different types of wounds were included. Studies looked at wounds 
after diabetic foot amputation, pilonidal sinus surgery, treatment of various types of abscess, surgery for haemorrhoids, complications after caesarean section and healing of openings created by operations such as colostomy.

Most studies compared a range of different types of antibacterial treatments to treatments without antibacterial activity, but four compared different antibacterial treatments. Although some of the trials suggested that one treatment may be better than another, this evidence was limited by the size of the studies and the ways they were carried out and reported. All of the studies had low numbers of participants and in some cases these numbers were very small. Many of the studies did not report important information about how they were carried out, so it was difficult to tell whether the results presented were likely to be true. More, better quality, research is needed to find out the effects of antimicrobial treatments on surgical wounds which are healing by secondary intention.

Assessed as up to date November 2015. 


\section{B A C K G R O U N D}

\section{Description of the condition}

Following surgery, incisions are usually closed by fixing the edges together with sutures (stitches), staples, adhesive glue or clips. This process helps the cut edges heal together and is called 'healing by primary intention'.

However, a minority of surgical wounds are not closed in this way. Where the risk of infection is high or there has been significant loss of tissue, wounds may be left open to heal by the growth of new tissue rather than by primary closure; this is known as 'healing by secondary intention'. This practice is commonly used following excision of pilonidal sinuses (chronic wounds which arise from hair follicles in the buttock cleft) or perianal or breast abscesses (although a Cochrane review did not find a clear benefit of open healing in pilonidal sinuses (AL-Khamis 2010)).

Wounds may also convert from healing by primary intention to healing by secondary intention when wound closure fails and dehiscence (full or partial separation of wound edges) occurs and cannot be rectified. A recent review using elements of systematic review methodology identified key risk factors for dehiscence as including obesity and wound infection, particularly in abdominal surgeries; however the methodology and quality of the fifteen included studies were highly variable and the review process was not well reported (Sandy-Hodgetts 2013). Dehisced wounds may be allowed to heal fully through secondary intention, or closed surgically after partial healing (delayed healing by primary intention). Delayed healing by primary intention may also be a planned approach.

Standard care for surgical wounds healing by secondary intention includes use of a range of dressings. The United Kingdom (UK) National Institute for Health and Care Excellence (NICE) currently recommends that the following not be used for SWHSI: Edinburgh University Solution of Lime (EUSOL) and gauze; moist cotton gauze; and mercuric antiseptic solutions, as small randomised studies suggest that these treatments are inferior to available alternatives. The use of 'an appropriate interactive dressing' and consultation with a professional with expertise in tissue viability are recommended (NICE 2008). Other treatments which may be given include negative pressure wound therapy (the use of a vacuum pump to reduce the pressure around the wound), debridement (the removal of foreign material and dead or damaged tissue), and skin grafting.

\section{Prevalence}

The data on the incidence and prevalence of SWHSI (both planned SWHSI and those that occur following breakdown of a previously closed wound) are limited. Two published audits from cities in the north of England estimated that SWHSI comprise approximately $28 \%$ of all acute wounds receiving wound care provision (Srinivasaiah 2007; Vowden 2009). A more recent UK study which evaluated the prevalence of SWHSI over a two-week period in community, primary and secondary care settings found a prevalence of 0.41 per 1000 population in a total population of 590,585 , almost half of which were planned to heal by secondary intention (Ashby 2014 [pers comm] - paper in preparation). An evaluation of the point prevalence of all types of complex wounds in a UK city (population 751,485 ) found a point prevalence of dehisced surgical wounds of 0.07 per 1000 population (Hall 2014). The same study reported a prevalence of 0.03 per 1000 population for pilonidal sinus surgical wounds, while the categories of 'other' and 'other surgical wound' had respective prevalences of 0.11 and 0.14 per 1000 population.

Published time-to-healing data for SWHSI are limited. Data from randomised controlled trials (RCTs) show median times to healing of between 54 and 68 days (ranges from 33 to 168 days) depending on aetiology, with pilonidal sinus excisions taking longer to heal than abdominal wounds (Berry 1996; Shackelford 2002; Viciano 2000).

\section{Costs}

Without good epidemiological data it is difficult to estimate the explicit costs to healthcare providers of managing SWHSI or the social costs including loss of income experienced by patients in work. The potential time to healing of these wounds, as well as possible requirements for further surgery and other complications including infection, indicate that costs for the broad category of SWHSI are likely to be substantial. The overwhelming majority of patients with SWHSI are treated with dressings of various types (AL-Khamis 2010 [pers comm]). Clearly this accounts for some proportion of the total UK National Health Service (NHS) spend of GBP 116 million on dressings and related wound care products (2008/9 prices) (MeReC 2010). However the majority of costs are likely to stem from the duration of hospital stays (although it is not clear that SWHSI necessitate longer hospital stays in all indications (AL-Khamis 2010)), and subsequent care requirements in the community. Wounds which become infected (develop a surgical site infection (SSI)) also incur increased cost - previously estimated at between GBP 814 and GBP 6626 per patient (Coello 2005; Plowman 2001). The prevalence of SSI was estimated at $5 \%$ of all surgeries in the UK and Ireland (Smyth 2008); this is likely to be conservative as many SSIs occur post-discharge from hospital (NICE 2008). These increased costs for SSI generally may apply equally to SWHSI.

\section{Impact on patients and carers}

In line with the paucity of epidemiological data, there is little evidence on the impact of SWHSI on patients' quality of life. A recent qualitative study explored the impact of these wounds on 20 patients and carers. It found that the constant need for treatments and care and the diminished quality of life were comparable to those reported by patients with different types of ulcers; feelings of shock, anguish, frustration and powerlessness were highlighted. The possibility of wound infection was viewed as a constant and insidious threat, representing a major setback to healing (McCaughan 2014 [pers comm]- paper in preparation).

\section{Wound infection}

Open wounds such as SWHSI offer an ideal environment for microbial colonisation, and most wounds will contain some microorganisms although this will not necessarily lead to adverse events. An RCT in 54 patients with wounds with delayed healing by primary intention found 353 isolates of 44 different species; many wounds had a bacterial load greater than $1 \times 10^{5} \mathrm{~g}^{-1}$ (previously considered a threshold predictive of infection (Robson 1968)) and healed without complication (Moues 2004). The isolates included Staphylococcus aureus and anaerobic species, often associated with infection and delayed healing (Madsen 1996). 
Bacteria may be more resistant to bacteriocidal agents because they grow on the surface of a wound forming a film of cells, a 'biofilm'. Recently opinion has shifted to the view that it is infection with enough or specific types, or both, of pathogenic microorganisms and possibly resulting biofilms (Percival 2004; Wolcott 2008) that may lead to negative outcomes and potentially delayed healing (Bowler 2003; Davies 2007; Madsen 1996; Trengove 1996). However, the impact of microbial colonisation on wound healing is not independent of the host response; the ability of the host to provide adequate immune response is likely to be as critical, if not more so, as the specifics of the flora in the wound in determining whether a wound heals.

The document 'Wound Infection in Clinical Practice - An International Consensus' (WUWHS 2008) outlines a scenario leading to wound infection where 'bacteria multiply, healing is disrupted and wound tissues are damaged (local infection)'. The document also notes that 'Bacteria may produce problems nearby (spreading infection) or cause systemic illness (systemic infection)'. Wound infection has also been seen as the far end of a continuum which starts with sterility (a brief period following surgery), moving to contamination (defined as the presence of microbes but little active growth and no clinical problems), then colonisation (considered as the normal status quo with growth in wound flora being managed by the host immune system and no damage to wound tissues) and finally to critical colonisation and then infection (Kingsley 2004). Critical colonisation is defined as a point between colonisation and infection where the 'healthy' balance of wound flora is no longer maintained by the host and the bacterial load or species present in the wound,or both shift away from a so-called safe level. (Kingsley 2004). Others have conceptualised critical colonisation as invasion of the wound surface by micro-organisms (AWMA 2011; Edwards 2004).

The classic clinical signs of infection include local pain, heat, redness, swelling and secretion of pus. The concept of critical colonisation lacks clear diagnostic criteria; it is generally described as being associated with delayed healing in the absence of overt signs of wound infection (Carville 2008; Cutting 2004) possibly with other symptoms such as increased exudate (though less than in infection) and hypergranulation/friable tissue (Cutting 2004; Gardner 2001) although associated evidence is limited.

Although there is a widespread view that healing of complex wounds is likely to be retarded by critical colonisation or topical/ local infection, the empirical evidence to support this is extremely limited (Howell-Jones 2005). The literature on the impact of critical colonisation or topical/local infection in SWHSI is even more limited and caution should be exercised in extrapolating from studies in other types of wounds healing by secondary intention; there are differences in the microbiology even between chronic wound types (Dowd 2008). The Australian Wound Management Association states that 'the true extent of bacterial impairment of wound healing is unknown' (AWMA 2011).

\section{Description of the intervention}

Where an antimicrobial intervention is considered clinically appropriate in the treatment of SWHSI there are two main approaches: an antibiotic may be administered systemically (orally, intravenously or intramuscularly) or a topical antibiotic or antiseptic may be applied. Systemic antibiotics affect the whole body while topical treatments affect only a specific area of the body.
Antibiotics are substances that destroy or inhibit the growth of micro-organisms (Macpherson 2004). Systemic antibiotic treatments include groups of drugs which share similar modes of action such as penicillins, cephalosporins, aminoglycosides, macrolides and quinolones. Other antibiotics which do not belong to one of these main groups include clindamycin, metronidazole, trimethoprim and co-trimazole.

Topical antimicrobial agents include both antibiotics and antiseptics. Antiseptics are thought to prevent the growth of pathogenic micro-organisms without damaging living tissue (Macpherson 2004). Topical applications broadly fall into two types: lotions used for wound irrigation or cleaning, or both, with a brief contact time (unless used as a pack/soak), and products which are in prolonged contact with the wound such as creams, ointments and impregnated dressings.

Agents used primarily for wound irrigation/cleaning are commonly based on povidone iodine, chlorhexidine and peroxide agents. Less commonly used are traditional agents such as gentian violet and hypochlorites. Longer contact creams and ointments include fusidic acid, mupirocin, neomycin sulphate and iodine (often as cadexomer iodine)

The British National Formulary categorises antimicrobial dressings as honey-based, iodine-based, silver-based and other, which includes dressings impregnated with agents such as chlorhexidine or peroxides. Recommendations on dressing type are based primarily on the level of wound exudate which determines the dressing substrate as well as the antimicrobial agent (BNF 2014).

\section{How the intervention might work}

The rationale for treating clinically infected wounds with antimicrobial agents like antibiotics and antiseptics is to kill or slow the growth of the pathogenic micro-organisms, thus preventing an infection from worsening and spreading. Improved healing may be a secondary benefit although evidence on the association between wound healing and infection is limited (AWMA 2011) (see Description of the condition).

There is a widely held view that wounds which do not have clear signs of clinical infection but which have characteristics such as retarded healing may also benefit from a reduction in bacterial load. Again, evidence for this is limited (e.g. Howell-Jones 2005) (see Description of the condition).

The normal mechanism of antibiotics is by inhibiting deoxyribonucleic acid (DNA) or protein synthesis or by disrupting the bacterial cell wall. Antiseptics can be bacteriocidal (in that they kill micro-organisms) or they can work by slowing the growth of organisms (bacteriostatic). Antiseptics can have a wider spectrum of action than just bacteria and often work by damaging the surface of microbes (Macpherson 2004).

\section{Why it is important to do this review}

Whether systemic antibiotics, topical antibiotics or topical antiseptics can promote healing in SWHSI remains uncertain. An earlier systematic review of antimicrobial agents used for the treatment of all types of chronic wounds (O'Meara 2001) included three small trials assessing topical agents for pilonidal sinus excision wounds (but that were closed rather then left open) and a further three small trials of systemic antibiotics in 
the same indication. The reviewers were not able to generate definitive conclusions about the use of systemic or topical agents in these wounds because of methodological problems in the primary literature. A Health Technology Assessment (HTA) review from the same year assessed debridement for SWHSI (Lewis 2001). Some of these studies reported the use of chemical debriding agents with antiseptic properties. The review found insufficient evidence to support the use of any particular dressing.

A subsequent Cochrane systematic review (Vermeulen 2004) identified 13 RCTs of dressings and topical treatments for SWHSI, all of which were small and of poor quality. Six of these trials enrolled only patients following surgery for pilonidal sinuses, and five trials enrolled only patients with dehisced abdominal wounds. Interventions assessed included antiseptics such as EUSOL and povidone iodine. There was no evidence that the choice of dressing or topical treatment had any impact on wound healing; no data on clinical infection status were reported. This review is now over 10 years old.

The current review is one of a number of Cochrane reviews investigating the use of antibiotics and antiseptics in the treatment of different types of wounds, each of which updates elements of O'Meara 2001. While there will be some overlap between trials included in this review and in other Cochrane reviews of individual antimicrobial agents in wounds (Jull 2013; Storm-Versloot 2010) or dressings for particular types of SWHSI (Smith 2014), this review will provide a single synthesis of the randomised evidence relating to all systemic and topical antimicrobials for SWHSI.

Many options are available to health professionals who are considering using antimicrobial therapy for patients with SWHSI, either as a treatment for, or prophylaxis against, clinical infection. Evidence-based decision-making on the impact of antimicrobial agents on healing of these wounds can be challenging. Key decision problems include whether to use an antibacterial agent instead of standard care and whether different antimicrobial preparations have a differential impact on healing when directly compared.

\section{O B JE C T IVES}

To assess the effects of systemic and topical antibiotics, and topical antiseptics for the treatment of surgical wounds healing by secondary intention.

\section{MET HOD S}

\section{Criteria for considering studies for this review}

\section{Types of studies}

We included published and unpublished randomised controlled trials (RCTs), including cluster RCTs, irrespective of language of report. Cross-over trials were only included if they reported outcome data at the end of the first treatment period, prior to crossover. Quasi-randomised studies were excluded. RCTs reported only as abstracts were included only when available data were sufficient for reasonable data extraction, either from the abstract itself or from the study authors.

\section{Types of participants}

People aged at least 18 years with SWHSI. Studies enrolling people with skin graft donor sites were not included, as these sites are superficial wounds which require specific care. Studies of wounds with a non-surgical origin which have subsequently undergone sharp or surgical debridement or other surgical treatments were also excluded. We also excluded studies of wounds where the intention was delayed closure followed by healing with primary intent and studies of wounds which have been created in order to provide an entry or exit point such as percutaneous endoscopic gastrostomy (PEG) wounds or stoma. Wounds within the oral or aural cavities were also excluded.

Studies which recruited people with a SWHSI alongside those with other types of wound were not included.

\section{Types of interventions}

The primary interventions of interest were topical antiseptic agents or antibiotic (antimicrobial) agents delivered either systemically or topically. We included any RCT in which the use of a topical or systemic antibiotic or a topical antiseptic is the only systematic difference between treatment groups. Systemic antibiotics may have been administered orally or by other routes (e.g. intravenously, intramuscularly). Both intervention and control regimens could consist of antibiotics or antiseptics administered singly or in combination; control regimens might also include placebo, another therapy, standard care or no treatment. Studies which evaluated intervention schedules including other therapies (e.g. pressure relieving devices, dressings) were included provided that these treatments were delivered in a standardised way across the trial arms. We excluded trials in which the presence or absence of a specific antibiotic/antiseptic was not the only systematic difference between trial arms.

We excluded studies evaluating antibiotic or antiseptic regimes that were part of pre-, intra- or post-operative surgical site infection (SSI) prevention practices. We also excluded physical and biological therapies sometimes purported to have incidental antibacterial properties such as heat therapy and larval therapy.

We anticipated that likely interventions would be antiseptic and antibiotic agents, which might include (but not be limited to) the following topical agents which can be available in the form of creams, sprays, ointments and impregnated into different types of dressings: chlorhexidine; povidone iodine; hydrogen peroxide and potassium permanganate; benzoyl peroxide; hypochlorites (e.g. EUSOL); gentian violet; mupirocin and fusidic acid; neomycin sulphate; peroxides; iodine; silver; and honey.

Systemic antibiotics could include: penicillins; cephalosporins; aminoglycosides; macrolides and quinolones; clindamycin; metronidazole; trimethoprim; and co-trimazole.

\section{Types of outcome measures}

We list primary and secondary outcome measures below. If a trial was otherwise eligible (correct study design, population and intervention/comparator) but did not report a listed outcome, then we contacted the study authors where possible in order to establish whether a relevant outcome was measured but not reported.

\section{Primary outcomes}

The primary efficacy outcome for this review was wound healing. Trialists use a range of different methods of measuring and reporting this outcome. RCTs which reported one or more of 
the following were considered to provide the most relevant and rigorous measures of wound healing:

- Time to complete wound healing (correctly analysed using survival, time-to-event approaches).

- Proportion of wounds completely healed during follow-up (frequency of complete healing).

We used authors' definitions of complete wound healing; these were reported where possible. We reported outcome measures at the latest time point available (assumed to be length of follow-up if not specified) and the time point specified in the methods as being of primary interest (if this was different from latest time point available).

Where both the outcomes above were reported, we presented all data in a summary outcome table for reference but focused on reporting time to healing where possible. When time was analysed as a continuous measure (i.e.mean time to healing), but it was not clear whether all wounds healed, we documented the use of the outcome in the study, but did not plan to include the data in any meta-analysis.

We grouped outcome data for wound healing using the following categories; the review authors used their judgement as to whether statistical pooling within these time categories was appropriate.

- Short term: 8 weeks

- Medium term: $>8$ weeks but $\leq 24$ weeks

- Long term: $>24$ weeks.

The primary safety outcome for the review was all reported adverse events. Where reported, we extracted data on all serious adverse events and all non-serious adverse events where a clear methodology for the collection of adverse event data was provided. This methodology should make it clear whether events were reported at the participant level or, where multiple events per person were reported, that an appropriate adjustment was made for data clustering.

We also treated wound infection as a primary safety outcome. This included changes in infection status as well as signs or symptoms of clinical infection. Study authors' definitions of clinical infection were used. We did not include data on bacterial load, diversity, or the presence of individual species where it was not clear how the outcome related to infection.

\section{Secondary outcomes}

The following secondary outcomes were included:

- Change (and rate of change) in wound size, with adjustment for baseline size (we planned to contact study authors to request adjusted means when not presented). When change or rate of change in wound size was reported without adjustment for baseline size, we documented use of the outcome in the study, but did not extract, summarise or use the data in any metaanalysis.

- Changes in bacterial (antibiotic) resistance.

- Health-related quality of life: quality of life was included where it was reported using a validated scale such as the SF-36 (Ware 1992) or EQ-5D (EuroQoL Group 1990). Ideally reported data were adjusted for the baseline score. We did not include ad hoc measures of quality of life that were unlikely to be validated and would not be common to multiple trials.

- Mean pain score (including pain at dressing change) as a continuous outcome using a validated scale such as a visual analogue scale (VAS) or other recognised measurement instrument.

- Number of wounds closed surgically (or time to surgical closure).

- Resource use (when presented as mean values with standard deviation) including measures of resource use such as number of dressing changes, number of nurse visits, length of hospital stay, and need for other interventions including return to theatre.

- Costs associated with resource use (including estimates of costeffectiveness).

\section{Search methods for identification of studies}

\section{Electronic searches}

We searched the following electronic databases to identify reports of relevant clinical trials:

- The Cochrane Wounds Specialised Register (searched 05 November 2015);

- The Cochrane Central Register of Controlled Trials (CENTRAL) (The Cochrane Library) (2015, Issue 10);

- Ovid MEDLINE (1946 to 05 November 2015);

- Ovid MEDLINE (In-Process \& Other Non-Indexed Citations) (searched 05 November 2015);

- Ovid EMBASE (1974 to 05 November 2015);

- EBSCO CINAHL Plus (1937 to 05 November 2015).

The search strategies used for CENTRAL, Ovid MEDLINE, Ovid EMBASE and EBSCO CINAHL Plus can be found in Appendix 1. We combined the Ovid MEDLINE search with the Cochrane Highly Sensitive Search Strategy for identifying randomised trials in MEDLINE: sensitivity- and precision-maximising version (2008 revision) (Lefebvre 2011). We combined the EMBASE search with the Ovid EMBASE filter developed by the UK Cochrane Centre (Lefebvre 2011). We combined the CINAHL searches with the trial filters developed by the Scottish Intercollegiate Guidelines Network (SIGN 2011). There were no restrictions of the searches with respect to language, date of publication or study setting.

We also searched the following clinical trials registries:

- ClinicalTrials.gov (http://www.clinicaltrials.gov/);

- WHO International Clinical Trials Registry Platform (ICTRP) (http://apps.who.int/trialsearch/Default.aspx);

- EU Clinical Trials Register (https://www.clinicaltrialsregister.eu/ ctr-search/search).

\section{Searching other resources}

We aimed to identify other potentially eligible trials or ancillary publications by searching the reference lists of retrieved included trials, as well as relevant systematic reviews, meta-analyses and Health Technology Assessment reports. 


\section{Data collection and analysis}

\section{Selection of studies}

Two review authors independently assessed the titles and abstracts of the citations retrieved by the searches for relevance. After this initial assessment, we obtained full-text copies of all studies considered to be potentially relevant. Two review authors independently checked the full papers for eligibility; we resolved disagreements by discussion and, where required, the input of a third review author. Where the eligibility of a study was unclear we attempted to contact study authors. We recorded all reasons for exclusion of studies for which we had obtained full copies. We completed a Preferred Reporting Items for Systematic Reviews and Meta-Analyses (PRISMA) flowchart to summarise this process (Liberati 2009).

Where studies had been reported in multiple publications/reports, we obtained all publications. Whilst the study was included only once in the review, we extracted data from all reports to ensure all available, relevant data were obtained.

\section{Data extraction and management}

We extracted and summarised details of the eligible studies. Where possible we extracted data by treatment group for the pre-specified interventions and outcomes in this review. Two review authors independently extracted data; we resolved discrepancies through discussion or by consultation with a third review author. Where data were missing from reports, we attempted to contact the study authors and request this information.

Outcome data were collected for relevant time points as described in Types of outcome measures.

Where possible we extracted the following data:

- bibliographic data including date of completion/publication;

- country of origin;

- unit of randomisation (participant/wound);

- unit of analysis;

- trial design e.g. parallel, cluster;

- care setting;

- number of participants randomised to each trial arm and number included in final analysis;

- eligibility criteria and key baseline participant data including indication for and type of surgery; location(s) of wounds and whether planned healing by secondary intention;

- details of treatment regimen received by each group;

- duration of treatment;

- details of any co-interventions;

- primary and secondary outcome(s) (with definitions and, where applicable, time points);

- outcome data for primary and secondary outcomes (by group);

- duration of follow-up;

- number of withdrawals (by group) and number of withdrawals (by group) due to adverse events;

- publication status of study;

- source of funding for trial.

\section{Assessment of risk of bias in included studies}

Two review authors independently assessed included studies using the Cochrane tool for assessing risk of bias (Higgins 2011a). This tool addresses six specific domains: sequence generation, allocation concealment, blinding, incomplete data, selective outcome reporting and other issues - in this review we recorded issues with unit of analysis, for example where a cluster trial had been undertaken but analysed at the individual level in the study report. We assessed blinding of outcome assessment and completeness of outcome data for each of the review outcomes separately. We have presented our assessment of risk of bias using two 'Risk of bias' summary figures; one which is a summary of bias for each item across all studies, and a second which shows a cross-tabulation of each trial by all of the 'Risk of bias' items. We summarised a study's risk of selection bias, detection bias, attrition bias, reporting bias and other bias. For trials using cluster randomisation, we also planned to consider the risk of bias in relation to: recruitment bias, baseline imbalance, loss of clusters, incorrect analysis and comparability with individually randomised trials (Higgins 2011b) (Appendix 2).

\section{Measures of treatment effect}

For dichotomous outcomes, we calculated the risk ratio (RR) with 95\% confidence intervals (Cls). For continuous outcome data, we used the mean difference (MD) with $95 \% \mathrm{Cls}$ for trials that used the same assessment scale. We planned to report time-to-event data (e.g. time to complete wound healing) as hazard ratios (HRs) where possible, in accordance with the methods described in the Cochrane Handbook for Systematic Reviews of Interventions (Deeks 2011). If studies reporting time-to-event data (e.g. time to healing) did not report a HR, then, when feasible, we planned to estimate this using other reported outcomes, such as numbers of events, through the application of available statistical methods (Parmar 1998; Tierney 2007) although we did not implement such an approach here.

\section{Unit of analysis issues}

Where studies were randomised at the participant level and outcomes measured at the wound level, for example for wound healing, we treated the participant as the unit of analysis when the number of wounds assessed appeared to be equal to the number of participants (e.g. one wound per person).

A possible unit of analysis issue we anticipated was that randomisation had been carried out at the participant level with the allocated treatment used on multiple wounds per participant (or perhaps only on some participants) but data were presented and analysed per wound (clustered data).

Where studies included some or all clustered data we planned to report this, noting whether data had been incorrectly treated as independent. We recorded this as part of the risk of bias assessment. We did not plan to undertake further calculation to adjust for clustering as part of this review.

\section{Dealing with missing data}

It is common to have data missing from trial reports. Excluding participants from the analysis post randomisation or ignoring participants who are lost to follow-up compromises the randomisation and potentially introduces bias into the trial. If it was thought that study authors might be able to provide some 
missing data, we planned to contact them; however, it is likely that data will often be missing because of loss to follow-up. In individual studies, when data on the proportion of wounds healed were presented, we assumed that randomly assigned participants not included in an analysis had an unhealed wound at the end of the follow-up period (i.e. they were considered in the denominator but not in the numerator). When a trial did not specify participant group numbers before dropout, we presented only complete case data. For time-to-healing analysis using survival analysis methods, dropouts should be accounted for as censored data. Hence all participants would contribute to the analysis. We acknowledge that such analysis assumes that dropouts are missing at random and there is no pattern of missingness. We have presented data for area change of wound and for all secondary dichotomous outcomes as a complete case analysis.

For continuous secondary outcome measures e.g. length of hospital stay we presented available data from the study reports/ study authors and did not impute missing data. Where measures of variance were missing these were calculated (Higgins 2011a) or study authors contacted where possible. Where these measures of variation remained unavailable we excluded the study from any relevant meta-analyses.

\section{Assessment of heterogeneity}

Assessment of heterogeneity is a complex, multi-faceted process. Firstly, we planned to consider clinical and methodological heterogeneity: that is the degree to which the included studies varied in terms of participant, intervention, outcome and characteristics such as length of follow-up. We planned to supplement this assessment of clinical and methodological heterogeneity with information regarding statistical heterogeneity - assessed using the $\mathrm{Chi}^{2}$ test (we considered a significance level of $\mathrm{P}<0.10$ to indicate statistically significant heterogeneity) in conjunction with the $I^{2}$ measure (Higgins 2003). $I^{2}$ examines the percentage of total variation across RCTs that is due to heterogeneity rather than chance (Higgins 2003). Very broadly, we considered that $\mathrm{I}^{2}$ values of $25 \%$, or less, meant a low level of heterogeneity (Higgins 2003), and values of more than $75 \%$ indicated very high heterogeneity (Deeks 2011). Where there was evidence of high heterogeneity we planned to explore this further if required: see Data synthesis.

\section{Assessment of reporting biases}

Reporting biases arise when the dissemination of research findings is influenced by the nature and direction of results. Publication bias is one of a number of possible causes of 'small study effects', that is, a tendency for estimates of the intervention effect to be more beneficial in smaller RCTs. Funnel plots allow a visual assessment of whether small study effects may be present in a meta-analysis. A funnel plot is a simple scatter plot of the intervention effect estimates from individual RCTs against some measure of each trial's size or precision (Sterne 2011). Funnel plots are only informative when there is a substantial number of studies included in an analysis; we planned to present funnel plots for meta-analyses which included at least 10 RCTs using Review Manager 5.3 (RevMan) (RevMan 2014).

\section{Data synthesis}

We combined details of included studies in a narrative review according to the comparison between intervention and comparator, the population and the time point of the outcome measurement. If studies had appeared appropriately similar in terms of wound type and location, intervention type and antibacterial agent, duration of treatment and outcome assessment, we would have considered clinical and methodological heterogeneity and undertaken pooling.

In terms of meta-analytical approach, in the presence of clinical heterogeneity (review author judgement) or evidence of statistical heterogeneity, or both, we planned to use the random-effects model. We planned to use a fixed-effect approach only when clinical heterogeneity was thought to be minimal and statistical heterogeneity was estimated as non-statistically significant for the $\mathrm{Chi}^{2}$ value and $0 \%$ for the $\mathrm{I}^{2}$ assessment (Kontopantelis 2013). This approach was planned as it is recognised that statistical assessments can miss potentially important betweenstudy heterogeneity in small samples, hence the preference for the more conservative random-effects model (Kontopantelis 2012). Where clinical heterogeneity was thought to be acceptable or of interest we potentially planned to meta-analyse even when statistical heterogeneity was high, with further exploration to interpret the causes behind this heterogeneity and using meta-regression for that purpose, if possible (Thompson 1999; Thompson 2002).

We presented data using forest plots where possible. For time-toevent data, we planned to plot (and, if appropriate, pool) estimates of HRs and $95 \% \mathrm{Cls}$ as presented in the study reports using the generic inverse variance method in RevMan 5.3 (RevMan 2014). Where time to healing was analysed as a continuous measure but it was not clear if all wounds healed, we documented use of the outcome in the study but data were not summarised or used in any meta-analysis.

\section{'Summary of findings' tables}

We planned to present the main results of the review in 'Summary of findings' tables. These tables present key information concerning the quality of the evidence, the magnitude of the effects of the interventions examined and the sum of available data for the main outcomes (Schünemann 2011a). The 'Summary of findings' tables also include an overall grading of the evidence related to each of the main outcomes using the GRADE (Grades of Recommendation, Assessment, Development and Evaluation) approach. The GRADE approach defines the quality of a body of evidence as the extent to which one can be confident that an estimate of effect or association is close to the true quantity of specific interest. The quality of a body of evidence involves consideration of within-trial risk of bias (methodological quality), directness of evidence, heterogeneity, precision of effect estimates and risk of publication bias (Schünemann 2011b). We planned to present the following outcomes in the 'Summary of findings' tables.

- Time to complete wound healing when analysed using appropriate survival analysis methods.

- Proportion of wounds completely healed during the trial period. - Changes in clinical infection status.

Where data were not pooled we have presented GRADE assessment without a 'Summary of findings' table - which was the case for all comparisons in this review. 
In terms of the GRADE assessment, when making decisions for the risk of bias domain we downgraded only when studies had been classed at high risk of bias for one or more domains. We did not downgrade for unclear risk of bias assessments. In assessing the precision of effect estimates we followed GRADE guidance (GRADE 2013) and calculated an optimal information size (OIS) using conventional sample size calculation methods. We used the OIS, along with the size of $95 \% \mathrm{Cl}$ in terms of whether they spanned estimates of benefit and harm, to assess for downgrading. We calculated the OIS based on GRADE guidance of using a relative risk reduction of between $20 \%$ and $30 \%$. The OIS is summarised below but should not be treated as optimal sample sizes for any future research - within a GRADE assessment the OIS is used to assess the stability of Cls rather than being used to assess the appropriateness of a sample size to detect a difference per se.

- Time to wound healing - detect a reduction in time to healing of eight days from 28 days to 21 days (with 100 days recruitment and 100 days follow-up: $80 \%$ power; alpha $5 \%$ ) = 388 participants

- Proportion of wounds healed - detect an increase in wound healing of $75 \%$ to $90 \%$ ( $80 \%$ power; alpha $5 \%$ ) $=200$ participants

- Changes in clinical infection status - detect a reduction in cases of wound infection from $14 \%$ to $10 \% 80 \%$ power; alpha $5 \%$ ) = 2070 participants

\section{Subgroup analysis and investigation of heterogeneity}

If possible, we planned to assess heterogeneity across the following areas: where there was evidence of between-trial heterogeneity we would have conducted a subgroup analysis if feasible.
- Locations of wound types: abdominal wounds and other wound types.

- Planned and unplanned healing by secondary intention.

If possible we planned to perform analyses to explore the influence of risk of bias on effect size. We would have assessed the influence of removing from meta-analyses studies classed as having high and unclear risk of bias. These analyses would have included only studies assessed as having low risk of bias in all key domains, namely, adequate generation of the randomisation sequence, adequate allocation concealment and blinding of outcome assessor for the estimates of treatment effect.

\section{Elements of this Methods section were based on the standard} Cochrane Wounds Protocol Template.

\section{RES U LTS}

\section{Description of studies}

\section{Results of the search}

The search for this review returned 3928 citations - 10 further citations were found from screening related systematic reviews and bibliographies. After screening we obtained full text 32 citations (relating to 28 studies). Of these studies 11 are included in the review: 13 were excluded. Four studies are awaiting assessment as they required further information before a decision on inclusion could be made and queries with study authors or translators are pending. See Figure 1. 
Figure 1. Study flow diagram.

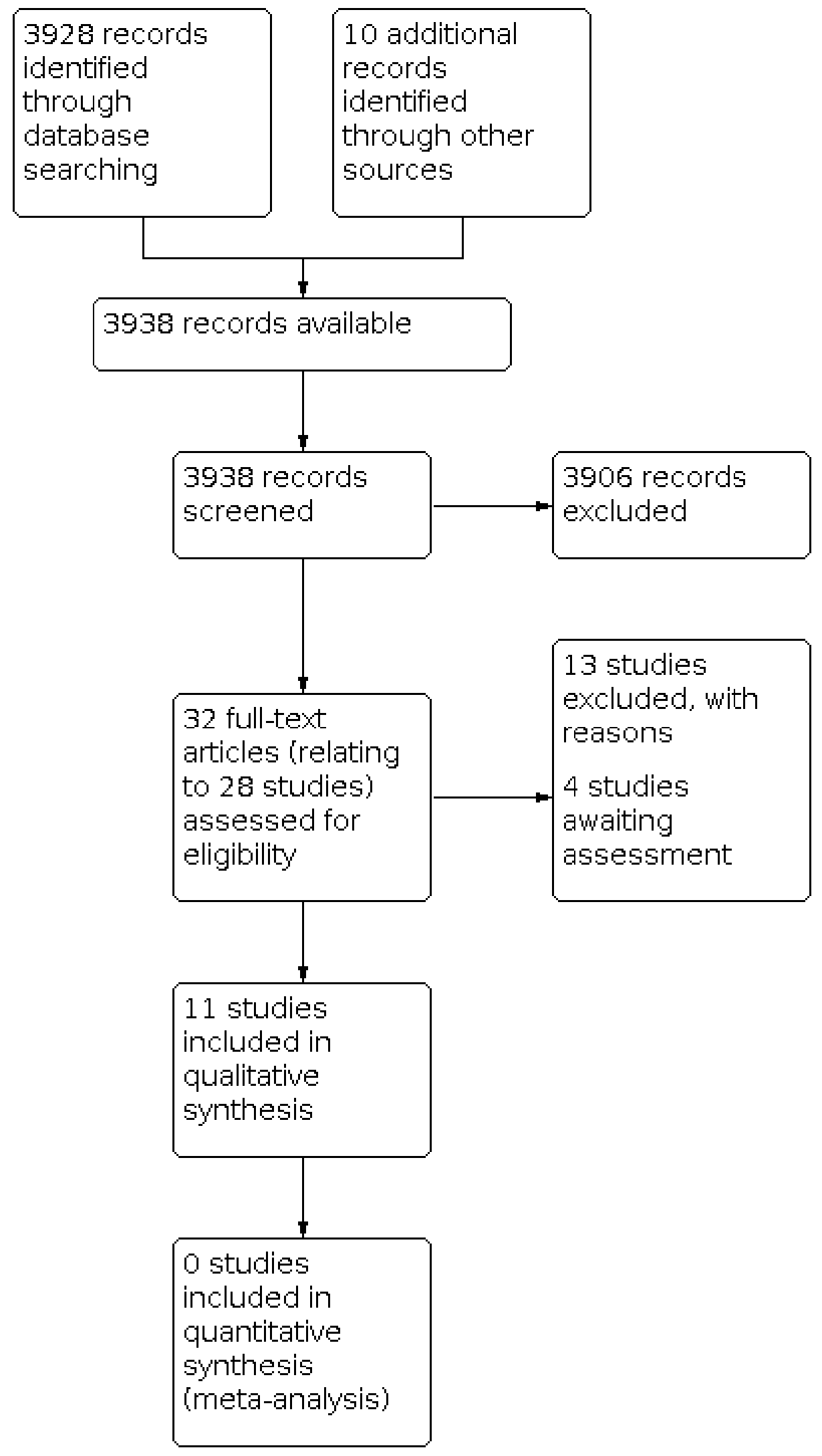




\section{Included studies}

Eleven studies (886 participants) are included in this review with each making a different pairwise comparison of treatment - that is no two studies compared the same two treatments. Nine studies investigated use of antiseptic/antibacterial solutions on wounds post-operatively, delivering these via gauze or other inert dressings (Agren 2006; Brehant 2009; Okeniyi 2005; Piaggesi 2010) via a soak (Tosti 2014) or wash (Giannini 2014) or topically (Fernandez 2002; Gupta 2008; Schmidt 1991). Two studies investigated the use of antibiotics - one (Duong 2010) investigated trimethoprimsulfamethoxazole post-operatively for people following surgery on skin abscesses while one (Khan 2014) investigated the use of antibiotics prior to haemorrhoidectomy surgery.

Included participants had a range of different wounds.

- Wound resulting from excision of pilonidal abscess/disease (Agren 2006; Fernandez 2002).

- Wound resulting from stoma orifice healing by secondary intention (Brehant 2009).

- Wound resulting from incision and drainage of a skin abscess (Duong 2010), pyomyositis abscesses (Okeniyi 2005) or hand abscess (Tosti 2014).

- Wound resulting from haemorrhoidectomy leaving open wounds (Giannini 2014; Gupta 2008; Khan 2014).

- Open post-surgical wounds on the foot/feet of people with diabetes (Piaggesi 2010).

- Wound complications following a caesarean section (c-section) resulting in an open wound Schmidt 1991.

Studies had generally small sample sizes with a minimum of 37 participants (Fernandez 2002) and a maximum of 162 (Duong 2010)
- the median sample size for the 11 included studies was 71 participants. The follow-up period of studies ranged from three weeks to six months and was unclear in one case (Schmidt 1991).

Detailed data on each study are found in the Characteristics of included studies tables and an overview of included studies with their extracted outcome data can be found in Table 1.

\section{Excluded studies}

In total we excluded 13 studies from this review for the following reasons.

- Use of antibiotic/antiseptic was not the only difference between groups $(n=9)$.

- $\operatorname{Not} \operatorname{RCT}(n=1)$.

- No outcome relevant to review $(n=1)$.

- Not conducted in participants with SWHSI $(n=2)$.

\section{Risk of bias in included studies}

Risk of bias assessments are summarised in Figure 2 and Figure 3. Briefly, two studies were considered at low risk of selection bias (Agren 2006; Gupta 2008) the remaining studies were classed at unclear risk of bias. Four studies were classed at low risk of blinding for both staff and patient and blinded outcome assessment (Agren 2006; Duong 2010; Giannini 2014; Gupta 2008), two studies were classed as being at high risk of bias (Schmidt 1991; Tosti 2014); the remaining studies were classed as being at unclear risk of bias for blinding. Seven studies were classed as being at low risk of attrition bias (Agren 2006; Fernandez 2002; Giannini 2014; Gupta 2008, Okeniyi 2005; Piaggesi 2010; Tosti 2014), one study was classed at high risk of bias for attrition bias (Schmidt 1991); the remaining studies were at unclear risk of bias.

Figure 2. Risk of bias graph: review authors' judgements about each risk of bias item presented as percentages across all included studies.

Random sequence generation (selection bias)

Allocation concealment (selection bias)

Blinding of participants and personnel (performance bias): All outcomes Blinding of outcome assessment (detection bias): All outcomes Incomplete outcome data (attrition bias): All outcomes

Selective reporting (reporting bias)

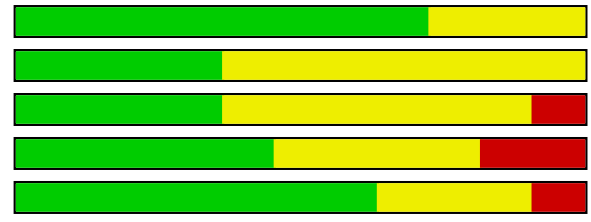

Other bias

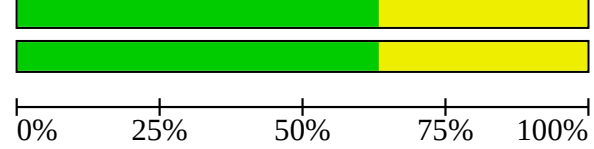

Low risk of bias

Unclear risk of bias

High risk of bias 
Figure 3. Risk of bias summary: review authors' judgements about each risk of bias item for each included study.

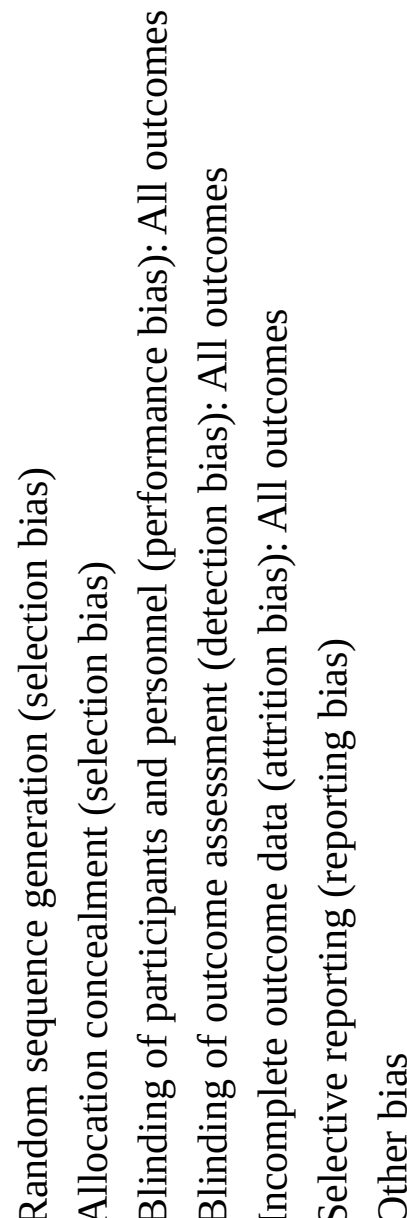

Agren 2006

Brehant 2009

Duong 2010

Fernandez 2002

Giannini 2014

Gupta 2008

Khan 2014

Okeniyi 2005

Piaggesi 2010

Schmidt 1991

Tosti 2014

\begin{tabular}{|c|c|c|c|c|c|c|}
\hline+ & + & + & + & + & + & + \\
\hline$?$ & $?$ & $?$ & $?$ & $?$ & + & + \\
\hline+ & + & + & + & $?$ & $?$ & $?$ \\
\hline+ & $?$ & $?$ & $?$ & + & + & + \\
\hline$?$ & + & + & + & + & + & + \\
\hline+ & + & + & + & + & + & + \\
\hline+ & $?$ & $?$ & $?$ & $?$ & $?$ & $?$ \\
\hline$?$ & $?$ & $?$ & $?$ & + & + & + \\
\hline+ & $?$ & $?$ & + & + & $?$ & $?$ \\
\hline+ & $?$ & $?$ & - & - & $?$ & $?$ \\
\hline+ & $?$ & - & - & + & + & + \\
\hline
\end{tabular}




\section{Effects of interventions}

We have presented the effects of interventions by comparison below.

\section{Antiseptic treatments compared with non-anti-microbial treatments}

Comparison 1: Polyvidone iodine (Povidone iodine)-impregnated mesh compared with alginate mesh (1 trial; 71 participants)

This comparison includes one study which had six weeks' follow-up (Brehant 2009) and assessed treatment for wounds resulting from the closure of stoma orifice by secondary intention.

\section{Primary outcomes}

Time to wound healing Mean time-to-healing data presented but not all wounds healed. Data not presented further.

Proportion of wounds healed There was no clear evidence of a difference in number of wounds healed between groups. There were $25 / 34(74 \%)$ wounds reported as healed in the iodine mesh group compared with $34 / 37(92 \%)$ in the alginate mesh group: RR $0.80,95 \% \mathrm{Cl} 0.64$ to 1.00 (Analysis 1.1). GRADE assessment for proportion of wounds healed: Low quality evidence. Downgraded twice due to imprecision with $95 \%$ Cls for risk of wound healing in the iodine group ranging from $36 \%$ reduction in risk to $0 \%$ reduction, so confidence intervals include $a R R$ of 1 and the estimate comes from a single small study with 71 participants $(O I S=200)$.

Wound infection There was no clear evidence of a difference in the number of wound infections between groups. In total 2/29 (7\%) of participants had a wound infection in the iodine-impregnated group compared with $3 / 37(8 \%)$ in the alginate mesh group. It was not clear from the report that the infection events occurred in different people but we have assumed this was the case: RR $0.85,95 \% \mathrm{Cl} 0.15$ to 4.76 (Analysis 1.2). GRADE assessment wound infection: Low quality evidence. Downgraded twice due to imprecision with $95 \% \mathrm{Cls}$ for risk of wound infection in the iodine group ranging from a reduction in risk of $85 \%$ to an increase risk of $476 \%$ so crossing a RR of 1 and the estimate comes from a single small study with 71 participants (OIS $=2070)$.

Adverse events There were 10 events in the iodine mesh group and 17 events in the alginate mesh group. It was not clear whether each event occurred in a different person or not. We did not analyse the data further.

\section{Secondary outcomes}

Resource use (mean number of dressing changes to achieve healing): There was evidence of fewer dressing changes in the alginate mesh group with a mean of $17.9(\mathrm{SD}=8)$ dressing changes in the iodine mesh group compared with a mean of 13.2 in the alginate mesh group $(S D=5)$. Mean difference $=4.70$ more dressing changes in the iodine mesh group, $95 \% \mathrm{Cl} 1.66$ to 7.74 (Analysis 1.3).

Costs associated with resource use (mean cost per participant included nursing time for dressing changes and cost of dressing): The mean cost of the treatment in the iodine mesh group was EUR 287 compared with EUR 268 in the alginate mesh group. The authors did not present any measures of variance around these estimates, and we have not analysed the data further.
Comparison 2: $10 \%$ povidone iodine solution soak compared with no soak (1 trial; 100 participants)

This comparison included one study which had six weeks' followup (Tosti 2014) and assessed treatment for wounds resulting from the closure of stoma orifice by secondary intention.

Primary outcomes

None reported.

\section{Secondary outcomes}

Resource use Mean length of stay, number of readmissions and number of re-operations are reported in Table 1. It is not clear the number of participants that these events occurred in (thus if data are clustered). We have not analysed the data further here.

\section{Comparison 3: Aloe vera compared with standard care (1 trial; 40 participants)}

This comparison contains one study with unclear follow-up (Schmidt 1991) and evaluated treatment of open wounds following a c-section.

\section{Primary outcomes}

Time to wound healing The mean time to wound healing in the aloe vera group was 53 days $(S D=24)$ compared with 83 days (SD $=28$ ) in the standard care group Table 1 . There was large loss to follow-up in this group which impacts on knowledge of who healed, thus we have not analysed these mean time-to-healing data further.

Adverse events The report notes that no adverse events were noted in either group, however data collection methods were not clear.

\section{Secondary outcomes}

None reported.

\section{Comparison 4: Zinc oxide povidone mesh dressing compared with povidone mesh dressing (classed as placebo by study authors) (1 trial; 64 participants)}

This comparison included one study which had 13 weeks' followup (Agren 2006) and assessed treatment for wounds resulting from excised pilonidal abscesses.

\section{Primary outcomes}

Time to wound healing Median time to healing was described as 54 days (interquartile range (IQR) 42 days to 71 days) in the zinc oxide mesh group and 62 days (IQR 55 to 82 days) for the placebo mesh group. The study authors presented this as an unadjusted hazard ratio of $1.30,95 \% \mathrm{Cl} 0.77$ to 2.19 in the direction of the zinc oxide group. GRADE assessment: Low quality evidence - downgraded twice for imprecision: once as $95 \% \mathrm{Cl}$ were very imprecise ranging from a $23 \%$ reduction in hazard of healing in the zinc oxide group to a 219\% increased hazard of healing (crossing RR 1) and once as data were from a single study with 64 participants (OIS $=388)$.

Wound infection Study authors presented wound infection 'manifest on presence of foul smell' with $1 / 33$ (3\%) of participants classed as having an infected wound in the zinc oxide mesh group compared with $8 / 31(26 \%)$ in the placebo group: RR 0.12 , $95 \% \mathrm{Cls} 0.02$ to 0.89 . Analysis 2.1. GRADE assessment for wound infection:Low quality evidence - downgraded once for indirectness 
of outcome which is a narrow definition of infection and once due to imprecision with data from a small single study with only 64 participants $(O I S=2070)$.

The study also recorded the number of participants prescribed antibiotics during the post-operative period - 3/33 (9\%) of participants in the zinc oxide group compared with $12 / 31$ (42\%) in the placebo group: RR $0.16,95 \% \mathrm{Cls} 0.04$ to 0.64 . (Analysis 2.2). GRADE assessment for wound infection: Low quality evidence - downgraded once for indirectness of outcome and once due to imprecision with data from a small single study with only 64 participants $(\mathrm{OIS}=2070)$.

\section{Secondary outcomes}

Pain We have extracted and presented data in Table 1 for information, however the instrument used to measure pain scores presented (at seven days pre and post mesh removal) was not clearly described. It was also not clear if a high or low score corresponded to more (or less) pain. We have not presented data further here.

\section{Antibiotic treatments compared with non-microbial treatments}

\section{Comparison 5: Sucralfate cream compared with petrolatum} cream (1 trial; 116 participants)

This comparison contained one trial with four weeks' follow-up (Gupta 2008) that evaluated treatments of participants with open wounds following haemorrhoidectomy

\section{Primary outcomes}

Proportion of wounds healed At four weeks 45/58 (78\%) participants in the sucralfate group had a healed wound compared with $30 / 58$ (52\%) in the control group RR: $1.50,95 \% \mathrm{Cl} 1.13$ to 1.99 . Analysis 3.1. GRADE assessment for proportion of wounds healed: Moderate quality evidence. Downgraded once due to imprecision with the estimate coming from a small study $(n=116)$ which did not meet the OIS (OIS = 200)

\section{Secondary outcomes}

Pain (measured using 10-point VAS scale $0=$ no pain to $10=$ very severe pain). Data are reported at seven days, 14 days and four weeks. We have presented all data in Table 1 . As noted in our methods we have summarised the latest time point here. The mean pain score at four weeks in the sucralfate group was $0.2(S D=0.1)$ compared with $1.4(0.3)$. Mean difference $=-1.20,95 \% \mathrm{Cl}-1.28$ to -01.12. Analysis 3.2.

\section{Comparison 6: Trimethoprim-sulfamethoxazole compared with placebo (1 trial; 162 participants)}

This comparison includes one study which had 90 days' follow-up (Duong 2010) and assessed treatment for wounds resulting from incision and drainage of a skin abscess.

\section{Primary outcomes}

Adverse events In the trimethoprim group 14/73 (19\%) participants had an adverse event attributed to medication compared with $9 / 76$ in the placebo group. RR $2.43,95 \% \mathrm{Cl} 0.99$ to 5.98 (Analysis 4.1). We have presented a complete case analysis. There were missing data in both groups.

\section{Secondary outcomes}

Wound recurrence (defined in this study as, "new lesions within $5 \mathrm{~cm}$ of original wound at 10 days"). At three months 13/46 (28\%) participants had a new lesion in the trimethoprim group compared with 15/52 (29\%) in the control. We have presented a complete case analysis. There was missing data in both groups. Mean difference: $0.98,95 \% \mathrm{Cl} 0.52$ to 1.84 . Analysis 4.2 .

\section{Comparison 7: Metronidazole/Ceftriaxone prophylactic antibiotic use compared with standard care (1 trial; 100 participants)}

This comparison contained one trial with six weeks' to eight weeks' follow-up (Khan 2014) that evaluated open wounds following haemorrhoidectomy.

\section{Primary outcomes}

Adverse events We have presented data for low grade fever in Table 1 but it is not clear how many participants had these events so we have not presented data further.

\section{Secondary outcomes}

None reported.

\section{Antiseptic treatment compared with an alternative antiseptic treatment}

Comparison 8: Rhizophora mangle bark extract compared with mercurochrome. (1 trial, 37 participants)

This comparison contained one trial with six weeks' follow-up (Fernandez 2002) that evaluated open wounds resulting from excision of pilonidal cyst/fistula.

Primary outcomes

No data available for narrative review - see Table 1.

\section{Secondary outcomes}

No data available for narrative review - see Table 1.

Comparison 9: Honey-soaked gauze compared with Edinburgh University Solution of Lime (EUSOL)-soaked gauze (1 trial; 43 participants)

This comparison contained one trial with three weeks' followup (Okeniyi 2005) that evaluated participants with open wounds resulting from excision of pyomyositis abscesses.

\section{Primary outcomes}

Proportion of wounds healed In the honey group 20/23 (87\%) of wounds healed compared to $11 / 20(55 \%)$ in the EUSOL group: RR; $1.58,95 \% \mathrm{Cl} 1.03$ to 2.42 (Analysis 5.1). GRADE assessment for proportion of wounds healed: Moderate quality evidence. Downgraded once due to imprecision with the estimate coming from a small study $(n=116)$ which did not meet the OIS (OIS = 200).

Adverse events No adverse events reported in either group.

\section{Secondary outcomes}

Resource use (mean length of hospital stay). The mean length of hospital stay in the honey group was 16.1 days $(S D=4.16)$ compared to 18.6 days $(S D=2.14)$ in the EUSOL group. Mean difference $=-2.50$ days, $95 \% \mathrm{Cl}-4.44$ to -0.56 . 
Comparison 10: Gauze with povidone iodine compared with gauze with Dermacyn ${ }^{\circledR}$ Wound Care (1 trial; 40 participants)

This comparison contained one trial with 24 weeks' follow-up (or until complete re-epithelialisation) (Piaggesi 2010) that evaluated diabetic participants with an infection on the foot requiring surgery resulting in an open wound.

\section{Primary outcomes}

Complete wound healing In the iodine group $11 / 20(55 \%)$ of wounds healed during the six-month follow-up compared to $18 / 20$ (90\%) in the Dermacyn ${ }^{\circledR}$ group: RR: $0.61,95 \% \mathrm{Cl} 0.40$ to 0.93 (Analysis 6.1). GRADE assessment for proportion of wounds healed: Moderate quality evidence. Downgraded once due to imprecision with the estimate coming from a small study $(n=116)$ which did not meet the OIS (OIS = 200).

Adverse events We have presented data for number of events in Table 1 but it is not clear how many participants had these events so we have not presented data further.

\section{Secondary outcomes}

None reported.

\section{Comparison 11: Triclosan compared with sodium hypochlorite (1 trial; 113 participants)}

This comparison contained one trial with three weeks' follow-up (Giannini 2014) that evaluated treatment of participants with open wound following haemorrhoidectomy.

\section{Primary outcomes}

Time to healing The mean time to healing in the triclosan group was 21.7 days $(S D=3.8)$ compared with 23.4 days $(S D=5.4)$ in the control group. We have presented summary data but it is not clear from the report that all wounds healed - and thus not clear that the mean is a valid measure of healing here. Mean difference $=-1.70$ days, $95 \% \mathrm{Cl}-3.41$ to 0.01 . Analysis 7.1. GRADE assessment for time to wound healing: Low quality evidence. Downgraded once due to imprecision with $95 \% \mathrm{Cls}$ for a difference in mean time to healing ranging from a 3.4 day reduction in time to healing in the triclosan group to almost 0 days difference; the estimate was from a small study that did not meet the OIS (OIS = 388). The study was also downgraded once for indirectness of outcome as we could not be sure that all wounds had healed and thus that mean time to healing was a valid measure.

Adverse events: The study reported only adverse events related to bleeding/secretions from the wound. At 21 days' follow-up adverse event scores in the triclosan group were 1.5 (SD 1.7) compared with 2.5 (SD 1.9) in the control group. Mean difference $=-1.00,95 \% \mathrm{Cl}$ -1.66 to -0.34 (Analysis 7.2 ).

\section{Secondary outcomes}

Table 1 reports data at one week, two weeks and three weeks for the following outcomes. Following our methods we have presented only three-week data here.

Pain (measured using 10-point VAS scale where lower score is better): At 21 days' follow-up pain scores in the triclosan group were 1.4 (SD 1.6) compared with 2.6 (SD 1.8) in the control group. Mean difference $=-1.20,95 \% \mathrm{Cl}-1.83$ to -0.57 (Analysis 7.3).

\section{DISCUSSION}

\section{Summary of main results}

This review includes all available RCT evidence for assessments of antiseptic/antibiotic agents in the treatment of populations with surgical wounds healing by secondary intention. Eleven trials with a total of 886 participants were included.

\section{Antiseptic treatments compared with non-anti-microbial treatments - four comparisons}

Two comparisons compared iodine preparations with no antiseptic treatment and found no clear evidence of effects on wound healing or wound infection for these treatments. Available outcome data were limited and what evidence there was low quality. One trial reported fewer dressing changes in the povidone iodine group.

One study compared a zinc oxide mesh dressing with a plain mesh dressing that was classed as placebo by study authors (Agren 2006). There was no clear evidence of a difference in time to wound healing between groups. There was some evidence of a difference in measures used to assess wound infection (wound with foul smell and number of participants prescribed antibiotics) which favoured the zinc oxide group. This was low quality evidence.

\section{Antibiotic treatments compared with non-microbial treatments - three comparisons}

One study reported that sucralfate cream increased the risk of healing open wounds following haemorrhoidectomy compared to a petrolatum cream (RR: $1.50,95 \% \mathrm{Cls} 1.13$ to 1.99 ) over a threeweek period. This evidence was graded as being of moderate quality and stems from one small study (Gupta 2008). The study also reported lower wound pain scores in the sucralfate group.

\section{Antiseptic treatment compared with an alternative antiseptic} treatment - four comparisons

There was a reduction in time to healing of open wounds following haemorrhoidectomy when treated with triclosan post-operatively compared with a standard sodium hypochlorite solution (mean difference -1.70 days, $95 \% \mathrm{Cl}-3.41$ to 0.01 ) (Giannini 2014). This was classed as low quality evidence.

There was moderate quality evidence that more open wounds resulting from excision of pyomyositis abscesses healed when treated with a honey-soaked gauze compared with a EUSOL-soaked gauze over three weeks' follow-up (Okeniyi 2005). There was also some evidence of a reduction in the mean length of hospital stay in the honey group. Evidence was taken from one small study that only had 43 participants.

There was moderate quality evidence that more Dermacyn ${ }^{\circledR}$ treated post-operative foot wounds in people with diabetes healed compared to those treated with iodine (Piaggesi 2010). Again estimates came from one small study with 40 participants.

Summary: there is no robust evidence on the relative effectiveness of any anti-microbial preparations evaluated to date for use on SWHSI. Where some evidence for possible treatment effects was reported, it stemmed from single studies with small participant numbers and was classed as moderate or low quality evidence. This means it is likely or very likely that further research will have an 
important impact on our confidence in the estimate of effect, and may change the estimate.

\section{Overall completeness and applicability of evidence}

Participants in the included trials had wounds which represented many of the types of surgery for which healing by secondary intention is commonly employed, and were therefore likely to be representative of clinical practice in terms of wounds which are intentionally healing in this way. However, only one trial appeared to include participants whose wounds were healing by secondary intention as a consequence of prior complications in healing by primary intention. The applicability of this review to patients with these types of wounds is therefore less clear.

\section{Quality of the evidence}

There was limited evidence available for this review. There were a small number of relevant studies eligible for inclusion and these evaluated a heterogenous range of treatments. It is not clear how the treatments evaluated related to common practices in terms of antiseptic and antibiotic use for SWHSI. The studies themselves had small sample sizes. RCTs need to be adequately powered so that they are able to detect treatment effects of a specified size if they exist. This means that sample size calculations should be used to help estimate the optimum number of people recruited to a trial. Evidence from limited numbers of participants or where limited numbers of events occur, or both, can also lead to confidence intervals that are fragile (i.e. not stable). This can be assessed by comparing the data available for a comparison to the optimal information size. All the comparisons in this review were informed by evidence where numbers of participants/events were lower than the calculated optimal information size.

It is also important that studies consider the outcome data that are being collected. Several studies presented data that could not easily be analysed here. Where time-to-healing data were presented it was as a mean time to healing. This is only valid if all participants have had the outcome of interest, otherwise the method cannot deal easily with participants who have not had the event, as mean time to event has to be imputed in these cases. Alternatively, people may only include data from those that had the event of interest in the mean calculation which places estimates at risk of bias. The correct approach is the use of survival (time to event methods). It is also important that trials clearly specify how outcome data are collected and defined. For example healing can be defined in a number of ways and this information was limited. We also note that given included studies were assessing antiseptics and antibiotics there was very limited presentation of wound infection data. Finally, studies should also clearly report how they planned to collect adverse event data and how this process was implemented in a standardised way across treatment arms. Overall the quality of outcome data presented was limited by both design and sample size.

Most studies were classed as being at low or unclear risk of bias. However, assessing risk of bias relies on good quality reporting of methods in study papers and this was limited in most of the eleven included studies. Key areas of good practice are the robust generation of a randomisation sequence, robust allocation concealment, and blinded outcome assessment where possible. All this information should be clearly included in the trial report, as trial authors should anticipate the inclusion of their trials in systematic reviews.

\section{Potential biases in the review process}

This review considered as much evidence as possible. It was not limited by language or publication status. We made attempts to identify studies which were not indexed on mainstream databases. We also contacted authors to try to ensure that limited reporting did not result in studies being excluded from the review. Although all of the included studies were published in English, we identified and assessed studies published in a range of languages. One of the excluded studies was published in Danish (Eldrup 1985) and three of the studies currently awaiting classification were published in other languages (Vasei 2008 (Farsi); Fillmann 2004 and Quilici 1998 (Portuguese)). It is possible that there may be unpublished data that we have been unable to identify. However, whilst we acknowledge the possibility of publication bias despite our attempts to locate unpublished studies, there were too few trials to test for its presence.

\section{Agreements and disagreements with other studies or reviews}

No other systematic review has specifically focused on antibacterial agents for surgical wounds healing by secondary intention. One previous Cochrane review (Vermeulen 2004) evaluated dressings and topical treatments for surgical wounds healing by secondary intention. Only two of the studies in our review were published before the Vermeulen review (Fernandez 2002; Schmidt 1991); Schmidt 1991 was included by the Vermeulen 2004 review but this did not identify Fernandez 2002. Our review identified and excluded several of the other trials included in Vermeulen's review (Cannavo 1998; Eldrup 1985; Viciano 2000; Walker 1991), principally because the use of an antibacterial agent was not the only systematic difference between trial arms.

A review of debridement for surgical wounds healing by secondary intention (Lewis 2001) was completed before the publication of any of the included studies except Schmidt 1991. There is overlap in scope with a more general review of treatments for wounds healing by secondary intention (Bradley 1999) but this was also published before any of the included studies from our review, except for Schmidt 1991 which is included in all three previous reviews as well as our review. As with the Vermeulen Cochrane review, our review identified and excluded some trials included in the older reviews (Viciano 2000 (included in Lewis 2001); Walker 1991; Williams 1981 (included in both Lewis 2001 and Bradley 1999)) because of additional differences between trial arms.

There was only very limited overlap between our review and reviews of specific types of antimicrobials used to treat wounds in general: iodine (Vermeulen 2010); silver (Storm-Versloot 2010), aloe vera, (Dat 2012), and honey (Jull 2013).

\section{AUTHORS' CONCLUSIONS}

\section{Implications for practice}

A comprehensive review of current evidence did not find convincing evidence in favour of the use of any particular antimicrobial treatment for surgical wounds healing by secondary intention for outcomes which matter (including wound healing and infection). Although some possible treatment effects were identified, the 
quality of the evidence varied from moderate to very low; all of the evidence was subject to some limitations. There was almost no evidence comparing different antimicrobial treatments. All of the evidence related to topical treatments.

\section{Implications for research}

Currently there is no consistent evidence of a difference in outcomes between open surgical wounds treated with antimicrobial and non-antimicrobial treatments or with different antimicrobial interventions. Any investment in future primary research on treatment choices for surgical wounds healing by secondary intention must maximise its value to decision-makers. Given the large number of treatment options, the design of future trials should be driven by high priority questions from patients and other decision makers. It is also important for research to ensure that the outcomes that are collected in research studies are those that matter to patients, carers and health professionals. Where trials are conducted, good practice guidelines must be followed in their design, implementation and reporting. Such trials should be adequately powered to detect differences in healing rates, should use appropriate statistical methods for time-to-event analyses and should include adequate follow-up (appropriate to the type of surgery undertaken) for all participants to heal.

\section{ACKNOWLEDGEMENTS}

The authors are grateful to the following peer reviewers for their time and comments: Kurinchi Gurusamy, Elizabeth Matovinovic, Roy Buffery, Gill Worthy, Anna Joseph and AG Rhadika. The authors acknowledge the contribution of Megan Prictor and Denise Mitchell, copy editors. They would also like to thank Zhenmi Liu for her assistance with screening of papers for inclusion, and Ana Luiza C Martimbianco for her translation services. 


\section{RE F E R E N C E S}

\section{References to studies included in this review}

\section{Agren 2006 \{published data only\}}

Agren MS, Ostenfeld U, Kallehave F, Gong Y, Raffn K, Crawford ME, et al.A randomized, double-blind, placebocontrolled multicenter trial evaluating topical zinc oxide for acute open wounds following pilonidal disease excision. Wound Repair and Regeneration 2006;15:526-35.

\section{Brehant 2009 \{published data only\}}

Brehant O, Pessaux P, Regenet N, Tuech JJ, Panaro F, Mantion G, et al. Healing of stoma orifices: multicenter, prospective, randomized study comparing calcium alginate mesh and polyvidone iodine mesh. World Journal of Surgery 2009;33:1795-1801.

\section{Duong 2010 \{published data only\}}

Duong M, Markwell S, Peter J, Barenkamp S.Randomized, controlled trial of antibiotics in the management of communityacquired skin abscesses in the paediatric patient. Annals of Emergency Medicine 2010;55:401-7.

Fernandez 2002 \{published data only\} Fernandez O, Capdevila JZ, Dalla G, Melchor G.Efficacy of Rhizophora mangle aqueous bark extract in the healing of open surgical wounds. Fitoterapia 2002;73:564-8.

\section{Giannini 2014 \{published data only\}}

Giannini I, Pecorella G, Pennisi D, Santangelo G, Digennaro R, Latorre $\mathrm{F}$ et al.Control of post-hemorrhoidectomy symptoms and wound healing by Triclosan: a randomized, double-blind, controlled trial. Minerva Chirurgica 2014;69:75-82.

\section{Gupta 2008 \{published data only\}}

Gupta PJ, Heda PS, Kalaskar S, Tamaskar VP.Topical sucralfate decreases pain after hemorrhoidectomy and improves healing: a randomized, blinded, controlled study. Diseases of the Colon and Rectum 2008;51:231-4.

\section{Khan 2014 \{published data only\}}

Khan KI, Akmal M, Waqas A, Mahmood S.Role of prophylactic antibiotics in Milligan Morgan hemorrhoidectomy - a randomized control trial. International Journal of Surgery 2014 2014;12:868-71.

\section{Okeniyi 2005 \{published data only\}}

Okeniyi JA, Olubanjo OO, Ogunlesi TA, Oyelami OA.Comparison of healing of incised abscess wounds with honey and EUSOL dressing. Journal of Alternative and Complementary Medicine 2005;11:511-13.

\section{Piaggesi 2010 \{published data only\}}

Piaggesi A, Goretti C, Mazzurco S, Tascini C, Leonildi A, Rizzo L et al.A randomized controlled trial to examine the efficacy and safety of a new super-oxidized solution for the management of wide post-surgical lesions of the diabetic foot. The International Journal of Lower Extremity Wounds 2010;9:10-15.
Schmidt 1991 \{published data only\}

Schmidt JM, Greenspoon JS.Aloe Vera dermal wound gel is associated with a delay in wound healing. Obstretics \& Gynaecology 1991 July;78:115-7.

Tosti 2014 \{published data only\}

Tosti R, lorio J, Fowler JR, Gaughan J, Thoder JJ, Schaffer AA.Povidone-iodine soaks for hand abscesses: a prospective randomized trial. The Journal of Hand Surgery 2014;39:962-5.

\section{References to studies excluded from this review}

Cannavo 1998 \{published data only\}

Cannavo M, Fairbrother G, Owen D, Ingle J, Lumley T.A comparison of dressings in the management of surgical abdominal wounds. Journal of Wound Care 1998;7(2):57-62.

\section{Eldrup 1985 \{published data only\}}

Eldrup J.Silastic foam dressing compared with mèche treatment in open treatment following excision of pilonidal cyst [Silastic foam dressing versus mèchebehandeling ved åben behandling efter excision af cystis pilonidalis]. Ugeskr Laeger 1985;147(5):408-9.

\section{Goetze 2006 \{published data only\}}

Goetze S, Ziemer M, Kaatz M, Lipman RD, Elsner P.Treatment of superficial surgical wounds after removal of seborrheic keratoses: a single-blinded randomized-controlled clinical study. Dermatologic Surgery 2006;32:661-8.

Hien 1988 \{published data only\}

Hien NT, Prawer SE, Katz HI.Facilitated wound healing using transparent film dressing following Mohs micrographic surgery. Archives of Dermatology 1988;124:903-06.

\section{Moore 2000 \{published data only\}}

* Foster L, Moore P.The application of a cellulose-based fibre dressing in surgical wounds. Journal of Wound Care 1997;6(10):469-73.

Moore PJ, Foster L.Cost benefits of two dressings in the management of surgical wounds. British Journal of Nursing 2000;9:1128-32.

\section{Murthy 2012 \{published data only\}}

Murthy MB, Murthy BK, Bhave S.Comparison of safety and efficacy of papaya dressing with hydrogen peroxide solution on wound bed preparation in patients with wound gape. Indian Journal of Pharmacology 2012;44:784-7.

Nielsen 2012 \{published data only\}

Nielsen AM, Andriessen A.Prospective cohort study on surgical wounds comparing a polyhexanide-containing biocellulose dressing with a dialkyl-carbamoyl-chloridecontaining hydrophobic dressing. Advances in Skin \& Wound Care 2012;25:409-13. 
Sozener 2011 \{published data only\}

Sozener U, Gedik E, Aslar AK, Ergun H, Elhan H, Memikoglu $O$ et al.Does adjuvant antibiotic treatment after drainage of anorectal abscess prevent development of anal fistulas? A randomized, placebo-controlled, double-blind, multicenter study. Diseases of the Colon and Rectum 2011;54:923-9.

Taylor 2011 \{published data only\}

Taylor S, Averyhart A, Heath C.A comparison of facial wound healing agents after removal of dermatosis papulosa nigra in an African American population. Journal of the American Academy of Dermatology 2011;64(2 (SUPPL 1)):AB173.

* Taylor SC, Averyhart AN, Heath CR.Postprocedural woundhealing efficacy following removal of dermatosis papulosa nigra lesions in an African American population: a comparison of a skin protectant ointment and a topical antibiotic. Journal of the American Academy of Dermatology 2011;64(3):S30-S35.

\section{Viciano 2000 \{published data only\}}

Viciano V, Castera JE, Medrano J, Aguilo J, Torro J, Botella MG, et al.Effect of hydrocolloid dressings on healing by second intention after excision of pilonidal sinus. European Journal of Surgery 2000 Mar;166:229-32.

\section{Walker 1991 \{published data only\}}

Walker AJ, Shoulert PJ, Leicester RJ.Comparison between Eusol and Silastic foam dressing in the postoperative management of pilonidal sinus. Journal Royal College Surgery Edinburgh 1991 Apr;36:105-6.

\section{Williams 1981 \{published data only\}}

Williams RHP.Multicentre prospective trial of silastic foam dressing in management of open granulating wounds. British Medical Journal 1981 Jan 3;282(6257):21-2.

\section{Yang 2013 \{published data only\}}

Yang X, Zhou H-F, Zhang S-M, Wang Y-Z, Ye N, Wang Y et al.Hydrofiber dressing with silver in wound healing after surgery for anal fistula. Chinese Journal of Tissue Engineering Research 2013;16:8835-41.

\section{References to studies awaiting assessment}

Fillmann 2004 \{published data only\}

Fillmann EEP, Fillmann LS, Fillmann HS, Pandolfo G.Antibiotic prophylaxis in surgical treatment of hemorrhoidal disease: effect on control of postoperative pain, healing and wound complications. [Antibioticoprofilaxia no tratamento cirurgico da doenca hemorroidaria: efeito sobre o controle da dor posoperatoria, cicatrizacao das feridas e complicacoes]. Revista Brasileira de Coloproctologia 2004;24(1):5-9.

\section{Mirzabeygi 2011 \{published data only\}}

Mirzabeygi P, Ala S, Saeedi M, Eshghi F. In:International journal of Clinical Pharmacy Conference: 39th ESCP European Symposium on Clinical Pharmacy and 13th SFPC Congress: Clinical Pharmacy at the Front Line of Innovations Lyon France. Conference 21 to 23 October 2010. 2011:334.

\section{Quilici 1998 \{published data only\}}

Quilici FA, Dos Reis Neto JA, Cordeiro F, De Moraes SP, Ciquini SA, Nogueira LAL, et al.Hemorrhoidectomys postsurgical. Lidocaine plus Neomycin sulfate unguent topical use with or without hyaluronidase. Revista Brasileira de Medicina 1998;55(11):911-18.

\section{Vasei 2008 \{published data only\}}

Vasei N, Jahangiri K.Application of honey in treatment of surgical wound of pilonidal sinus: a randomized clinical trial. Payesh Health Monitor 2008;7(4):210.

\section{Additional references}

\section{AL-Khamis 2010}

AL-Khamis A, McCallum I, King PM, Bruce J.Healing by primary versus secondary intention after surgical treatment for pilonidal sinus. Cochrane Database of Systematic Reviews 2010, Issue 1. Art. No: CD006213. [DOI: 10.1002/14651858.CD006213.pub3]

\section{Ashby 2014 [pers comm]}

Ashby R, Dumville JC, Fletcher M, Cullum NA, Chetter IC.A survey of surgical wounds healing by secondary intention; assessment of prevalence, aetiology, duration and management. Personal communication to J Dumville October 2014.

\section{AWMA 2011}

Australian Wound Management Association Inc.Position document of the Australian Wound Management Association: Bacterial impact on wound healing: from contamination to infection. http://www.awma.com.au/publications/2011_ bacterial_impact_position_1.5.pdf (accessed 3 February 2016).

\section{Berry 1996}

Berry DP, Bale S, Harding KG.Dressings for treating cavity wounds. Journal of Wound Care 1996;5(1):10-17.

\section{BNF 2014}

British National Formulary, British Medical Association, British Royal Pharmaceutical Society of Great Britain.British National Formulary 66. London: British Medical Association, 2014.

\section{Bowler 2003}

Bowler PG.The 105 bacterial growth guideline: reassessing its clinical relevance in wound healing. Ostomy Wound Management 2003;49(1):44-53.

\section{Bradley 1999}

Bradley M, Cullum N, Nelson E A, Petticrew M, Sheldon T, Torgerson D.Systematic reviews of wound care management: (2) dressings and topical agents used in the healing of chronic wounds. Health Technology Assessment 1999;3(17 Part 2):1-135.

\section{Carville 2008}

Carville K, Cuddigan J, Fletcher J, Fuchs P, Harding K, Ishikawa O, et al.Wound infection in clinical practice: shaping the future. An International Consensus Document. International Wound Journal 2008;5(Supp 3):1-11. 


\section{Coello 2005}

Coello R, Charlett A, Wilson J, Ward V, Pearson A, Borriello P.Adverse impact of surgical site infections in English hospitals. Journal of Hospital Infection 2005;60(2):93-103.

\section{Cutting 2004}

Cutting KF, White R.Defined and refined: criteria for identifying wound infection revisited. British Journal of Community Nursing 2004;9(3 Supp 1):6-15.

\section{Dat 2012}

Dat AD, Poon F, Pham KBT, Doust J.Aloe vera for treating acute and chronic wounds. Cochrane Database of Systematic Reviews 2012, Issue 2. Art. No: CD008762. [DOI: 10.1002/14651858.CD008762.pub2]

\section{Davies 2007}

Davies CE, Hill KE, Newcombe RG, Stephens P, Wilson MJ, Harding KG, et al.A prospective study of the microbiology of chronic venous leg ulcers to reevaluate the clinical predictive value of tissue biopsies and swabs. Wound Repair and Regeneration 2007;15(1):17-22.

\section{Deeks 2011}

Deeks JJ, Higgins JPT, Altman DG (editors).Chapter 9: Analysing data and undertaking meta-analyses. In: Higgins JPT, Green $\mathrm{S}$ (editors). Cochrane Handbook for Systematic Reviews of Interventions. Version 5.1.0 [updated March 2011]. The Cochrane Collaboration 2011. Available from www.cochranehandbook.org.

\section{Dowd 2008}

Dowd SE, Sun Y, Secor PR, Rhoads DD, Wolcott BM, James GA, et al.Survey of bacterial diversity in chronic wounds using Pyrosequencing, DGGE, and full ribosome shotgun sequencing. BMC Microbiology 2008;8(43):DOI: 10.1186/1471-2180-8-43.

\section{Edwards 2004}

Edwards R, Harding KG.Bacteria and wound healing. Current Opinion in Infectious Disease 2004;17:91-6.

\section{EuroQoL Group 1990}

EuroQuoL Group.EuroQoL: a new facility for the measurement of heath-related quality of life. Health Policy 1990;16:199-208.

\section{Gardner 2001}

Gardner SE, Franz RA, Doebbeling BN.The validity of the clinical signs and symptoms used to identify localized chronic wound infection. Wound Repair and Regeneration 2001;9(3):178-86.

\section{GRADE 2013}

GRADE working group: Schünemann $\mathrm{H}$, Brożek J, Guyatt G, Oxman A (Eds).GRADE Handbook. http:// gdt.guidelinedevelopment.org/central_prod/_design/client/ handbook/handbook.html (accessed 5 February 2016).

\section{Hahn 2005}

Hahn S, Puffer S, Torgerson DJ, Watson J.Methodological bias in cluster randomised trials. BMC Medical Research Methodology 2005;5(10):DOI: 10.1186/1471-2288-5-10.

\section{Hall 2014}

Hall J, Buckley HL, Lamb KA, Stubbs N, Saramago P, Dumville JC, et al.Point prevalence of complex wounds in a defined United Kingdom population. Wound Repair and Regeneration 2014;22(6):694-700. [DOI: 10.1111/wrr.12230]

\section{Higgins 2003}

Higgins JPT, Thompson SG, Deeks JJ, Altman DG.Measuring inconsistency in meta-analyses. BMJ 2003;327(7414):557-60.

\section{Higgins 2011a}

Higgins JPT, Altman DG (editors).Chapter 8: Searching for studies. In: Higgins JPT, Green S (editors). Cochrane Handbook for Systematic Reviews of Interventions Version 5.1.0 [updated March 2011]. The Cochrane Collaboration, 2011. Available from www.cochrane-handbook.org.

\section{Higgins 2011b}

Higgins JPT, Deeks JJ, Altman DG (editors).Chapter 16: Special topics in statistics. In: Higgins JPT, Green S (editors). Cochrane Handbook for Systematic Reviews of Interventions Version 5.1.0 [updated March 2011]. The Cochrane Collaboration, 2011. Available from www.cochrane-handbook.org.

\section{Howell-Jones 2005}

Howell-Jones RS, Wilson MJ, Hill KE, Price PE, Thomas DW.A review of the microbiology, antibiotic usage and resistance in chronic skin wounds. Journal of Antimicrobial Chemotherapy 2005;55(2):143-9.

\section{Jull 2013}

Jull AB, Walker N, Deshpande S. Honey as a topical treatment for wounds. Cochrane Database of Systematic Reviews 2013, Issue 2. Art. No: CD005083. [DOI: 10.1002/14651858.CD005083.pub3]

\section{Kingsley 2004}

Kingsley A, White R, Gray D.The wound infection continuum: a revised perspective. APW Supplement. Wounds UK 2004;1(1):13-8.

\section{Kontopantelis 2012}

Kontopantelis E, Reeves D.Performance of statistical methods for meta-analysis when true study effects are non-normally distributed: a simulation study. Statistical Methods in Medical Research 2012;21(4):409-26.

\section{Kontopantelis 2013}

Kontopantelis E, Springate DA, Reeves D.A re-analysis of the Cochrane Library data: the dangers of unobserved heterogeneity in meta-analyses. PLoS One 2013;26:e69930.

\section{Lefebvre 2011}

Lefebvre C, Manheimer E, Glanville J.Chapter 6: Searching for studies. In: Higgins JPT, Green S (editors). Cochrane Handbook for Systematic Reviews of Interventions Version 5.1.0 [updated March 2011]. The Cochrane Collaboration, 2011. Available from www.cochrane-handbook.org.

\section{Lewis 2001}

Lewis R, Whiting P, ter Riet G, O'Meara S, Glanville J.A rapid and systematic review of the clinical and cost-effectiveness 
of debriding agents in treating surgical wounds healing by secondary intention. Health Technology Assessment 2001;5(14):1-131.

\section{Liberati 2009}

Liberati A, Altman DG, Tetzlaff J, Mulrow C, Gotzsche PC, loannidis JP, et al.The PRISMA statement for reporting systematic reviews and meta-analyses of studies that evaluate health care interventions: explanation and elaboration. PLOS Medicine 2009;6:e1000100.

\section{Macpherson 2004}

Macpherson G (ed).Black's Student Medical Dictionary. London: A\&C Black Publishers Limited, 2004.

\section{Madsen 1996}

Madsen SM, Westh H, Danielsen L, Rosdahl VT.Bacterial colonisation and healing of venous leg ulcers. APMIS: Acta Pathologica, Microbiologica, et Immunologica Scandinavica 1996;104(2):895-9.

\section{McCaughan 2014 [pers comm]}

McCaughan D, Sheard L, Dumville JC, Cullum NA, Chetter IC, Oswald $A$, et al.Patients' perceptions and experiences of living with a surgical wound healing by secondary intention: an indepth qualitative study. Personal communication to J Dumville October 2014.

\section{MeReC 2010}

MeReC.Evidence-based prescribing of advanced wound dressings for chronic wounds in primary care. MeReC Bulletin 2010;21(01).

\section{Moues 2004}

Moues CM, Vos MC, Van Den Bend G-JCM, Stijnen TH.Bacterial load in relation to vacuum-assisted closure wound therapy: a prospective randomized trial. Wound Repair and Regeneration 2004;12(1):11-17.

\section{NICE 2008}

National Institute for Health and Care Excellence.Surgical site infection: prevention and treatment of surgical site infection. https://www.nice.org.uk/guidance/cg74 (accessed 3 February 2016).

\section{O'Meara 2001}

O'Meara S, Cullum NA, Majid M, Sheldon TA.Systematic review of antimicrobial agents used for chronic wounds. British Journal of Surgery 2001;88(1):4-21.

\section{Parmar 1998}

Parmar MKB, Torri V, Stewart L.Extracting summary statistics to perform meta-analyses of the published literature for survival endpoints. Statistics in Medicine 1998;17:2815-34.

\section{Percival 2004}

Percival SL, Bowler PG.Biofilms and their potential role in wound healing. Wounds 2004;16(7):234-40.

\section{Plowman 2001}

Plowman R, Graves N, Griffin MAS, Roberts JA, Swan AV, Cookson $\mathrm{B}$, et al.The rate and cost of hospital-acquired infections occurring in patients admitted to selected specialties of a district general hospital in England and the national burden imposed. Journal of Hospital Infection 2001;47(3):198-209.

\section{RevMan 2014 [Computer program]}

The Nordic Cochrane Centre Review Manager (RevMan).The Cochrane Collaboration, Version 5.3. Copenhagen: The Nordic Cochrane Centre, 2014.

\section{Robson 1968}

Robson MC, Lea CE, Dalton JB, Heggers JP.Quantitative bacteriology and delayed wound closure. Surgical Forum 1968;19:501.

\section{Sandy-Hodgetts 2013}

Sandy-Hodgetts K, Carville K, Leslie GD.Determining risk factors for surgical wound dehiscence: a literature review. International Wound Journal 2013;May:epub ahead of print. [DOI: 10.1111/ iwj.12088

\section{Schünemann 2011a}

Schünemann HJ, Oxman AD, Higgins JPT, Deeks JJ, Glasziou P, Guyatt GH.Chapter 12: Interpreting results and drawing conclusions. In: Higgins JPT, Green S (editors). Cochrane Handbook for Systematic Reviews of Interventions Version 5.1.0 [updated March 2011]. The Cochrane Collaboration, 2011. Available from www.cochrane-handbook.org.

\section{Schünemann 2011b}

Schünemann HJ, Oxman AD, Higgins JPT, Vist GE, Glasziou P, Guyatt GH.Chapter 11: Presenting results and 'Summary of findings' tables. In: Higgins JPT, Green S (editors). Cochrane Handbook for Systematic Reviews of Interventions Version 5.1.0 [updated March 2011]. The Cochrane Collaboration, 2011. Available from www.cochrane-handbook.org.

\section{Shackelford 2002}

Shackelford DP, Fackler E, Hoffman MK, Atkinson S.Use of topical recombinant human platelet-derived growth factor BB in abdominal wound separation. American Journal of Obstetrics and Gynecology 2002;186(4):701-4.

\section{SIGN 2011}

Scottish Intercollegiate Guidelines Network (SIGN).Search filters. http://www.sign.ac.uk/methodology/ filters.html\#random (accessed 5 February 2016).

\section{Smith 2014}

Smith SR, Pearce LE, Newton K, Dumville JC, Smith JA, Barrow PJ, et al.Internal dressings for healing perianal abscess cavities. Cochrane Database of Systematic Reviews 2014, Issue 7. Art. No: CD011193. [DOI: 10.1002/14651858.CD011193]

\section{Smyth 2008}

Smyth ETM, Mcllvenny G, Enstone JE, Emmerson AM, Humphreys $\mathrm{H}$, Fitzpatrick F, et al.Four country healthcare associated infection prevalence survey 2006: overview of the results. Journal of Hospital Infection 2008;69(3):230-48. 


\section{Srinivasaiah 2007}

Srinivasaiah N, Dugdall H, Barrett S, Drew PJ.A point prevalence survey of wounds in north-east England. Journal of Wound Care 2007;16(10):413-9.

\section{Sterne 2011}

Sterne JAC, Egger M, Moher D.Chapter 10: Addressing reporting biases. In: Higgins JPT, Green S (editors). Cochrane Handbook for Systematic Reviews of Interventions. Version 5.1.0 [updated March 2011]. The Cochrane Collaboration, 2011. Available from www.cochrane-handbook.org.

\section{Storm-Versloot 2010}

Storm-Versloot MN, Vos CG, Ubbink DT, Vermeulen H.Topical silver for preventing wound infection. Cochrane Database of Systematic Reviews 2010, Issue 3. Art. No: CD006478. [DOI: 10.1002/14651858.CD006478.pub2]

\section{Thompson 1999}

Thompson SG, Sharp SJ.Explaining heterogeneity in metaanalysis: a comparison of methods. Statistics in Medicine 1999;18:2693-708.

\section{Thompson 2002}

Thompson SG, Higgins JPT. How should meta-regression analyses be undertaken and interpreted? Statistics in Medicine 2002;21:1559-74.

\section{Tierney 2007}

Tierney JF, Stewart LA, Ghersi D, Burdett S, Sydes MR.Practical methods for incorporating summary time-to-event data into meta-analysis. Trials 2007;7(8):16.

\section{Trengove 1996}

Trengove NJ, Stacey MC, McGechie DF, Stingemore NF, Mata S.Qualitative bacteriology and leg ulcer healing. Journal of Wound Care 1996;5:277-80.

\section{CHARACTERISTICS OF STUDIES}

Characteristics of included studies [ordered by study ID]

\section{Vermeulen 2004}

Vermueulen H, Ubbink DT, Goosens A, De Vos R, Legemate DA, Westerbos SJ.Dressings and topical agents for surgical wounds healing by secondary intention. Cochrane Database of Systematic Reviews 2004, Issue 1. Art. No: CD003554. [DOI: 10.1002/14651858.CD003554.pub2]

\section{Vermeulen 2010}

Vermeulen $\mathrm{H}$, Westerbos SJ, Ubbink DT.Benefit and harm of iodine in wound care: a systematic review. Journal of Hospital Infection 2010;76(3):191-9.

\section{Vowden 2009}

Vowden KR, Vowden P.The prevalence, management and outcome for acute wounds identified in a wound care survey within one English health care district. Journal of Tissue Viability 2009;18:7-12.

\section{Ware 1992}

Ware JE, Sherbourne CD.The MOS 36-item short-form health survey (SF-36). I. Conceptual framework and item selection. Medical Care 1992;30(6):473-83.

\section{Wolcott 2008}

Wolcott RD, Rhoads DD, Dowd SE.Biofilms and chronic wound inflammation. Journal of Wound Care 2008;17(8):333-41.

\section{WUWHS 2008}

World Union of Wound Healing Societies.Principles of Best Practice. Wound infection in clinical practice: an international consensus. London: MEP Ltd, 2008.

* Indicates the major publication for the study

\section{Agren 2006}

\section{Study characteristics}

\begin{tabular}{ll} 
Methods & Two-arm RCT \\
& Multi-centred, conducted in two hospitals in Denmark \\
& Patients were re-examined post-operative day $7,30,60$, and 90 \\
\hline Participants & $\begin{array}{l}\text { In participants were randomised } \\
\text { Inclusion criteria: } 18 \text { years or older, operated on for the first time for pilonidal abscess or chronic pi- } \\
\text { Exclusion criteria: hypersensitivity to zinc, dementia, insufficient in Danish, or pregnant/lactating }\end{array}$
\end{tabular}


Agren 2006 (Continued)

Interventions
Group A: Zinc oxide (3\%) polyvinylpyrrolidone (povidone) bound to a $50 \mathrm{~cm}$-long cotton mesh of 2 ( 0.5 g) or $5(1.25 \mathrm{~g}) \mathrm{cm}$ widths. Median zinc oxide concentration of mesh reported as $33 \mathrm{mg} / \mathrm{g}$ (interquartile range $33 \mathrm{mg} / \mathrm{g}$ to $35 \mathrm{mg} / \mathrm{g})(\mathrm{n}=33)$

Group B: Polyvinylpyrrolidone (povidone) bound to a $50 \mathrm{~cm}$-long cotton fine mesh of 2 ( $0.5 \mathrm{~g}$ ) or 5 (1.25 g) $\mathrm{cm}$ widths $(\mathrm{n}=31)$

The dry meshes were applied to the wounds in at least four layers. Wounds were treated daily during the first seven post-operative days with either zinc oxide or placebo meshes and thereafter every second day

Perioperative prophylactic antibiotics were not given. The necessity of systemic antibiotic treatment post-operatively was judged on clinical signs of wound infection

\section{Outcomes}

Notes

\section{Primary outcomes:}

- Time to complete wound closure (defined as complete coverage of the wound with visible epithelium)

- Adverse events (Any serious or non-serious adverse events occurring until wound closure or day 90 were reported to the co-ordinating investigator. The investigator judged the adverse event as definitely not, improbable, probable, or most probably related to the intervention).

- Wound infection (defined by smell; the number of people given antibiotics post-operatively was also reported)

\section{Secondary outcomes:}

- Pain measured at day 7 post-op as pain intensity. The scale used was not reported although a VAS score measured as $\mathrm{mm}$ is mentioned. It is not clear if higher or low scores relate to more pain)

Funding source: The Pharmacy Foundation of 1991, Denmark, and the Danish Medical Research Council (22-02-0287).

Missing data were replaced by the mean value of both groups of respective covariates in the Cox model.

\section{Risk of bias}

\begin{tabular}{lll}
\hline Bias & Authors' judgement & Support for judgement \\
\hline $\begin{array}{ll}\text { Random sequence genera- } \\
\text { tion (selection bias) }\end{array}$ & Low risk & $\begin{array}{l}\text { Quote: The patient allocation sequence was computer-generated 1:1 in vari- } \\
\text { able block sizes of four or six stratified for center. }\end{array}$ \\
& & Comment: Adequate
\end{tabular}

Allocation concealment Low risk

(selection bias)
Quotes: Allocation concealment was performed using centrally packaged, consecutively numbered, identical packages containing zinc oxide or placebo meshes.

The investigators were asked to use the next available number when a new patient entered the trial.

Randomization codes were kept confidential until final assessments of the patients, data entry, statistical analyses, and main conclusions were completed.

Comment: Adequate

Blinding of participants Low risk and personnel (perfor-

Quotes: The zinc and placebo meshes were manufactured in Class 100,000 facilities, sterile, and indistinguishable in color, texture, and smell.

In this randomized, double-blind, placebo-controlled multicentre trial, the patients were centrally randomized to receive either topical zinc oxide meshes or placebo meshes during pilonidal wound healing. 
Comment: Blinding occurred.

\section{Blinding of outcome as- Low risk} sessment (detection bias) All outcomes

\section{Outcome - wound healing}

Quote: The wound was evaluated clinically with respect to complete wound closure by assessors blinded to treatment.

Comment: Adequate

\section{Outcome - wound infection}

Quote: In the present trial, we took all precautions to avoid bias including a priori sample-size calculation, adequate allocation

concealment, placebo-controlled, blinded outcome assessment, a predefined primary outcome measure, and intention-

to-treat analyses.

Comment: Suggests that other outcomes were also assessed in blinded way

Incomplete outcome data Low risk

(attrition bias)

Quotes: A 17-year-old female patient was included by mistake, but has been retained in the trial for analyses. Three patients in the zinc oxide group and two patients in the placebo group withdrew from the study within 2 weeks after randomization for unknown reasons. Participants lost to follow-up were censored at the date of last contact to the investigators.

Comments: As close to ITT as possible. Limited loss of data.

Selective reporting (re- Low risk None-protocol not obtained
porting bias)

Other bias Low risk None noted

Brehant 2009

\section{Study characteristics}

Mwo-arm RCT
Multi-centred, conducted in four hospitals in France
The patients were examined every day while they were in hospital. The volumetric measurement of the
SO was carried
out every 7 days for 1 month on days $0,7,14,21$, and 28 . All the patients were reviewed during the sixth
post-operative
week for the end-of-study visit

\section{Participants}

\section{1 participants randomised}

Inclusion criteria: patients having re-establishment of digestive continuity with closure of the stoma orifice by secondary intention

Exclusion criteria: patients aged 17 years or younger, emergency surgery, serious allergy to iodine or to one of the treatments used, a stoma affecting a digestive segment other than the small intestine or the colon, patient with dysthyroidia, patients requiring additional protection (pregnant or breast-feeding woman, subject under wardship or guardianship), and informed consent not signed

Group B: alginate mesh $(n=37)$ 
Brehant 2009 (Continued)

No manufacturer details for meshes given in paper. The length of the dressings was based on the volume of the whole cavity. No other local drainage was used. Dressings were changed every two days, with only one dressing whenever possible

\section{No co-interventions listed}

Primary outcomes:
- Proportion of wounds healed (mean time to healing data
-
- Cxtracted as not all wounds healed).
Secondary outcomes:
- Change in size (percentage filling of the SO cavity at day 28)
- Surgical site infection (CDC definition)
- Resource use (number of dressing change)

Notes Funding source: not reported

\section{Risk of bias}

\begin{tabular}{lll}
\hline Bias & Authors' judgement & Support for judgement \\
\hline $\begin{array}{l}\text { Random sequence genera- } \\
\text { tion (selection bias) }\end{array}$ & Unclear risk & No information reported \\
\hline $\begin{array}{l}\text { Allocation concealment } \\
\text { (selection bias) }\end{array}$ & Unclear risk & No information reported \\
\hline $\begin{array}{l}\text { Blinding of participants } \\
\text { and personnel (perfor- } \\
\text { mance bias) }\end{array}$ & Unclear risk & No information reported \\
All outcomes & & \\
\hline
\end{tabular}

Blinding of outcome as-
sessment (detection bias) $\quad$ Unclear risk information on who collected any outcome data reported

All outcomes

Incomplete outcome data Unclear risk
(attrition bias)

Quote: "Five patients (all in the polyvidone iodine mesh group) were excluded from the analysis either because they refused to follow the protocol $(n=2)$, or be-

All outcomes cause of the occurrence of an anastomotic fistula exteriorized through the old stoma orifice $(n=3)$. The statistical analysis therefore involved 66 patients"

Comment: Five participants in one group were excluded completely from analysis. Not clear what implications this has on attrition bias

\begin{tabular}{lll}
\hline $\begin{array}{l}\text { Selective reporting (re- } \\
\text { porting bias) }\end{array}$ & Low risk & None noted - protocol not obtained \\
\hline Other bias & Low risk & None noted \\
\hline
\end{tabular}

Duong 2010

\section{Study characteristics}

Methods Two-arm RCT


Duong 2010 (Continued)

Undertaken in the emergency department of one hospital in the USA

Follow-up took place at 10 to 14 days and 90 days

Participants were undergoing incision and drainage of a skin abscess
161 Participants were randomised
Inclusion criteria: aged 3 months to 18 years with a skin abscess; non-toxic with a temperature less
than $38.4^{\circ} \mathrm{C}\left(101.1^{\circ} \mathrm{F}\right)$. Diagnostic criteria for skin abscess included the presence of all of the following
features: $(1)$ acute onset within 1 week, $(2)$ fluctuance, (3) erythema, (4) induration, and (5) tenderness,
with or without purulent drainage; patients or parent/guardian able to give informed consent
Exclusion criteria: known chronic health problems, such as diabetes; receiving immunosuppressive
medications, such as oral steroids for asthma; recent (within the last week) or current antibiotic usage;
contraindication to trimethoprimsulfamethoxazole, did not require surgery - for example for more su-
perficial skin infections such as folliculitis
The surgery performed involved cleansing of the skin overlying all skin abscesses with 10\% povidone
iodine solution and then incision with a no. 11 blade, probing for loculations, and irrigation with nor-
mal saline solution. Decisions concerning the need for procedural sedation, the incision size, and $24-$
hour wound packing were physician dependent

Interventions Group A: trimethoprim-sulfamethoxazole (10 mg to $12 \mathrm{mg}$ trimethoprim/ $\mathrm{kg} /$ day divided into 2 doses, with a maximum dose of $160 \mathrm{mg}$

trimethoprim/dose). Given for 10 days post-operatively. Only the liquid formulation of the antibiotic was used. The concentration of the antibiotic solution was $200 \mathrm{mg}$ sulfamethoxazole/40 $\mathrm{mg}$ trimethoprim per $5 \mathrm{ml}(\mathrm{n}=77)$

Group B: placebo given for 10 days post-op $(n=84)$

Patients and their parents were asked to monitor for any adverse effects of the medication and to call if they had any questions or concerns. At home, they were instructed to remove and discard the gauze packing, if used, 24 hours after it was placed in situ and to perform warm water soaks at least twice a day per standard of care. They were instructed to keep the wound clean and covered by a layer of gauze with taping around the edges and to avoid using topical antibiotic ointment/cream, hydrogen peroxide, alcohol, or Betadine to decrease the chance of confounding factors.

\section{Outcomes Primary outcomes:}

- Adverse events: clinical failure at day 10 (defined as presence of erythema, warmth, induration, fluctuance, tenderness, and drainage or worsening of symptoms requiring drainage, change in mediation or hospital admission); adverse event attributed to medication

\section{Secondary outcomes:}

- Wound recurrence (defined as new lesion within $5 \mathrm{~cm}$ of original abscess site - new lesions could be folliculitis, furuncles, carbuncles, or abscesses.)

Study was a non-inferiority study

\section{Risk of bias}

\begin{tabular}{lll}
\hline Bias & Authors' judgement & Support for judgement \\
\hline $\begin{array}{ll}\text { Random sequence genera- } \\
\text { tion (selection bias) }\end{array}$ & Low risk & $\begin{array}{l}\text { Quote: With a computer randomization program, subjects were then ran- } \\
\text { domized in permuted blocks of } 50 \text { to receive a 10-day course of placebo or } \\
\text { trimethoprim-sulfamethoxazole. The placebo consisted of a Maalox and tonic } \\
\text { water combination that resembled the antibiotic in color, texture, and taste. }\end{array}$
\end{tabular}


Duong 2010 (Continued)

Comment: Adequate

\begin{tabular}{ll}
\hline $\begin{array}{l}\text { Allocation concealment } \\
\text { (selection bias) }\end{array}$ & $\begin{array}{l}\text { Quote: The medications were prepared, stored, and dispensed by the inpatient } \\
\text { pharmacist who also generated the randomization sequence and assigned the } \\
\text { participants to their groups. }\end{array}$ \\
Comment: Unclear if the pharmacist knew what was being dispensed when al- \\
locating but assumed this was likely the case
\end{tabular}

\begin{tabular}{ll}
\hline $\begin{array}{l}\text { Blinding of participants } \\
\text { and personnel (perfor- }\end{array}$ & Low risk \\
$\begin{array}{l}\text { mance bias) } \\
\text { All outcomes }\end{array}$ & $\begin{array}{l}\text { Quote: The patient, parents, and clinician who assessed the clinical outcome } \\
\text { were blinded to group assignment. }\end{array}$ \\
\end{tabular}

\begin{tabular}{|c|c|c|}
\hline $\begin{array}{l}\text { Blinding of outcome as- } \\
\text { sessment (detection bias) } \\
\text { All outcomes }\end{array}$ & Low risk & $\begin{array}{l}\text { All outcomes } \\
\text { Quote: The patient, parents, and clinician who assessed the clinical outcome } \\
\text { were blinded to group assignment. } \\
\text { Comment: Adequate }\end{array}$ \\
\hline $\begin{array}{l}\text { Incomplete outcome data } \\
\text { (attrition bias) } \\
\text { All outcomes }\end{array}$ & Unclear risk & $\begin{array}{l}\text { Quote: One hundred sixty-one subjects were enrolled, with } 12 \text { lost to fol- } \\
\text { low-up. The patients who were lost to follow-up did not differ from the rest of } \\
\text { study participants in terms of demographics or clinical presentation. } \\
\text { Comment: Some lost to follow-up - but relatively small number - classed as } \\
\text { low risk for adverse event data. There is more missing data for the wound re- } \\
\text { currence outcome. Classed as unclear for this and unclear overall }\end{array}$ \\
\hline $\begin{array}{l}\text { Selective reporting (re- } \\
\text { porting bias) }\end{array}$ & Unclear risk & None noted - protocol not obtained \\
\hline Other bias & Unclear risk & None noted \\
\hline
\end{tabular}

Fernandez 2002

\section{Study characteristics}

\begin{tabular}{ll}
\hline Methods & Three-arm RCT \\
& Undertaken in one centre in Cuba \\
& Duration of follow-up 6 weeks \\
\hline Participants & 37 participants randomised \\
& Inclusion criteria: open wounds from surgical intervention of pilonidal cyst or pilonidal fistula \\
\hline Interventions & Group A: Rhizophora mangle bark extract. Applied once a day $(\mathrm{n}=12)$ \\
& Group B: Rhizophora mangle bark extract. Applied twice a day $(10 \mathrm{~h}$ to $12 \mathrm{~h}$ interval) $(\mathrm{n}=12)$ \\
& Group C: Mercurocrome. Applied twice a day $(10 \mathrm{~h}$ to $12 \mathrm{~h}$ interval $)(\mathrm{n}=13)$ \\
\hline
\end{tabular}

Outcomes

Primary outcomes:

- None

\section{Secondary outcomes:}


Fernandez 2002 (Continued)

- Change in wound size (limited data for extraction)

- Adverse events (but methods not defined - very unclear and data not extracted)

Notes $\quad$ Funding source: not reported

\section{Risk of bias}

\begin{tabular}{|c|c|c|}
\hline Bias & Authors' judgement & Support for judgement \\
\hline \multirow{3}{*}{$\begin{array}{l}\text { Random sequence genera- } \\
\text { tion (selection bias) }\end{array}$} & Low risk & Quote: The trial was single blind, randomized and comparative \\
\hline & & Three groups of patients were randomly created and assigned \\
\hline & & $\begin{array}{l}\text { Comment: Methodology unclearly reported in paper - authors of another re- } \\
\text { view contacted the study authors and were informed that randomisation was } \\
\text { performed with a random generated list }\end{array}$ \\
\hline
\end{tabular}

Allocation concealment Unclear risk Not details-methodology unclear

(selection bias)

\begin{tabular}{|c|c|c|}
\hline $\begin{array}{l}\text { Blinding of participants } \\
\text { and personnel (perfor- } \\
\text { mance bias) }\end{array}$ & Unclear risk & $\begin{array}{l}\text { All outcomes } \\
\text { Quote: The trial was single blind, randomized and comparative... }\end{array}$ \\
\hline All outcomes & & $\begin{array}{l}\text { Comment: Unclear who was blinded from paper. Authors of another review } \\
\text { contacted the study author and were able to establish that the patients were } \\
\text { blinded. }\end{array}$ \\
\hline
\end{tabular}

Blinding of outcome as-
sessment (detection bias)

All outcomes

\section{All outcomes}

Quote: The trial was single blind, randomized and comparative

Comment: Unclear whether blinded outcome assessment was conducted

Incomplete outcome data Low risk Comment: Appears that all those randomised were included in analyses
(attrition bias)

All outcomes

Selective reporting (re- Low risk None noted - protocol not obtained

porting bias)

Other bias Low risk None noted

Giannini 2014

\section{Study characteristics}

\begin{tabular}{ll}
\hline Methods & Two-arm RCT \\
& Multi-centred study undertaken in Italy \\
& Three weeks' follow-up \\
\hline Participants & 113 participants randomised \\
Inclusion criteria: undergoing Milligan-Morgan haemorrhoidectomy for grade III or IV haemorrhoids
\end{tabular}


Giannini 2014 (Continued)

Exclusion criteria: patients with cancer, HIV, insulin-dependent diabetes, severe liver disease, Crohn's disease, anal abscess/fistula, anal fissure, thrombosed haemorrhoids, anti-coagulant treatment and pregnancy

Group A: Triclosan (Proctocid, Uniderm Farmaceutici, Srl, Rome, Italy) $(\mathrm{n}=55)$
Group B: Sodium hypochlorite solution $1.15 \mathrm{~g} / 100 \mathrm{ml})(\mathrm{n}=58)$
In each group treatment consisted of anal wound washes using $10 \mathrm{ml}$ of solutions diluted in a basin (no
further details) three times a day and after defecation.
Other drugs were discontinued during the treatment except stool softeners and painkillers. Painkiller
tablets were administered as required

\begin{tabular}{ll}
\hline Outcomes & Primary outcomes: \\
- Wound healing (time to healing - healing not defined) \\
- Adverse events (bleeding/secretions - measured using a 10-point VAS scale - high and low not defined \\
but seems lower scores refer to less bleeding/secretions)
\end{tabular}

\section{Secondary outcomes:}

- Pain (measured using a 10-point VAS scale - high and low not defined but seems lower scores refer to less pain)

Notes

Funding source: not reported but authors stated that there were no financial conflicts of interest

\section{Risk of bias}

\begin{tabular}{lll}
\hline Bias & Authors' judgement & Support for judgement \\
\hline $\begin{array}{l}\text { Random sequence genera- } \\
\text { tion (selection bias) }\end{array}$ & Unclear risk & $\begin{array}{l}\text { Quote: Each centre participating the study [sic] received the randomisation } \\
\text { code using } 40 \text { progressively numbered closed envelopes...the randomisation } \\
\text { list was generated using random permutated blocks. }\end{array}$ \\
& & Comment: No detail about method of sequence generation
\end{tabular}

\begin{tabular}{|c|c|c|}
\hline $\begin{array}{l}\text { Allocation concealment } \\
\text { (selection bias) }\end{array}$ & Low risk & $\begin{array}{l}\text { Quote: See above and treatments were identical and participants and doctors } \\
\text { blinded - assumes that those allocating were also blinded. } \\
\text { Comment: Adequate }\end{array}$ \\
\hline $\begin{array}{l}\text { Blinding of participants } \\
\text { and personnel (perfor- } \\
\text { mance bias) } \\
\text { All outcomes }\end{array}$ & Low risk & $\begin{array}{l}\text { Quote: Triclosan and the hypochlorite solution were made indistinguishable } \\
\text { (colour, texture fragrance) and were stored in similar bottles with the randomi- } \\
\text { sation code. blinded to physician and patient. } \\
\text { Comment: Adequate }\end{array}$ \\
\hline
\end{tabular}

\begin{tabular}{|c|c|c|}
\hline $\begin{array}{l}\text { Blinding of outcome as- } \\
\text { sessment (detection bias) }\end{array}$ & Low risk & All outcomes \\
\hline All outcomes & & $\begin{array}{l}\text { Considered blinded. For wound healing it is noted that a photograph was sent } \\
\text { to the co-ordinating centre. It is not explicit that the assessment was blinded } \\
\text { but given the study methods we have inferred this }\end{array}$ \\
\hline
\end{tabular}

\begin{tabular}{ll}
\hline $\begin{array}{l}\text { Incomplete outcome data } \\
\text { (attrition bias) }\end{array}$ & Low risk \\
All outcomes & $\begin{array}{l}\text { Quote: There was one case of dropout in the Triclosan group } \\
\text { Comment: Note one drop-out and flow chart presented suggests no data ex- } \\
\text { cluded from analysis. Considered low risk }\end{array}$ \\
\hline
\end{tabular}

Selective reporting (re- Low risk No evidence from paper - protocol not obtained
porting bias)


Giannini 2014 (Continued)
Other bias
Low risk
None noted

Gupta 2008

\section{Study characteristics}

\begin{tabular}{ll}
\hline Methods & Two-arm RCT \\
& Undertaken in a single hospital in India \\
& Duration of follow-up 4 weeks
\end{tabular}

\begin{tabular}{|c|c|}
\hline Participants & $\begin{array}{l}116 \text { participants undergoing haemorrhoidectomy resulting in an open wound } \\
\text { Inclusion criteria: symptomatic and prolapsing haemorrhoids Grades III or IV and able to provide in- } \\
\text { formed consent }\end{array}$ \\
\hline & $\begin{array}{l}\text { Exclusion criteria: associated fistula or fissure-in-ano, inflammatory bowel disease, dermatitis, or proc } \\
\text { titis, patient unable to complete study documentation } \\
\text { A single surgeon performed all the procedures, with the patient in the lithotomy position. Patients un- } \\
\text { derwent a standard Milligan-Morgan haemorrhoidectomy. }\end{array}$ \\
\hline Interventions & $\begin{array}{l}\text { Group A: Sucralfate cream - applied to the wounds three times daily }(n=58) \\
\text { Group B: Placebo (petrolatum cream) - applied to the wounds three times daily }(n=58) \\
\text { All patients were supplied with standard analgesic tablets containing a combination of tramadol hy- } \\
\text { drochloride } 37.5 \mathrm{mg} \text { and } \\
\text { acetaminophen } 500 \mathrm{mg} \text {. The patients also received tablets containing } 250 \mathrm{mg} \text { of metronidazole to be } \\
\text { taken twice daily for seven days and } 30 \mathrm{ml} \text { of lactulose }\end{array}$ \\
\hline
\end{tabular}

\begin{tabular}{ll}
\hline Outcomes & Primary outcomes: \\
- Time to healing (time to $100 \%$ complete wound healing) \\
- Number of wounds completely healed (wound healing was defined as complete epithelial covering as \\
observed by physical examination (per-rectal examination and anoscopy)
\end{tabular}

\section{Secondary outcomes:}

- Post operative pain (measured using 0 to 10 VAS scale with $0=$ no pain)

\begin{tabular}{|c|c|c|}
\hline Notes & \multicolumn{2}{|c|}{ Funding source: not reported } \\
\hline Risk of bias & & \\
\hline Bias & Authors' judgement & Support for judgement \\
\hline $\begin{array}{l}\text { Random sequence genera- } \\
\text { tion (selection bias) }\end{array}$ & Low risk & $\begin{array}{l}\text { Quote: In this double-blind study, patients were prospectively randomized by } \\
\text { computer-based sequential method into one of the two groups. } \\
\text { Comment: Adequate method }\end{array}$ \\
\hline $\begin{array}{l}\text { Allocation concealment } \\
\text { (selection bias) }\end{array}$ & Low risk & $\begin{array}{l}\text { Quote: Randomization was performed at the completion of surgery; both } \\
\text { creams looked the same and were impossible to distinguish. } \\
\text { Comment: Adequate method }\end{array}$ \\
\hline
\end{tabular}




\section{Gupta 2008 (Continued)}

Blinding of participant and personnel (performance bias)

All outcomes
Low risk See above quote and comment

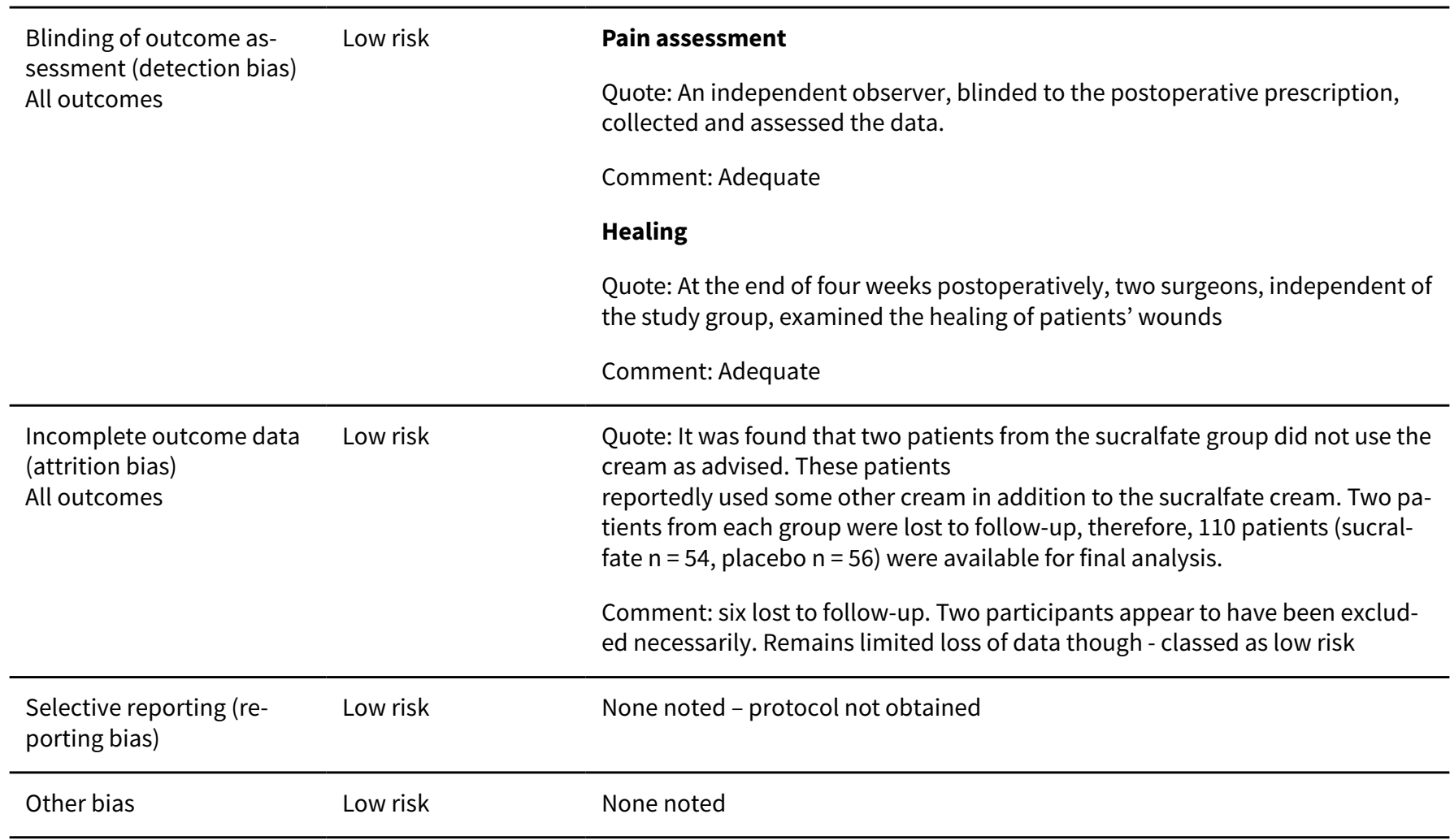

\section{Khan 2014}

\section{Study characteristics}

\begin{tabular}{ll}
\hline Methods & Two-arm RCT \\
& Multi-centred study undertaken in Saudi Arabia and Pakistan \\
& Duration of follow-up 6 weeks to 8 weeks or until complete healing occurred - with an assessment at 2 \\
& weeks \\
\hline Participants & 100 participants undergoing Milligan Morgan haemorrhoidectomy \\
& Inclusion criteria: undergoing Milligan Morgan haemorrhoidectomy for grade III and IV haemorrhoids \\
& $\begin{array}{l}\text { Exclusion criteria: patients having some other concomitant perianal pathology warranting surgery, im- } \\
\text { munocompromised patients and patients who had recently (within last } 2 \text { weeks) taken any antibiotics, } \\
\text { pregnant and lactating women were excluded from the study }\end{array}$ \\
Group A: 500 mg I/V metronidazole and $1 \mathrm{~g}$ Ceftriaxone I/V before induction of anaesthesia ( $\mathrm{n}=50$ ) \\
Group B: Standard care with no prophylactic antibiotic ( $\mathrm{n}=50$ ) \\
All participants underwent standard Milligan Morgan haemorrhoidectomy by the same surgeon in each \\
centre under \\
regional (spinal) or general anaesthesia as per choice of the anaesthetist.
\end{tabular}


Khan 2014 (Continued)

All the patients were given $75 \mathrm{mg} \mathrm{I/M} \mathrm{Diclofenac} \mathrm{Sodium} 12$ hourly on operation day

From first post-operative day and onwards patients were advised to take sitz bath in lukewarm water for minimum of $10 \mathrm{~min}$, twice daily and also to apply the $0.2 \%$ GTN ointment with the finger tip after taking the sitz bath. Stool softeners were also advised to be taken (syrup lactulose $30 \mathrm{ml}$ twice daily) from first post-operative day till complete wound healing. All the patients were advised to take tablet codeine phosphate and tablet paracetamol when required from first post-operative day and onwards

\section{Outcomes}

\section{Primary outcomes:}

- Complete wound healing (defined as complete epithelialisation of the wound). Data not extracted as data unclear - presented as mean but referred to as complete healing - no units given). Study authors contacted to query, awaiting response

\section{Secondary outcomes:}

- Post-operative pain (measured using 0 to $100 \mathrm{~mm}$ VAS scale with $0=$ no pain). Pain scores were taken daily - preferably after defecation. Data not presented continuously and not extracted - presented using \% in stacked graphs only

- Adverse events (participants asked to report any complication occurring especially headache, fever and/or excessive purulent discharge from the wound)

Notes Funding source: no funding was received for this study

Query sent to authors regarding outcome data

\section{Risk of bias}

\begin{tabular}{lll}
\hline Bias & Authors' judgement & Support for judgement \\
\hline $\begin{array}{ll}\text { Random sequence genera- } \\
\text { tion (selection bias) }\end{array}$ & Low risk & $\begin{array}{l}\text { Quote: Eligible patients were randomly assigned to one of the two treatment } \\
\text { groups according to a computer generated list using Random Allocation Soft- } \\
\text { ware. } \\
\end{array}$ \\
& \\
& \\
&
\end{tabular}

Allocation concealment Unclear risk
(selection bias)

Quote: The double blinding was ensured by not disclosing the treatment group to the patient and to the surgeon who examined the patients on each visit and filled the performa [sic].

Comment: Suggests that the control group were given a placebo - but this is not clear from the study report

Blinding of participants Unclear risk and personnel (performance bias)

All outcomes
Quote: The double blinding was ensured by not disclosing the treatment group to the patient and to the surgeon who examined the patients on each visit and filled the performa.

Comment: Suggests that the control group were given a placebo - but this is not clear from the study report

\section{Blinding of outcome as- Unclear risk} sessment (detection bias) All outcomes

\section{All outcomes:}

Quote: The double blinding was ensured by not disclosing the treatment group to the patient and to the surgeon who examined the patients on each visit and filled the performa.

Comment: Suggests that the control group were given a placebo - but this is not clear from the study report 
Khan 2014 (Continued)

\begin{tabular}{lll}
$\begin{array}{l}\text { Incomplete outcome data } \\
\text { (attrition bias) } \\
\text { All outcomes }\end{array}$ & Unclear risk & $\begin{array}{l}\text { A total of 96 patients out of } 100 \text { patients (47 in group A and 49 in group B) com- } \\
\text { pleted the study. In group A 3 patients and in group B 1 patient did not com- } \\
\text { plete the study }\end{array}$ \\
\hline $\begin{array}{l}\text { Selective reporting (re- } \\
\text { porting bias) }\end{array}$ & Unclear risk & $\begin{array}{l}\text { None noted - protocol not obtained. Presentation of data unclear to review } \\
\text { authors }\end{array}$ \\
\hline Other bias & Unclear risk & None noted \\
\hline
\end{tabular}

Okeniyi 2005

\section{Study characteristics}

\begin{tabular}{ll}
\hline Methods & RCT \\
& Undertaken in single hospital setting, Nigeria \\
& Duration of follow-up 3 weeks \\
\hline Participants & 32 Nigerian children with 43 pyomyositis abscesses \\
& 10 patients had multiple pyomyositis \\
& Inclusion criteria: Children with pyomyositis, included patients with multiple pyomyositis sites \\
\hline Interventions & Group A: Honey-soaked gauze. Wounds were packed twice daily (n = 23 wounds) \\
Group B: Edinburgh University Solution of Lime (EUSOL)-soaked gauze. Wounds were packed twice dai- \\
ly (n=20 wounds) \\
Co-interventions: following fresh surgical incisions and drainage, all subjects had 21-day course of \\
ampicillin plus cloxacillin (Ampiclox) and gentamicin \\
Number of participants in each group not reported
\end{tabular}

\begin{tabular}{ll}
\hline Outcomes & Primary outcomes: \\
- Complete wound healing (completion of epithelialization) \\
- Adverse events \\
Secondary outcomes: \\
- Resource use (length of hospital stay)
\end{tabular}

Notes Funding source: no information given

\section{Risk of bias}

\begin{tabular}{lll}
\hline Bias & Authors' judgement & Support for judgement \\
\hline $\begin{array}{l}\text { Random sequence genera- } \\
\text { tion (selection bias) }\end{array}$ & Unclear risk & $\begin{array}{l}\text { Quote:The dressing of the individual sites were randomly allocated to give } \\
\text { insight into the rate of wound healing with honey and EUSOL devoid of con- } \\
\text { founding host factors. } \\
\text { Comment: Methodology unclear }\end{array}$ \\
\hline $\begin{array}{l}\text { Allocation concealment } \\
\text { (selection bias) }\end{array}$ & Unclear risk & No information given \\
\hline \hline
\end{tabular}


Okeniyi 2005 (Continued)
Blinding of participants
Unclear risk No information given and personnel (perfor- mance bias)
All outcomes

\begin{tabular}{|c|c|c|}
\hline $\begin{array}{l}\text { Blinding of outcome as- } \\
\text { sessment (detection bias) }\end{array}$ & Unclear risk & $\begin{array}{l}\text { Quote: Epithelialization was determined clinically in each case by the first in- } \\
\text { vestigator to avoid observer bias. }\end{array}$ \\
\hline
\end{tabular}

All outcomes

Comment: Not clear if assessment was blinded

Incomplete outcome data Low risk Appears to be no loss to follow up. No adverse events reported
(attrition bias)

All outcomes

\begin{tabular}{|c|c|c|}
\hline $\begin{array}{l}\text { Selective reporting (re- } \\
\text { porting bias) }\end{array}$ & Low risk & None noted - protocol not obtained \\
\hline \multirow[t]{2}{*}{ Other bias } & Low risk & $\begin{array}{l}\text { Quote: Among the subjects were } 10 \text { patients who had multiple pyomyositis. } \\
\text { The dressing of the individual sites were randomly allocated to give insight in- } \\
\text { to the rate of wound healing with honey and EUSOL devoid of confounding } \\
\text { host factors. }\end{array}$ \\
\hline & & $\begin{array}{l}\text { Comment: Seems that some participants had more than one wound. Cluster- } \\
\text { ing not alluded to in study report }\end{array}$ \\
\hline
\end{tabular}

Piaggesi 2010

\section{Study characteristics}

\begin{tabular}{ll}
\hline Methods & Two-arm RCT \\
& Undertaken in a centre in Italy \\
Duration of follow-up 6 months or to complete re-epithelization
\end{tabular}

Participants 40 diabetic participants with an infection on the foot requiring surgery resulting in an open wound
Inclusion criteria: a surgical lesion resulting from drainage or minor amputation, including trans-
metatarsal amputations to treat an infected lesion distal to the ankle. Lesion grade $2 \mathrm{~B} / 3 \mathrm{~B}$ Texas Univer-
sity grading score for diabetic foot ulcers, wider than $5 \mathrm{~cm}^{2}$ and left open to heal by secondary inten-
tion; transcutaneous oxygen tension (TcPo2) value $>50 \mathrm{~mm} \mathrm{Hg}$ distal to the ankle.
Exclusion criteria: bilateral lesions, having had a lesion in the same foot of duration longer than 6
months, HIV positive and any cause of immunodepression other than diabetes, local or systemic docu-
mented intolerance to povidone iodine, serum creatinine $>2 \mathrm{mg} / \mathrm{dL}$, and life expectancy shorter than 1
year

Interventions

Group A: Gauze with povidone iodine diluted with $50 \%$ saline $(n=20)$

Group B: Gauze with Dermacyn ${ }^{\circledast}$ Wound Care a stable super-oxide solution with neutral pH $(n=20)$

Both groups were treated with a standardised clinical approach, comprising empiric systemic antibiotic therapy (piperacillin/tazobactam and metronidazole with the adjunct of teicoplanin when methicillin-resistant Staphylococcus aureus was present), prompt and aggressive surgical debridement, metabolic control, and stabilisation of the systemic condition of the patient. 
Piaggesi 2010 (Continued)

All the patients were on insulin therapy and they monitored blood glucose; the adjustment of antidiabetic therapy was part of the weekly control visit. Offloading was achieved using irremovable offload-

ing devices and crutches, or alternatively, wheelchairs

Primary outcomes:
- Time to healing; complete wound healing (not defined)
- Adverse events
Secondary outcomes:
- Number of re-interventions (any procedure carried out in operating theatre)

Notes

Funding source: a non-restricted research grant from Oculus Innovative Sciences (Petaluma, CA), manufacturers of Dermacyn ${ }^{\circledR}$ Wound Care

\begin{tabular}{|c|c|c|}
\hline \multicolumn{3}{|l|}{ Risk of bias } \\
\hline Bias & Authors' judgement & Support for judgement \\
\hline \multirow[t]{2}{*}{$\begin{array}{l}\text { Random sequence genera- } \\
\text { tion (selection bias) }\end{array}$} & Low risk & $\begin{array}{l}\text { Quote: The patients were randomized into } 2 \text { groups: group A and group B by } \\
\text { means of a computer-generated randomization code }\end{array}$ \\
\hline & & Comment: Adequate methodology \\
\hline $\begin{array}{l}\text { Allocation concealment } \\
\text { (selection bias) }\end{array}$ & Unclear risk & No specific methodology noted \\
\hline $\begin{array}{l}\text { Blinding of participants } \\
\text { and personnel (perfor- } \\
\text { mance bias) } \\
\text { All outcomes }\end{array}$ & Unclear risk & $\begin{array}{l}\text { Comment: No details but at discharge patients attended their own wounds, as } \\
\text { iodine has a distinctive colour patients could probably not be blinded for the } \\
\text { intervention. }\end{array}$ \\
\hline \multirow{2}{*}{$\begin{array}{l}\text { Blinding of outcome as- } \\
\text { sessment (detection bias) } \\
\text { All outcomes }\end{array}$} & Low risk & $\begin{array}{l}\text { Quote: Measurements and evaluations were performed by another diabetolo- } \\
\text { gist.... unaware of the allocation of the patients to the different groups. }\end{array}$ \\
\hline & & Comment: Adequate blinding \\
\hline $\begin{array}{l}\text { Incomplete outcome data } \\
\text { (attrition bias) } \\
\text { All outcomes }\end{array}$ & Low risk & No drop outs noted \\
\hline $\begin{array}{l}\text { Selective reporting (re- } \\
\text { porting bias) }\end{array}$ & Unclear risk & $\begin{array}{l}\text { Comment: No reports on costs in the results, costs is mentioned as one of the } \\
\text { endpoints in the methods section }\end{array}$ \\
\hline Other bias & Unclear risk & None noted \\
\hline
\end{tabular}

Schmidt 1991

\section{Study characteristics}

\begin{tabular}{ll}
\hline Methods & Two-arm RCT \\
& Single hospital centre in USA \\
& Duration of follow-up unclear
\end{tabular}


Schmidt 1991 (Continued)

Participants

40 participants were randomised following wound complications following a c-section resulting in an open wound. Twenty-one participants had vertical incisions and 19 had transverse incisions.

Inclusion criteria: women with surgical wounds that required healing by secondary intention after either caesarean section or laparotomy for gynaecological surgery. All incisions had opened spontaneously or had been drained to treat a seroma, haematoma or wound abscess before referral to clinic

Exclusion criteria: Patients with diabetes or cancer, requiring treatment with glucocorticoids or immunosuppressive drugs, had a history of abdominal irradiation, or a chronic debilitating disease

Interventions

Group A: standard treatment and aloe vera dermal gel (Carrington Laboratories, Irving, TX). The gel was applied with each dressing change to the granulation tissue in the wound bed at the level of the subcutaneous tissue and dermis ( $n=20 ; 10$ with vertical incision; 9 with transverse incision)

Group B: standard treatment only ( $n=20 ; 11$ with vertical incisions, 9 with transverse incisions)

Standard treatment: blunt debridement with gauze pad or sharp debridement of necrotic tissue. Wound then irrigated with high-volume, high-pressure irrigations using a $60 \mathrm{ml}$ Luer Lock syringe with an 18-gauge angiocath and an irrigating volume of $1000 \mathrm{ml}$. A wet-to-dry dressing was applied, using a solution of equal parts of saline and sodium hypochlorite $0.025 \%$. Wound care was performed every 8 hours initially and then every 12 hours after granulation tissue developed

\begin{tabular}{ll}
\hline Outcomes & Primary outcomes: \\
- Time to healing (defined as when wound was completely epithelialised) \\
- Adverse events
\end{tabular}

Secondary outcomes:

- None

Notes Funding

source: no information given

\section{Risk of bias}

\begin{tabular}{lll}
\hline Bias & Authors' judgement & Support for judgement \\
\hline $\begin{array}{l}\text { Random sequence genera- } \\
\text { tion (selection bias) }\end{array}$ & Low risk & $\begin{array}{l}\text { Quote: Randomised using a random number sequence generated by a com- } \\
\text { puter program. } \\
\text { Comment: Adequate methodology }\end{array}$ \\
\hline $\begin{array}{l}\text { Allocation concealment } \\
\text { (selection bias) }\end{array}$ & Unclear risk & No information given \\
\hline $\begin{array}{l}\text { Blinding of participants } \\
\text { and personnel (perfor- } \\
\text { mance bias) } \\
\begin{array}{l}\text { All outcomes } \\
\text { Onclear risk }\end{array}\end{array}$ & No details \\
\hline
\end{tabular}

\begin{tabular}{|c|c|c|}
\hline $\begin{array}{l}\text { Blinding of outcome as- } \\
\text { sessment (detection bias) }\end{array}$ & High risk & $\begin{array}{l}\text { Quote The study was not blinded } \\
\text { Comment: Taken as not blinded for any outcome }\end{array}$ \\
\hline
\end{tabular}

Incomplete outcome data High risk
(attrition bias)

Comment: 19 participants ( 12 receiving standard treatment and 7 receiving All outcomes aloe vera) 
Schmidt 1991 (Continued)

were lost to follow up. No additional data was available for those lost to follow-up. Classed as high risk of attrition bias as large $\%$ of participants lost to follow-up

\begin{tabular}{lll}
\hline $\begin{array}{l}\text { Selective reporting (re- } \\
\text { porting bias) }\end{array}$ & Unclear risk & None noted - protocol not obtained \\
\hline Other bias & Unclear risk & No defined follow up period \\
\hline
\end{tabular}

Tosti 2014

\section{Study characteristics}

\begin{tabular}{|c|c|}
\hline Methods & $\begin{array}{l}\text { Two-arm RCT } \\
\text { Undertaken in one centre in the USA } \\
\text { Duration of follow-up } 6 \text { weeks }\end{array}$ \\
\hline Participants & $\begin{array}{l}100 \text { participants undergoing surgery for all hand abscesses } \\
\text { Inclusion criteria: no further criteria listed } \\
\text { Exclusion criteria: purulence proximal to the wrist, absence of purulent fluid, chronic wound infections, } \\
\text { and premature discharge from the hospital against medical advice (this final criterion seems to be a } \\
\text { post-randomisation exclusion). } \\
\text { All patients received a thorough debridement in the operating room with excision of necrotic tissue. } \\
\text { The wounds were irrigated with } 3 \mathrm{~L} \text { normal saline under a low-velocity irrigation system and then par- } \\
\text { tially closed over a Penrose drain or an iodinated gauze wick. The wounds were then dressed with an } \\
\text { iodine-petroleum gauze, sterile gauze, and an orthosis. Patients returned to the operating room if per- } \\
\text { sistent or progressive erythema was noted or if purulent fluid was expressed from the wound. On the } \\
\text { first post-operative day, the Penrose drain or gauze wicks were removed leaving open areas of the } \\
\text { wound which were then exposed to the intervention or not, based on randomisation }\end{array}$ \\
\hline
\end{tabular}

Interventions

Group A: a $10 \%$ povidone iodine solution mixed with saline in a 1:1 ratio hand soak. Hands were submerged for 20 minutes, three times per day. After each soak wounds were redressed with sterile gauze and an orthosis. Soaks were stopped on discharge. $(n=50)$

Group B: no soaks, the wounds were treated with a daily dressing change with sterile gauze and an orthosis $(n=50)$

Empiric antibiotic coverage at time of admission (intravenous ampicillin-sulbactam if history of bite wound; otherwise vancomycin)

Patients were given 10 days of oral antibiotics at discharge unless they had had positive blood cultures. In that case, they received 6 weeks of intravenous antibiotics and were observed by an infectious disease consultant

Outcomes Primary outcomes:

- None

\section{Secondary outcomes:}

- Resource use (length of hospital stay; re-admissions and re-operations)

Notes Funding source: not reported


Tosti 2014 (Continued)

Authors were contacted and confirmed that these were all partially open wounds

\section{Risk of bias}

Bias Authors' judgement Support for judgement

Random sequence genera- Low risk tion (selection bias)

Quote: when purulent fluid was confirmed at the time of debridement, patients were randomized via a computer-generated schedule

Comment: Computer-generated randomisation sequence - adequate

\begin{tabular}{|c|c|c|}
\hline $\begin{array}{l}\text { Allocation concealment } \\
\text { (selection bias) }\end{array}$ & Unclear risk & No information provided \\
\hline $\begin{array}{l}\text { Blinding of participants } \\
\text { and personnel (perfor- } \\
\text { mance bias) } \\
\text { All outcomes }\end{array}$ & High risk & $\begin{array}{l}\text { Quote: It was not possible to blind subjects and observers to the study proto- } \\
\text { col, which could have influenced the decision to perform repeated debride- } \\
\text { ments. } \\
\text { Comment: No blinding took place }\end{array}$ \\
\hline $\begin{array}{l}\text { Blinding of outcome as- } \\
\text { sessment (detection bias) } \\
\text { All outcomes }\end{array}$ & High risk & $\begin{array}{l}\text { Quote: It was not possible to blind subjects and observers to the study proto- } \\
\text { col, which could have influenced the decision to perform repeated debride- } \\
\text { ments. } \\
\text { Comment: No blinding took place }\end{array}$ \\
\hline $\begin{array}{l}\text { Incomplete outcome data } \\
\text { (attrition bias) } \\
\text { All outcomes }\end{array}$ & Low risk & $\begin{array}{l}\text { Quote: Two patients from each group were excluded from the final analysis for } \\
\text { leaving the hospital against } \\
\text { medical advice. } \\
\text { Comment: Post-randomisation exclusions - but small number. Classed as low } \\
\text { risk }\end{array}$ \\
\hline $\begin{array}{l}\text { Selective reporting (re- } \\
\text { porting bias) }\end{array}$ & Low risk & None noted - protocol not obtained \\
\hline Other bias & Low risk & None noted \\
\hline
\end{tabular}

Randomised controlled trial - RCT

Characteristics of excluded studies [ordered by study ID]

\begin{tabular}{ll}
\hline Study & Reason for exclusion \\
\hline Cannavo 1998 & Use of antibiotic/antiseptic was not the only difference between groups \\
\hline Eldrup 1985 & Use of antibiotic/antiseptic was not the only difference between groups \\
\hline Goetze 2006 & Use of antibiotic/antiseptic was not the only difference between groups \\
\hline Hien 1988 & $\begin{array}{l}\text { Not considered RCT based on available information, abstract only and no outcome data reported - } \\
\text { unable to contact authors }\end{array}$ \\
\hline Moore 2000 & Use of antibiotic/antiseptic was not the only difference between groups \\
\hline Murthy 2012 & Not surgical wound healing by secondary intention \\
\hline
\end{tabular}




\begin{tabular}{ll}
\hline Study & Reason for exclusion \\
\hline Nielsen 2012 & Use of antibiotic/antiseptic was not the only difference between groups \\
\hline Sozener 2011 & $\begin{array}{l}\text { No relevant outcome data for review collected - confirmed with author; purpose of study was to as- } \\
\text { sess occurrence of fistula over year following surgery }\end{array}$ \\
\hline Taylor 2011 & Not surgical wounds healing by secondary intention \\
\hline Viciano 2000 & Use of antibiotic/antiseptic was not the only difference between groups \\
\hline Walker 1991 & Use of antibiotic/antiseptic was not the only difference between groups \\
\hline Williams 1981 & Use of antibiotic/antiseptic was not the only difference between groups \\
\hline Yang 2013 & Use of antibiotic/antiseptic was not the only difference between groups \\
\hline
\end{tabular}

\section{Characteristics of studies awaiting classification [ordered by study ID]}

\section{Fillmann 2004}

\begin{tabular}{ll}
\hline Methods & RCT \\
\hline Participants & 30 participants undergoing haemorrhoidectomy \\
\hline Interventions & Intravenous cefoxitin $1 \mathrm{~g} / 6$ hours \\
\hline Outcomes & Pain \\
\hline Notes & Portuguese; identified in search update \\
\hline
\end{tabular}

Mirzabeygi 2011

\begin{tabular}{ll}
\hline Methods & RCT \\
\hline Participants & 47 participants undergoing haemorrhoidectomy \\
\hline Interventions & Metronidazole versus placebo \\
\hline Outcomes & Post-operative pain \\
\hline Notes & Abstract only; attempt to contact author unsuccessful \\
\hline
\end{tabular}

\section{Quilici 1998}

\begin{tabular}{ll}
\hline Methods & RCT \\
\hline Participants & 40 participants undergoing haemorrhoidectomy \\
\hline Interventions & $\begin{array}{l}\text { Unguent containing neomycin sulfate antibiotic versus unguent containing (Xilodase(R)) plus } \\
\text { hyaluronidase (50 UTR) }\end{array}$
\end{tabular}


Quilici 1998 (Continued)

\begin{tabular}{|c|c|}
\hline Outcomes & $\begin{array}{l}\text { Wound closure time } \\
\text { Surgical wound pain } \\
\text { Local infection prevention } \\
\text { Post-operative adverse effects }\end{array}$ \\
\hline Notes & English abstract; full text in Portuguese (not yet obtained) \\
\hline Vasei 2008 & \\
\hline Methods & Randomized controlled clinical trial \\
\hline Participants & 24 patients with surgical wound of pilonidal sinuses \\
\hline Interventions & Honey dressing $(n=12)$ versus saline-soaked dressing $(n=12)$ \\
\hline Outcomes & $\begin{array}{l}\text { Complete wound healing } \\
\text { Eradication of infection } \\
\text { Adverse effects } \\
\text { Resource use (length of hospital stay) }\end{array}$ \\
\hline Notes & English abstract; full text in Farsi (not yet obtained) \\
\hline
\end{tabular}

\section{DATA AND ANALYSES}

\section{Comparison 1. Polyvidone iodine-impregnated mesh compared with alginate mesh}

\begin{tabular}{lllll}
\hline Outcome or subgroup title & No. of studies & $\begin{array}{l}\text { No. of partici- } \\
\text { pants }\end{array}$ & Statistical method & Effect size \\
\hline $\begin{array}{l}1.1 \text { Proportion of wounds } \\
\text { healed }\end{array}$ & 1 & Risk Ratio (M-H, Fixed, 95\% Cl) & Subtotals only \\
\hline $\begin{array}{llll}1.2 \text { Wound infection } \\
1.3 \text { Mean number of dressing }\end{array}$ & 1 & Risk Ratio (M-H, Fixed, 95\% Cl) & Subtotals only \\
\hline changes & 1 & Mean Difference (IV, Fixed, 95\% Cl) & Subtotals only \\
\hline
\end{tabular}


Analysis 1.1. Comparison 1: Polyvidone iodine-impregnated mesh compared with alginate mesh, Outcome 1: Proportion of wounds healed

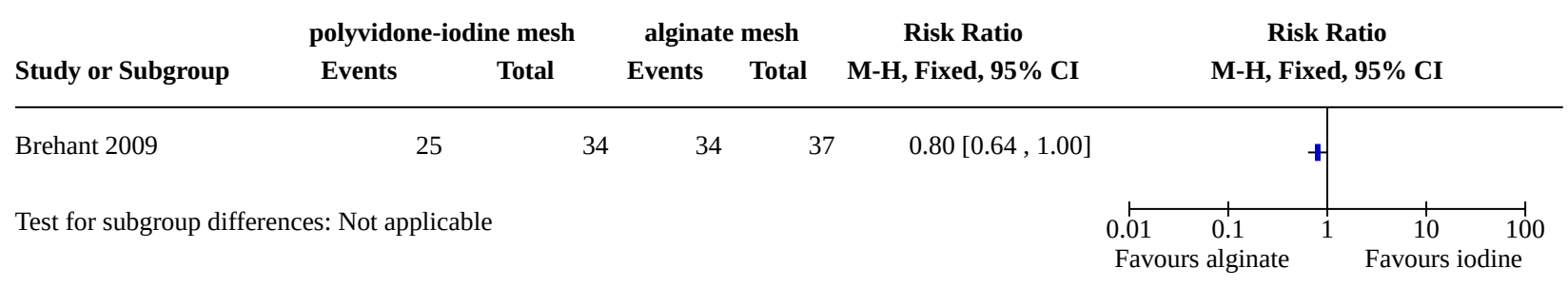

Analysis 1.2. Comparison 1: Polyvidone iodine-impregnated
mesh compared with alginate mesh, Outcome 2: Wound infection

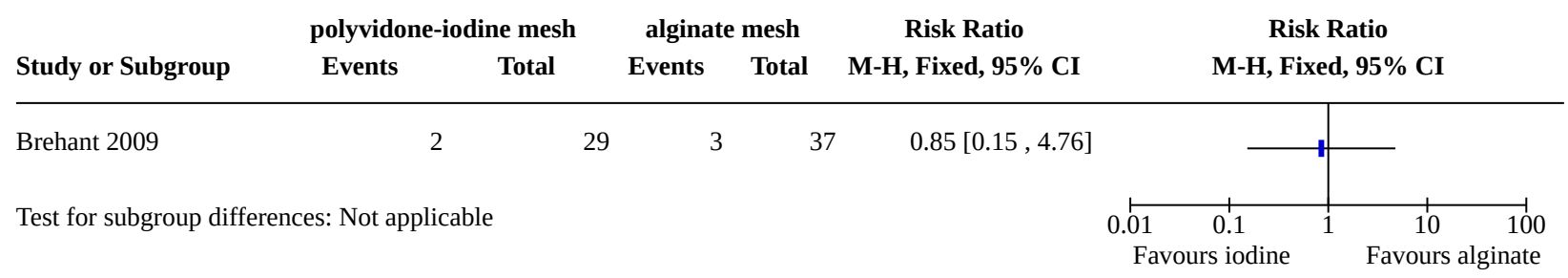

Analysis 1.3. Comparison 1: Polyvidone iodine-impregnated mesh compared with alginate mesh, Outcome 3: Mean number of dressing changes

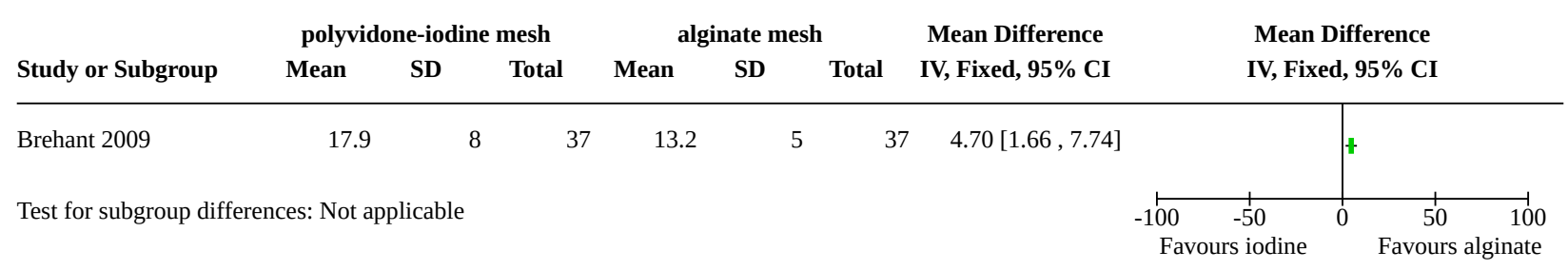

\section{Comparison 2. Zinc oxide mesh compared with placebo}

\begin{tabular}{llll}
\hline Outcome or subgroup title & No. of studies & $\begin{array}{l}\text { No. of partici- } \\
\text { pants }\end{array}$ & Statistical method \\
\hline $\begin{array}{l}2.1 \text { Wound infection (based on pres- } \\
\text { ence of smell) }\end{array}$ & 1 & $\begin{array}{l}\text { Risk Ratio (M-H, Fixed, 95\% } \\
\mathrm{Cl})\end{array}$ & $\begin{array}{l}\text { Totals not select- } \\
\text { ed }\end{array}$ \\
\hline 2.2 Participants prescribed antibiotics & 1 & Odds Ratio (M-H, Fixed, 95\% & $\begin{array}{l}\text { Totals not select- } \\
\text { ed }\end{array}$ \\
\hline
\end{tabular}


Analysis 2.1. Comparison 2: Zinc oxide mesh compared with placebo, Outcome 1: Wound infection (based on presence of smell)

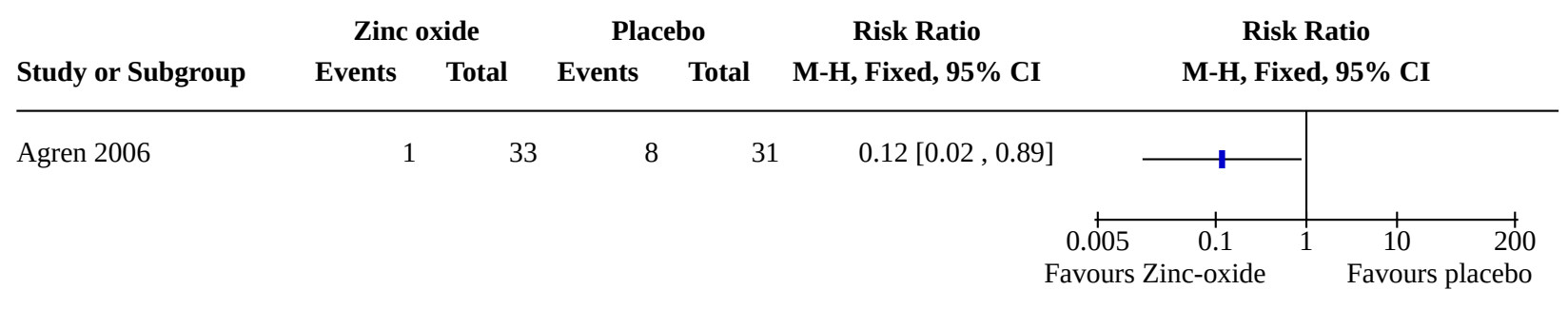

\section{Analysis 2.2. Comparison 2: Zinc oxide mesh compared with placebo, Outcome 2: Participants prescribed antibiotics}

$$
\text { Zinc oxide Placebo Odds Ratio Odds Ratio }
$$

Study or Subgroup $\quad$ Events $\quad$ Total $\quad$ Events $\quad$ Total $\quad$ M-H, Fixed, 95\% CI $\quad$ M-H, Fixed, 95\% CI

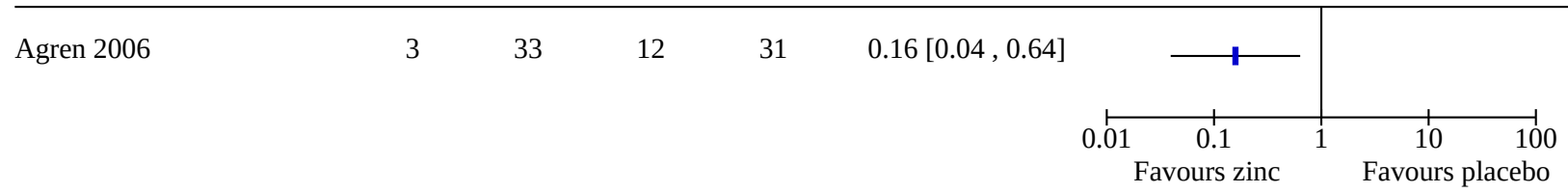

Comparison 3. Sucralfate compared with petrolatum

\begin{tabular}{lllll}
\hline Outcome or subgroup title & No. of studies & $\begin{array}{l}\text { No. of partici- } \\
\text { pants }\end{array}$ & Statistical method & Effect size \\
\hline 3.1 Proportion of wounds healed & 1 & Risk Ratio (M-H, Fixed, 95\% Cl) & Subtotals only \\
\hline 3.2 Pain score (10-point VAS scale) & 1 & $\begin{array}{l}\text { Mean Difference (IV, Fixed, 95\% } \\
\text { Cl) }\end{array}$ & Subtotals only \\
\hline
\end{tabular}

Analysis 3.1. Comparison 3: Sucralfate compared with petrolatum, Outcome 1: Proportion of wounds healed

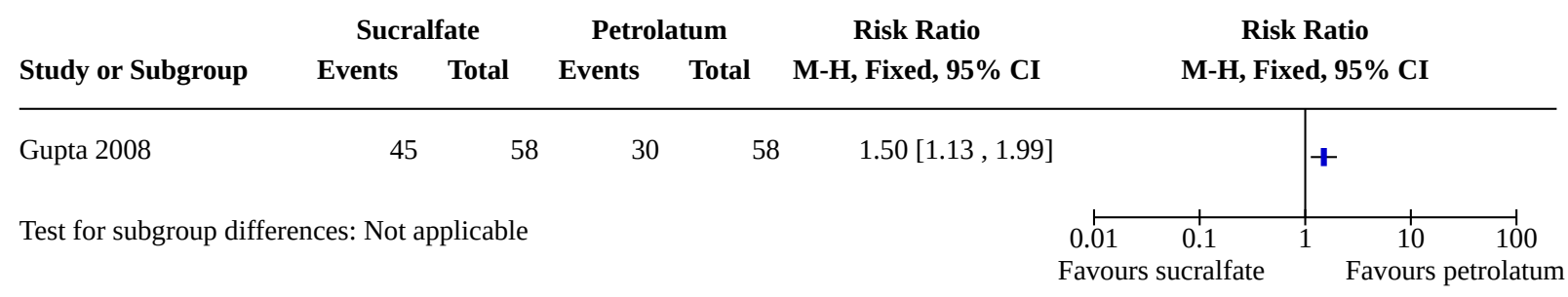


Analysis 3.2. Comparison 3: Sucralfate compared with petrolatum, Outcome 2: Pain score (10-point VAS scale)

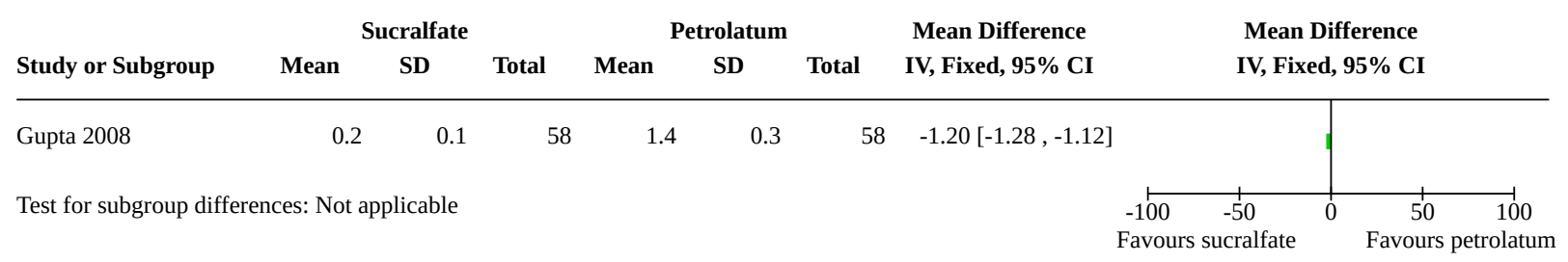

Comparison 4. Trimethoprim-sulfamethoxazole compared with placebo

\begin{tabular}{lllll}
\hline Outcome or subgroup title & No. of studies & $\begin{array}{l}\text { No. of partici- } \\
\text { pants }\end{array}$ & Statistical method & Effect size \\
\hline $\begin{array}{l}4.1 \text { Adverse events (attributed to } \\
\text { medication) }\end{array}$ & 1 & Risk Ratio (M-H, Fixed, 95\% Cl) & Subtotals only \\
\hline 4.2 Wound recurrence & 1 & Risk Ratio (M-H, Fixed, 95\% Cl) & Subtotals only \\
\hline
\end{tabular}

\section{Analysis 4.1. Comparison 4: Trimethoprim-sulfamethoxazole compared with placebo, Outcome 1: Adverse events (attributed to medication)}

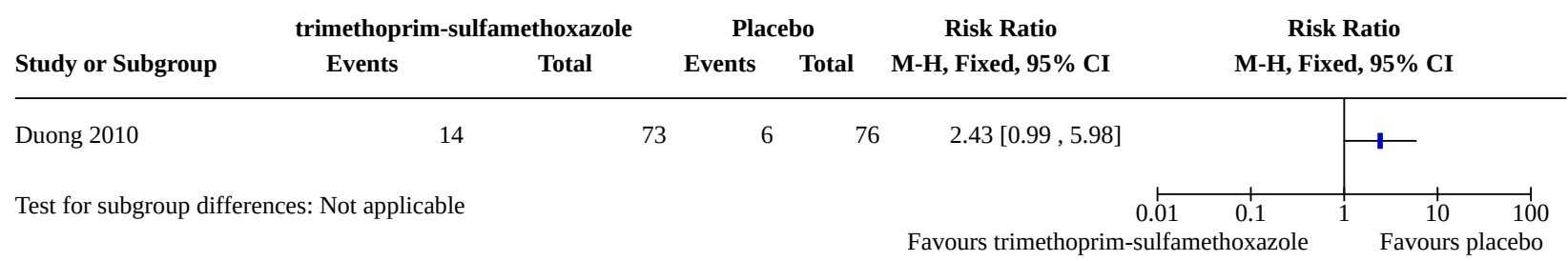

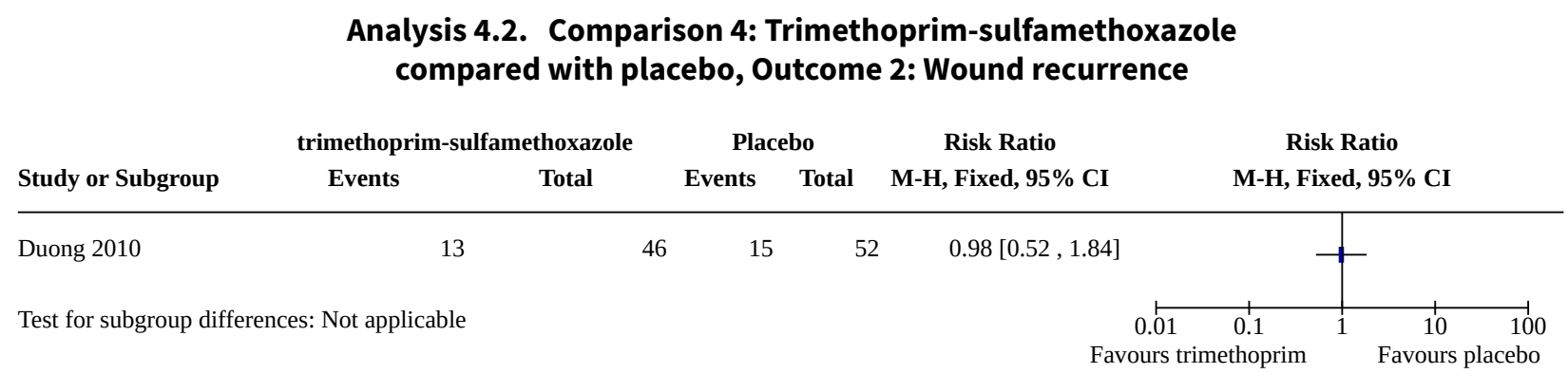

Comparison 5. Honey compared with EUSOL

\begin{tabular}{lllll}
\hline Outcome or subgroup title & No. of studies & $\begin{array}{l}\text { No. of partici- } \\
\text { pants }\end{array}$ & Statistical method & Effect size \\
\hline 5.1 Proportion of wounds healed & 1 & Risk Ratio (M-H, Fixed, 95\% Cl) & Subtotals only \\
\hline 5.2 Mean length of hospital stay & 1 & $\begin{array}{l}\text { Mean Difference (IV, Fixed, 95\% } \\
\text { Cl) }\end{array}$ & Subtotals only \\
\hline
\end{tabular}


Analysis 5.1. Comparison 5: Honey compared with EUSOL, Outcome 1: Proportion of wounds healed

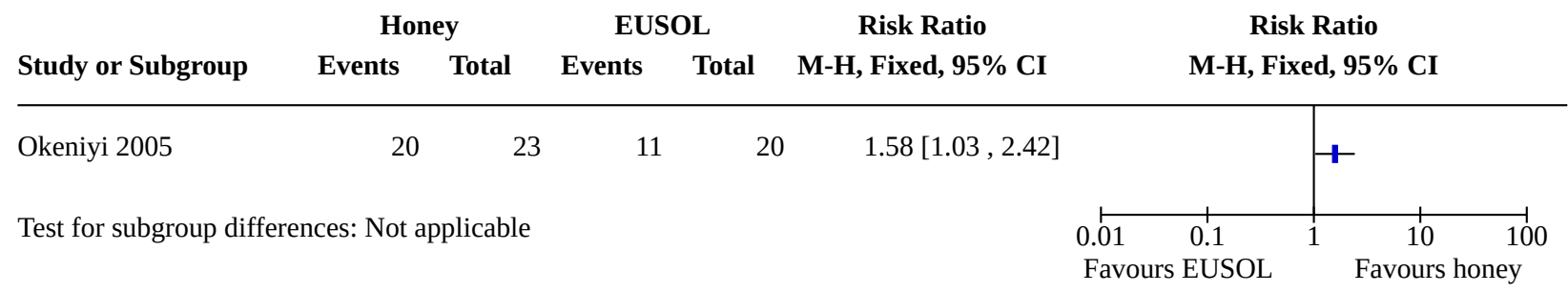

Analysis 5.2. Comparison 5: Honey compared with EUSOL, Outcome 2: Mean length of hospital stay

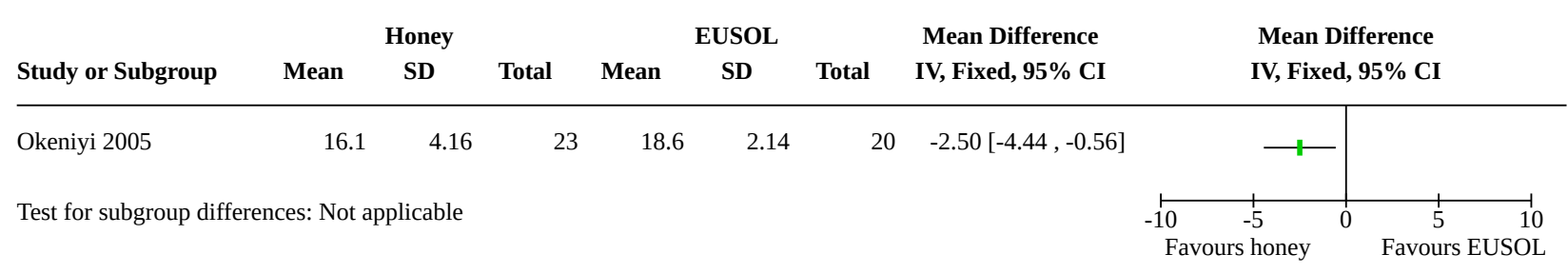

Comparison 6. Iodine compared with Dermacyn ${ }^{\circledR}$

\begin{tabular}{lllll}
\hline Outcome or subgroup title & No. of studies & $\begin{array}{l}\text { No. of partici- } \\
\text { pants }\end{array}$ & Statistical method & Effect size \\
\hline 6.1 Proportion of wounds healed & 1 & & Risk Ratio (M-H, Fixed, 95\% Cl) & Subtotals only \\
\hline
\end{tabular}

Analysis 6.1. Comparison 6: lodine compared with Dermacyn ${ }^{\circledR}$, Outcome 1: Proportion of wounds healed

\begin{tabular}{|c|c|c|c|c|c|c|}
\hline & & & Derm & $\mathbf{y n}{ }^{\circledR}$ & Risk Ratio & Risk Ratio \\
\hline Study or Subgroup & Events & Total & Events & Total & M-H, Fixed, 95\% CI & M-H. Fixed. 95\% CI \\
\hline
\end{tabular}

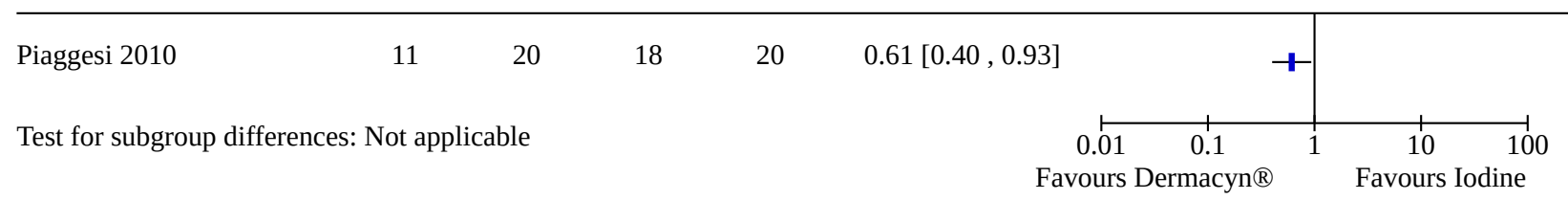

\section{Comparison 7. Triclosan compared with sodium hypochlorite}

\begin{tabular}{lllll}
\hline Outcome or subgroup title & No. of studies & $\begin{array}{l}\text { No. of partici- } \\
\text { pants }\end{array}$ & Statistical method & Effect size \\
\hline 7.1 Time to wound healing & 1 & Mean Difference (IV, Fixed, 95\% Cl) & Subtotals only \\
\hline $\begin{array}{l}7.2 \text { Adverse events (bleed- } \\
\text { ing/secretions) }\end{array}$ & 1 & Mean Difference (IV, Fixed, 95\% Cl) & Subtotals only \\
\hline
\end{tabular}




\begin{tabular}{lllll}
\hline Outcome or subgroup title & No. of studies & $\begin{array}{l}\text { No. of partici- } \\
\text { pants }\end{array}$ & Statistical method & Effect size \\
\hline 7.3 Pain & 1 & Mean Difference (IV, Fixed, 95\% CI) & Subtotals only \\
\hline
\end{tabular}

\section{Analysis 7.1. Comparison 7: Triclosan compared with sodium hypochlorite, Outcome 1: Time to wound healing}

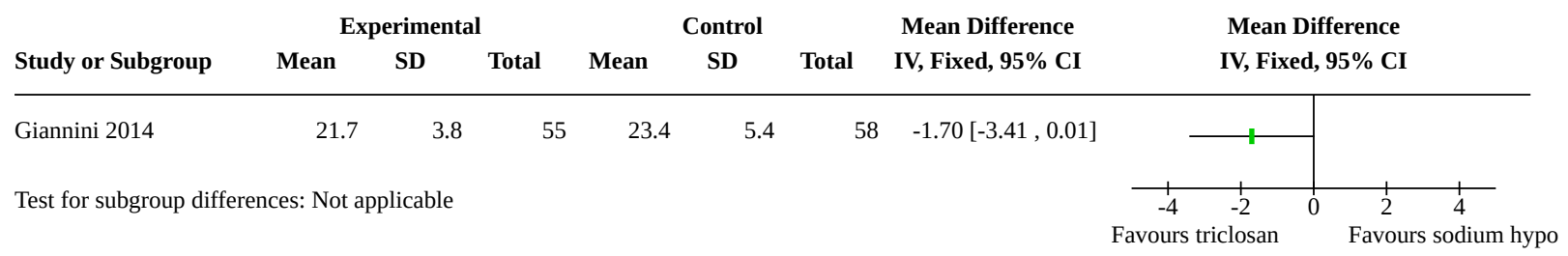

Analysis 7.2. Comparison 7: Triclosan compared with sodium hypochlorite, Outcome 2: Adverse events (bleeding/secretions)

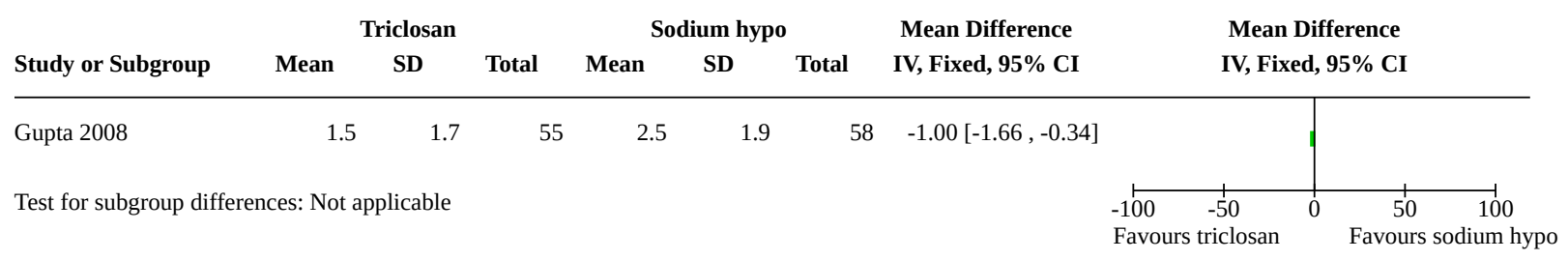

Analysis 7.3. Comparison 7: Triclosan compared with sodium hypochlorite, Outcome 3: Pain

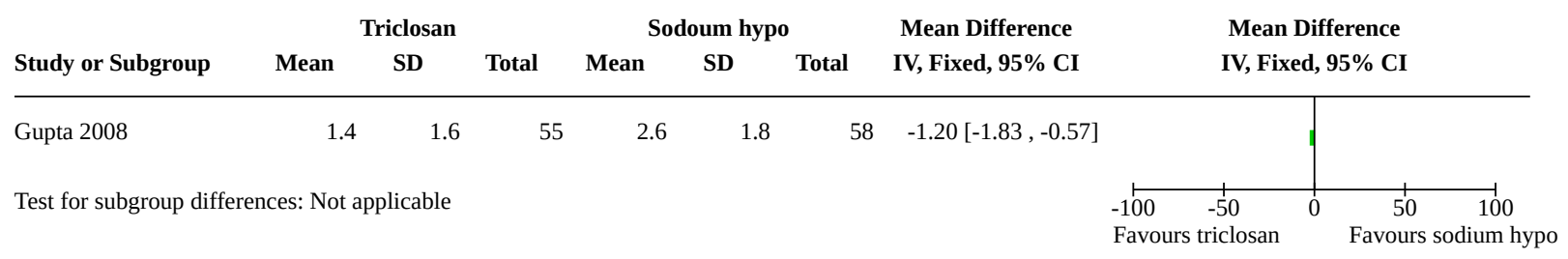




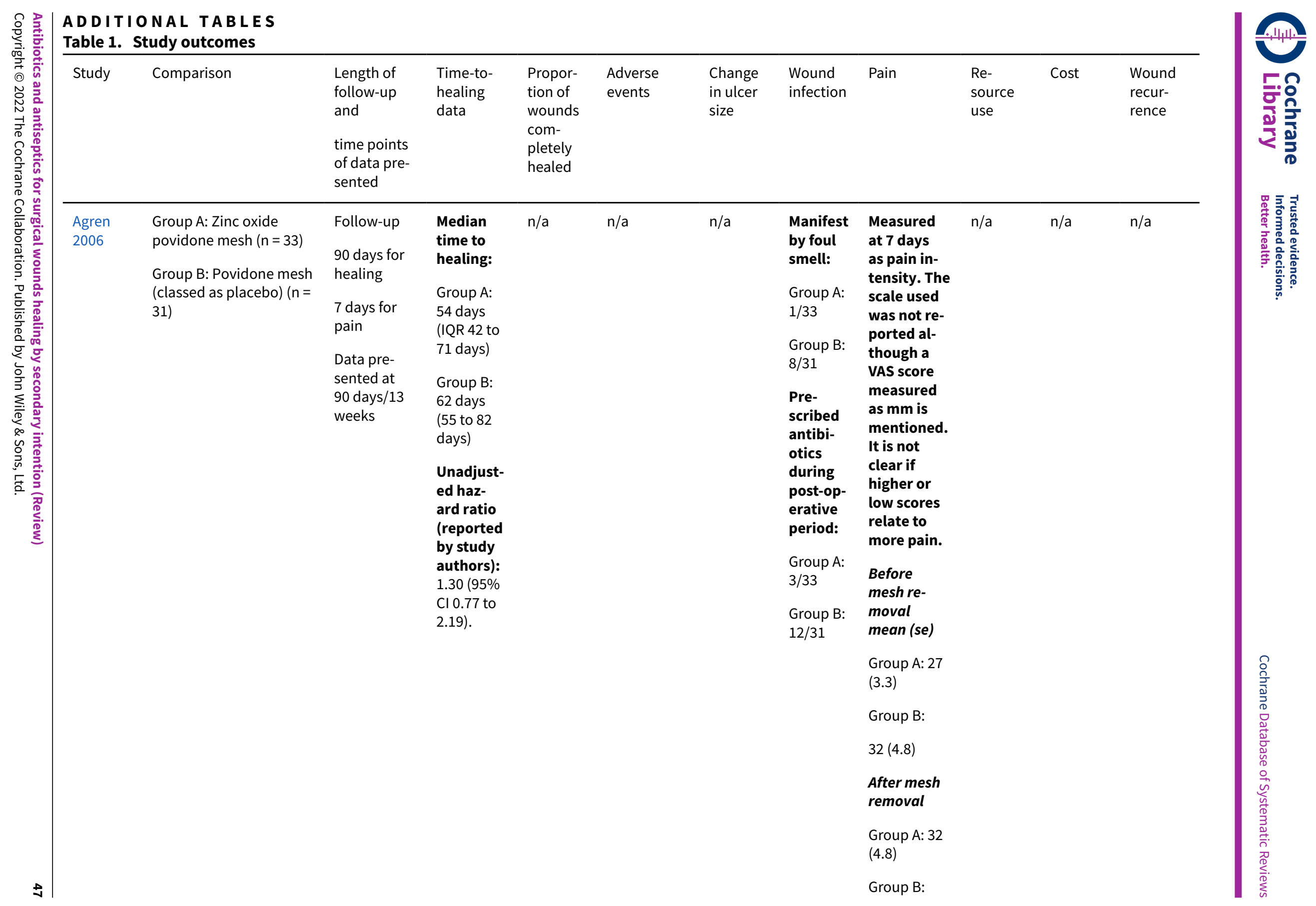




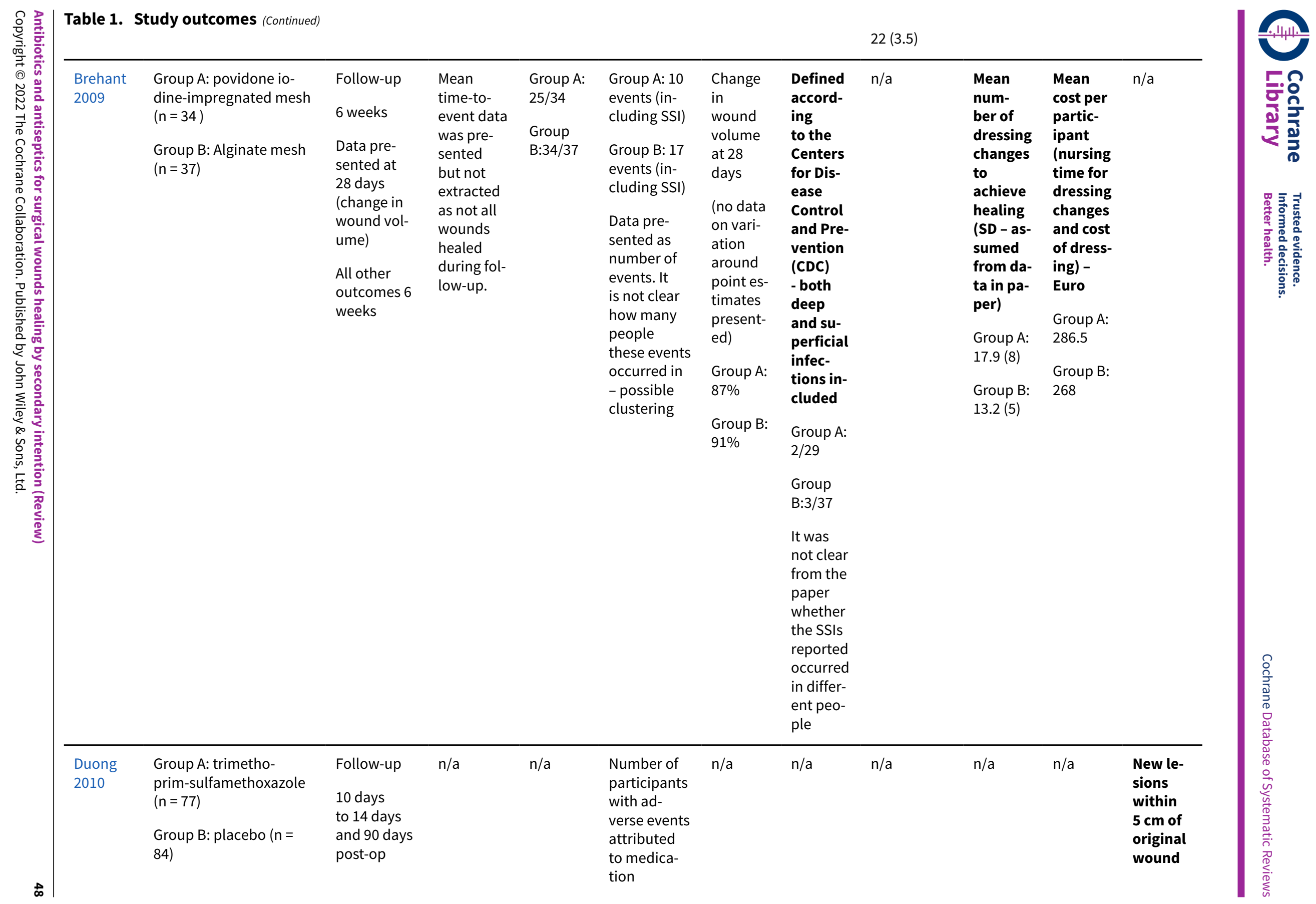




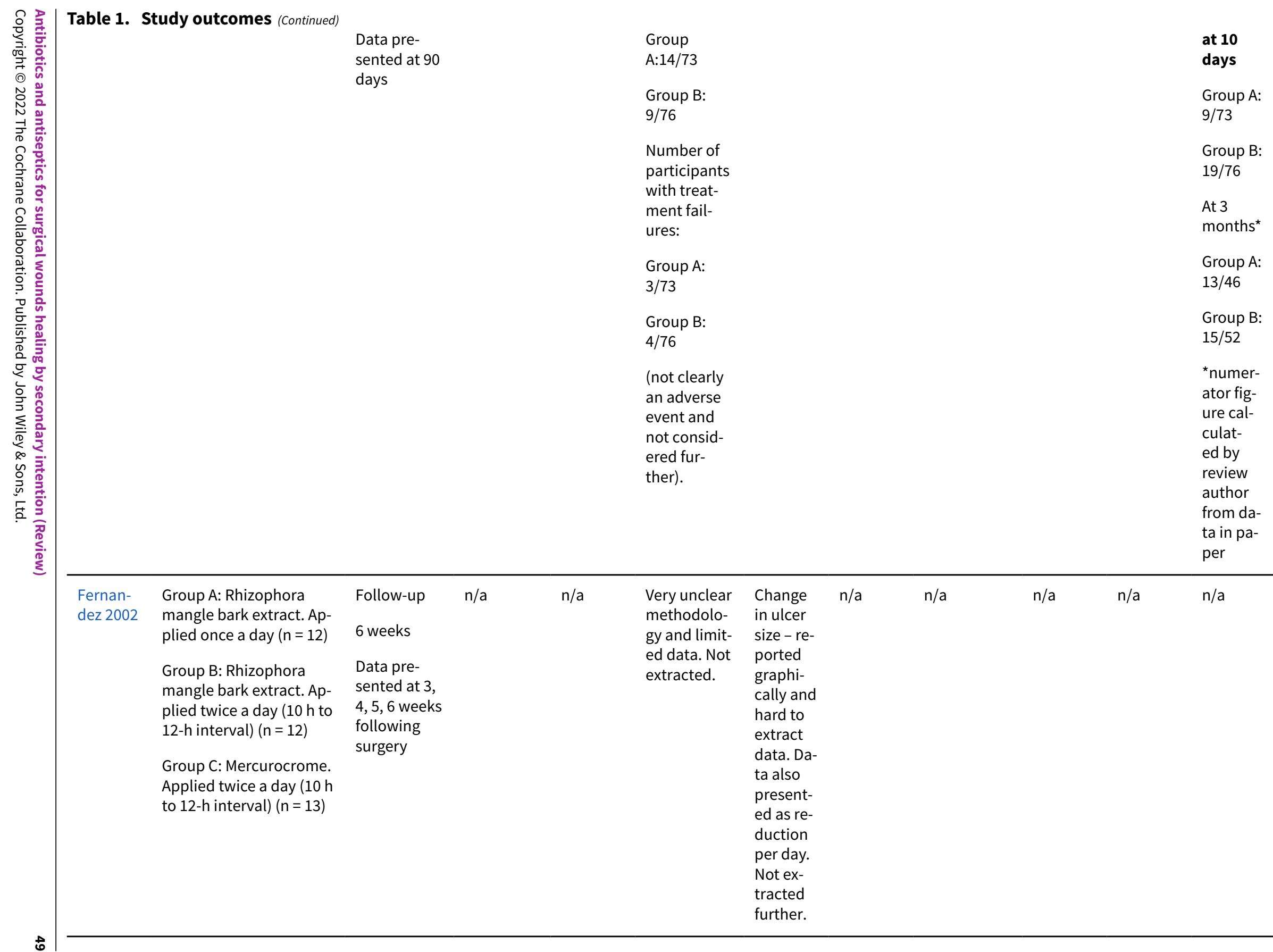




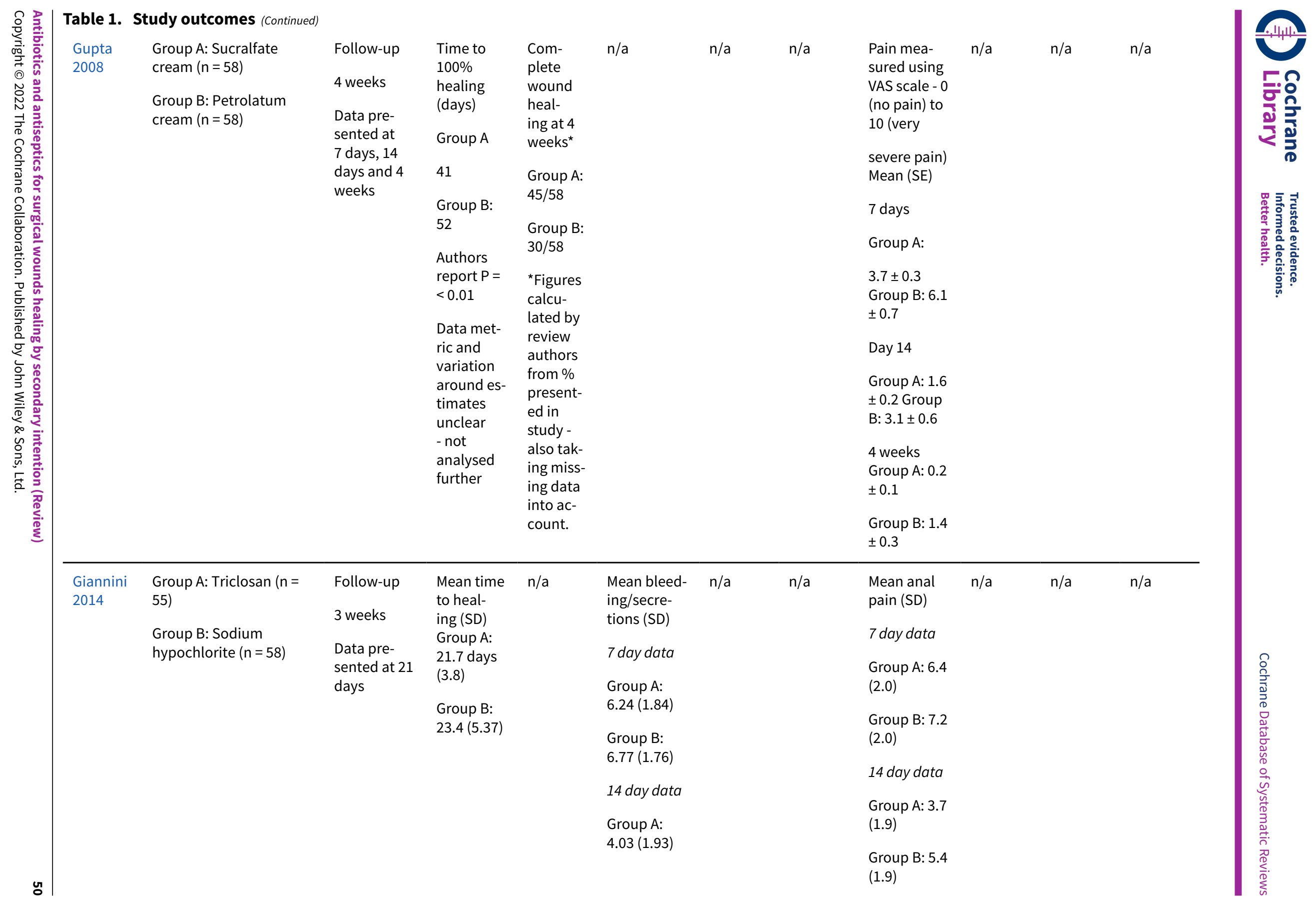




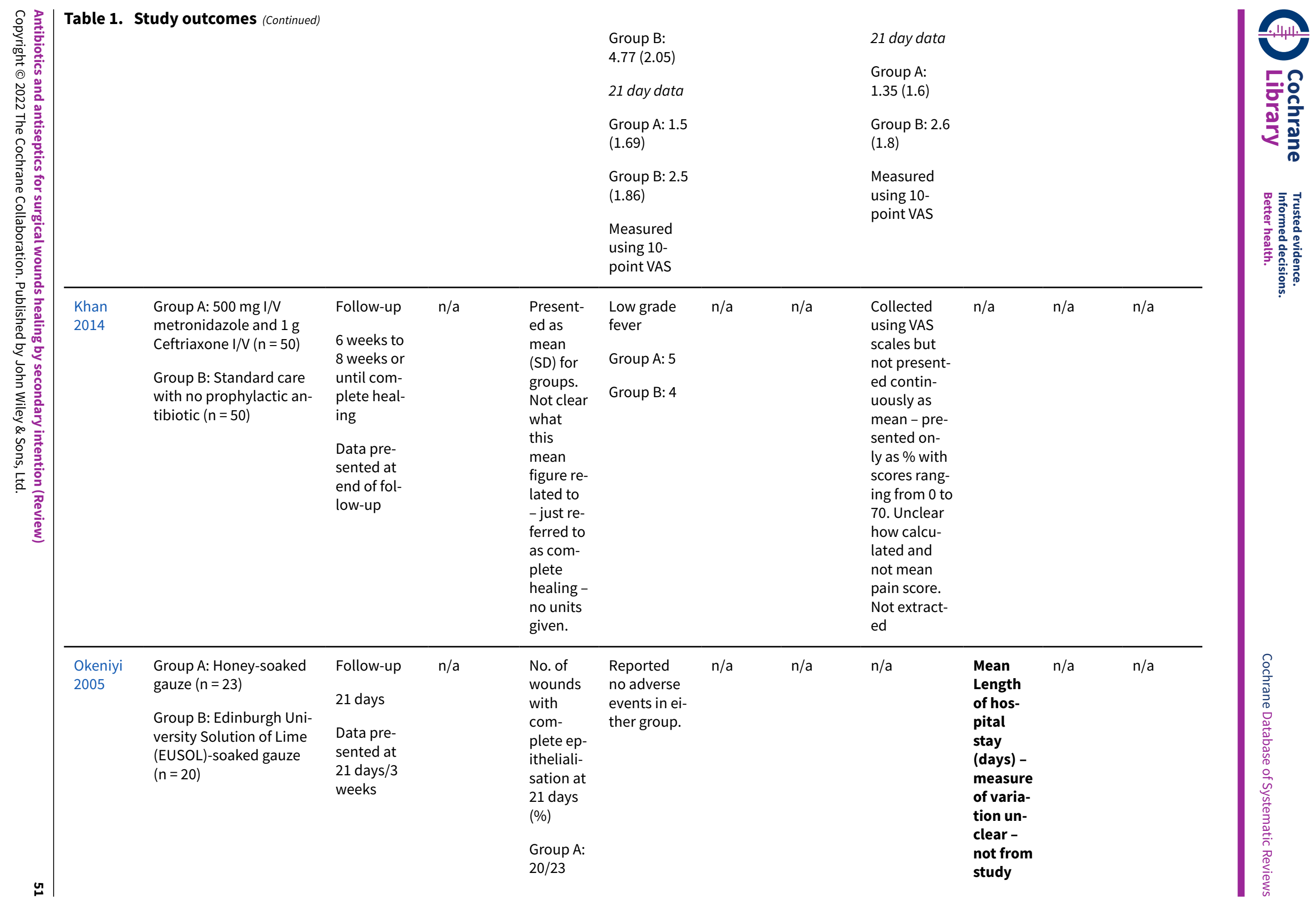




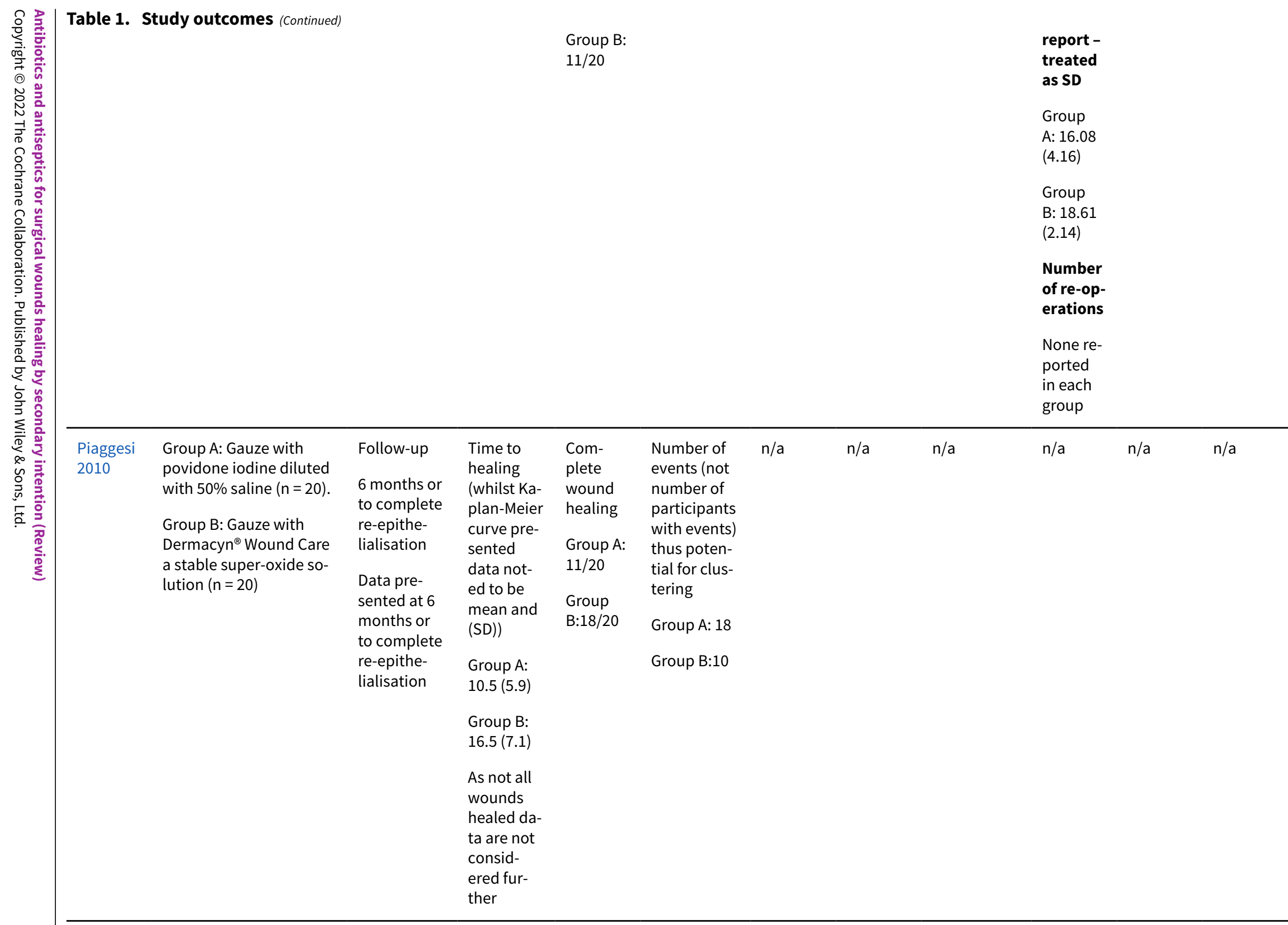




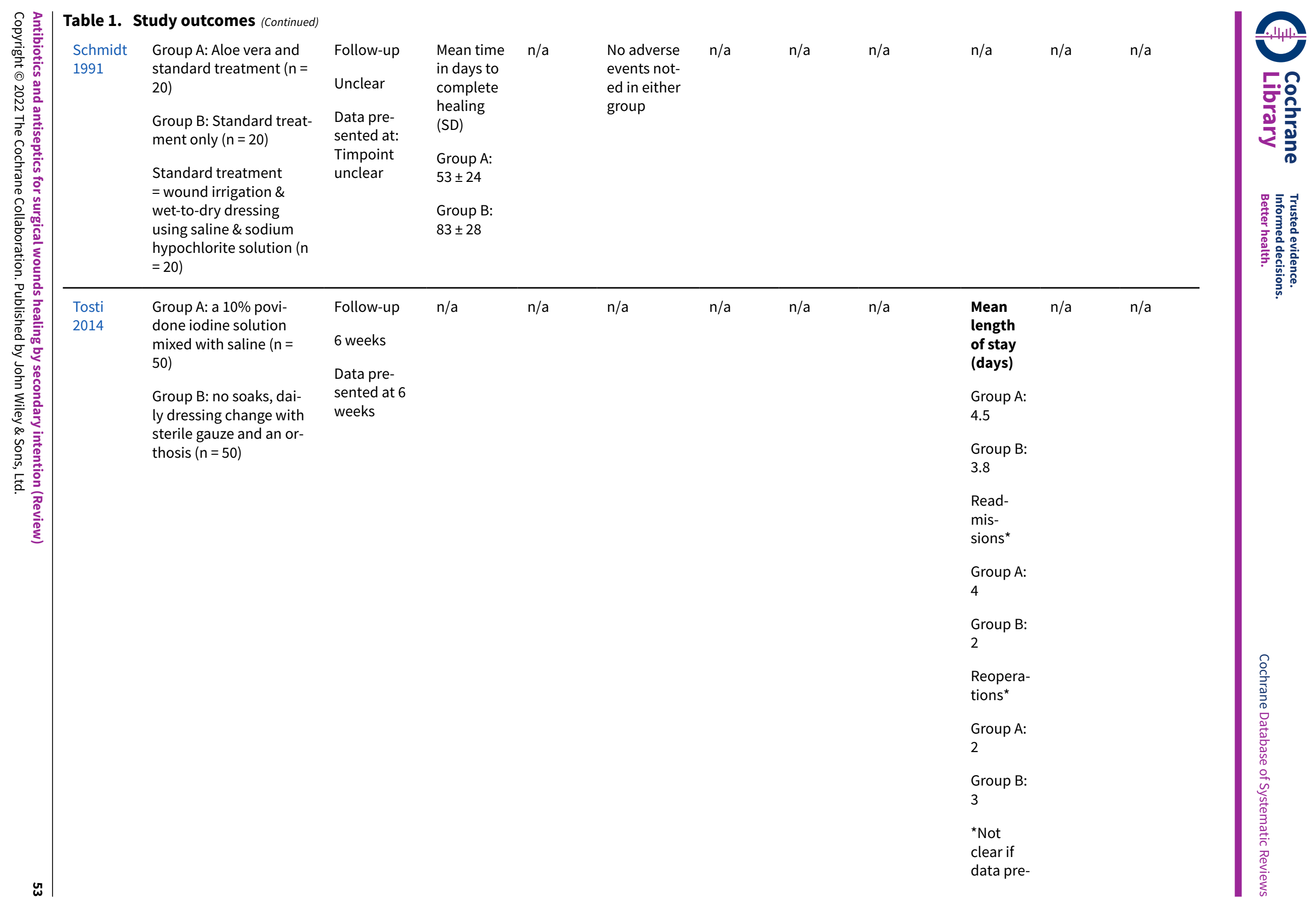




\section{APPENDICES}

\section{Appendix 1. Search Strategies}

\section{The Cochrane Central Register of Controlled Trials (CENTRAL) (The Cochrane Library)}

\#1 MeSH descriptor: [Anti-Infective Agents] explode all trees \#2 MeSH descriptor: [Penicillins] explode all trees \#3 MeSH descriptor: [Cephalosporins] explode all trees \#4 MeSH descriptor: [Aminoglycosides] explode all trees \#5 MeSH descriptor: [Quinolones] explode all trees \#6 MeSH descriptor: [Clindamycin] explode all trees \#7 MeSH descriptor: [Metronidazole] explode all trees \#8 MeSH descriptor: [Trimethoprim] explode all trees \#9 MeSH descriptor: [Mupirocin] explode all trees \#10 MeSH descriptor: [Neomycin] explode all trees \#11 MeSH descriptor: [Fusidic Acid] explode all trees \#12 MeSH descriptor: [Framycetin] explode all trees \#13 MeSH descriptor: [Polymyxins] explode all trees \#14 MeSH descriptor: [Chlortetracycline] explode all trees \#15 (antibiotic* or antimicrobial ${ }^{\star}$ or antibacterial ${ }^{\star}$ or penicillin ${ }^{\star}$ or cephalosporin* or aminoglycoside* or quinolone* or clindamycin or metronidazole or trimethoprim or mupirocin or pseudomonic acid or neomycin or fusidic acid or framycetin or polymyxin* or chlortetracycline):ti and (antibiotic* or antimicrobial* or antibacterial ${ }^{\star}$ or penicillin ${ }^{\star}$ or cephalosporin ${ }^{\star}$ or aminoglycoside* or quinolone ${ }^{\star}$ or clindamycin or metronidazole or trimethoprim or mupirocin or pseudomonic acid or neomycin or fusidic acid or framycetin or polymyxin* or chlortetracycline):ab (Word variations have been searched)

\#16 MeSH descriptor: [Antisepsis] explode all trees

$\# 17$ antiseptic*:ti and antiseptic*:ab (Word variations have been searched)

\#18 MeSH descriptor: [Soaps] explode all trees

\#19 MeSH descriptor: [lodophors] explode all trees

\#20 MeSH descriptor: [Chlorhexidine] explode all trees

\#21 MeSH descriptor: [Alcohols] explode all trees

\#22 MeSH descriptor: [Hydrogen Peroxide] explode all trees

\#23 MeSH descriptor: [Benzoyl Peroxide] explode all trees

\#24 MeSH descriptor: [Gentian Violet] explode all trees

\#25 MeSH descriptor: [Hypochlorous Acid] explode all trees

\#26 MeSH descriptor: [Hexachlorophene] explode all trees

\#27 MeSH descriptor: [Potassium Permanganate] explode all trees

\#28 MeSH descriptor: [Silver] explode all trees

\#29 MeSH descriptor: [Silver Sulfadiazine] explode all trees

\#30 MeSH descriptor: [Honey] explode all trees

\#31 (soap*1 or iodophor ${ }^{\star}$ or povidone or iodine or chlorhexidine or betadine or alcohol?1 or disinfectant* or hydrogen peroxide or benzoyl peroxide or gentian violet or hypochlorit* or eusol or dakin* or hexachlorophene or benzalkonium or potassium permanganate or silver sulfadiazine or silver sulphadiazine or honey ${ }^{\star}$ ):ti and (soap ${ }^{\star} 1$ or iodophor ${ }^{\star}$ or povidone or iodine or chlorhexidine or betadine or alcohol* 1 or disinfectant* or hydrogen peroxide or benzoyl peroxide or gentian violet or hypochlorit ${ }^{\star}$ or eusol or dakin ${ }^{\star}$ or hexachlorophene or benzalkonium or potassium permanganate or silver sulfadiazine or silver sulphadiazine or honey*):ab (Word variations have been searched)

$\# 32$ \{or \#1-\#31\}

\#33 MeSH descriptor: [Surgical Wound Infection] explode all trees

\#34 MeSH descriptor: [Surgical Wound Dehiscence] explode all trees

\#35 ( surg $^{\star}$ near/5 infect*):ti and (surg* near/5 infect*):ab (Word variations have been searched)

\#36 (surg* near/5 wound $\left.{ }^{\star}\right)$ :ti and (surg* near/5 wound $\left.{ }^{\star}\right)$ :ab (Word variations have been searched)

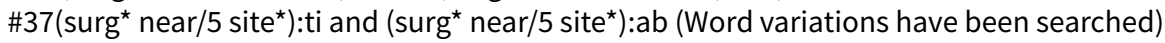

\#38 (surg* near/5 incision*):ti and (surg* near/5 incision*):ab (Word variations have been searched)

\#39 ( surg $^{\star}$ near/5 dehisc $\left.{ }^{\star}\right)$ :ti and ( surg* near/5 dehisc $\left.^{\star}\right):$ ab (Word variations have been searched)

\#40 (wound ${ }^{\star}$ near/5 dehisc $\left.{ }^{\star}\right):$ ti and (wound ${ }^{\star}$ near $/ 5$ dehisc $^{*}$ ):ab (Word variations have been searched)

\#41 (wound ${ }^{\star}$ near/5 infect $\left.{ }^{\star}\right)$ :ti and (wound ${ }^{\star}$ near/5 infect $\left.{ }^{\star}\right):$ ab (Word variations have been searched)

\#42 (wound near/5 disrupt $\left.{ }^{\star}\right)$ :ti and (wound near/5 disrupt $\left.{ }^{\star}\right)$ :ab (Word variations have been searched)

\#43 wound complication*:ti and wound complication*:ab (Word variations have been searched)

\#44 \{or \#33-\#43\}

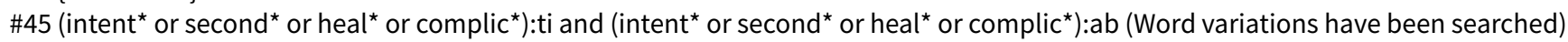
\#46 ((open* or clos $\left.{ }^{\star}\right)$ near/5 wound $\left.{ }^{\star}\right)$ :ti and ((open* or clos*) near/5 wound $\left.{ }^{\star}\right)$ :ab (Word variations have been searched) 
\#47 \{or \#45-\#46\}

\#48 \{and \#44, \#47\}

\#49 \{and \#32, \#48\} in Trials

\section{Ovid MEDLINE}

1 exp Anti-Infective Agents/

2 exp Penicillins/

3 exp Cephalosporins/

4 exp Aminoglycosides/

5 exp Quinolones/

6 exp Clindamycin/

7 exp Metronidazole/

8 exp Trimethoprim/

9 exp Mupirocin/

10 exp Neomycin/

11 exp Fusidic Acid/

12 exp Framycetin/

13 exp Polymyxins/

14 exp Chlortetracycline/

15 (antibiotic $^{\star}$ or antimicrobial* ${ }^{\star}$ or antibacterial ${ }^{\star}$ or penicillin ${ }^{\star}$ or cephalosporin* or aminoglycoside ${ }^{\star}$ or quinolone ${ }^{\star}$ or clindamycin or metronidazole or trimethoprim or mupirocin or pseudomonic acid or neomycin or fusidic acid or framycetin or polymyxin ${ }^{\star}$ or chlortetracycline).ti,ab.

16 exp Antisepsis/

17 antiseptic ${ }^{\star} . t i, a b$.

18 exp Soaps/

19 exp lodophors/

20 exp Chlorhexidine/

21 exp Alcohols/

22 exp Hydrogen Peroxide/

23 exp Benzoyl Peroxide/

24 exp Gentian Violet/

25 exp Hypochlorous Acid/

26 exp Hexachlorophene/

27 exp Potassium Permanganate/

28 exp Silver/

29 exp Silver Sulfadiazine/

30 exp Honey/

31 (soap $^{\star} 1$ or iodophor ${ }^{\star}$ or povidone or iodine or chlorhexidine or betadine or alcohol ${ }^{\star} 1$ or disinfectant* or hydrogen peroxide or benzoyl peroxide or gentian violet or hypochlorit* or eusol or dakin* or hexachlorophene or benzalkonium or potassium permanganate or silver sulfadiazine or silver sulphadiazine or honey $\left.{ }^{\star}\right)$.ti,ab.

32 or/1-31

33 exp Surgical Wound Infection/

34 exp Surgical Wound Dehiscence/

35 (surg* adj5 infect $^{\star}$ ).tw.

36 (surg* $^{\star}$ adj5 wound $\left.{ }^{\star}\right)$.tw.

37 (surg $^{\star}$ adj5 site $\left.{ }^{\star}\right)$.tw.

38 (surg $^{\star}$ adj5 incision $\left.{ }^{\star}\right)$.tw.

39 (surg* adj5 dehisc $\left.^{\star}\right)$.tw.

40 (wound $^{\star}$ adj5 dehisc ${ }^{\star}$ ).tw.

41 (wound $^{\star}$ adj5 infect $\left.{ }^{\star}\right)$.tw.

42 (wound adj5 disrupt $\left.{ }^{\star}\right)$.tw.

43 wound complication*.tw.

44 or/33-43

45 (intent $^{\star}$ or second ${ }^{\star}$ or heal ${ }^{\star}$ or complic ${ }^{\star}$ ).tw.

46 ((open* or clos $\left.^{\star}\right)$ adj5 wound $\left.{ }^{\star}\right)$.tw.

47 or/45-46

4844 and 47

4932 and 48

50 randomized controlled trial.pt.

51 controlled clinical trial.pt.

52 randomi?ed.ab. 
53 placebo.ab.

54 clinical trials as topic.sh.

55 randomly.ab.

56 trial.ti.

57 or/50-56

58 exp animals/ not humans.sh.

5957 not 58

6049 and 59

\section{Ovid EMBASE}

1 exp antiinfective agent/

2 exp penicillin derivative/

3 exp cephalosporin derivative/

4 exp aminoglycoside/

5 exp quinolone derivative/

6 exp clindamycin/

7 exp metronidazole/

8 exp trimethoprim/

9 exp pseudomonic acid/

10 exp neomycin/

11 exp fusidic acid/

12 exp framycetin/

13 exp polymyxin/

14 exp chlortetracycline/

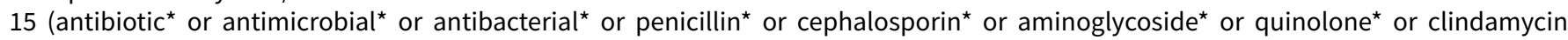
or metronidazole or trimethoprim or mupirocin or pseudomonic acid or neomycin or fusidic acid or framycetin or polymyxin* or chlortetracycline).ti,ab.

16 exp antisepsis/

17 antiseptic ${ }^{\star}$.ti,ab.

18 Soaps/

19 exp iodophor/

20 exp chlorhexidine/

21 exp alcohol derivative/

22 exp hydrogen peroxide/

23 exp benzoyl peroxide/

24 exp crystal violet/

25 exp hypochlorous acid/

26 exp hexachlorophene/

27 exp permanganate potassium/

28 exp silver/

29 exp sulfadiazine silver/

30 exp honey/

31 (soap $^{\star} 1$ or iodophor ${ }^{\star}$ or povidone or iodine or chlorhexidine or betadine or alcohol ${ }^{\star} 1$ or disinfectant ${ }^{\star}$ or hydrogen peroxide or benzoyl peroxide or gentian violet or hypochlorit* or eusol or dakin* or hexachlorophene or benzalkonium or potassium permanganate or silver sulfadiazine or silver sulphadiazine or honey $\left.{ }^{\star}\right) . \mathrm{ti}, \mathrm{ab}$.

32 or $/ 1-31$

33 exp surgical infection/

34 exp wound dehiscence/

35 (surg* adj5 infect $\left.^{\star}\right)$.tw.

36 (surg $^{\star}$ adj5 wound $\left.{ }^{\star}\right)$.tw.

37 (surg $^{\star}$ adj5 site $\left.{ }^{\star}\right)$.tw.

38 ( surg $^{\star}$ adj5 incision*).tw.

39 (surg* $^{\star}$ adj5 dehisc $\left.{ }^{\star}\right)$.tw.

40 (wound $^{\star}$ adj5 dehisc ${ }^{\star}$ ).tw.

41 (wound $^{\star}$ adj5 infect* ${ }^{\star}$ ).tw.

42 (wound adj5 disrupt*).tw.

43 wound complication*.tw.

44 or/33-43

45 (intent $^{\star}$ or second $^{\star}$ or heal $^{\star}$ or complic $\left.{ }^{\star}\right)$.tw.

46 ((open ${ }^{\star}$ or clos $\left.^{\star}\right) \operatorname{adj} 5$ wound $\left.{ }^{\star}\right)$.tw.

47 or/45-46 
4844 and 47

4932 and 48

50 Randomized controlled trials/

51 Single-Blind Method/

52 Double-Blind Method/

53 Crossover Procedure/

54 (random $^{\star}$ or factorial ${ }^{\star}$ or crossover ${ }^{\star}$ or cross over $^{\star}$ or cross-over ${ }^{\star}$ or placebo* or assign $^{\star}$ or allocat ${ }^{\star}$ or volunteer $\left.{ }^{\star}\right)$.ti,ab.

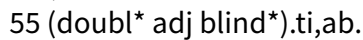

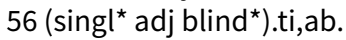

57 or $/ 50-56$

58 exp animals/ or exp invertebrate/ or animal experiment/ or animal model/ or animal tissue/ or animal cell/ or nonhuman/

59 human/ or human cell/

60 and/58-59

6158 not 60

6257 not 61

6349 and 62

\section{EBSCO CINAHL}

S60 S47 AND S59

$\mathrm{S} 59 \mathrm{~S} 48$ or $\mathrm{S} 49$ or $\mathrm{S} 50$ or $\mathrm{S} 51$ or $\mathrm{S} 52$ or $\mathrm{S} 53$ or $\mathrm{S} 54$ or $\mathrm{S} 55$ or $\mathrm{S} 56$ or $\mathrm{S} 57$ or $\mathrm{S} 58$

S58 MH "Quantitative Studies"

S57 TI placebo* or AB placebo*

S56 MH "Placebos"

S55 TI random* allocat* or AB random* allocat*

S54 MH "Random Assignment"

S53 TI randomi?ed control ${ }^{\star}$ trial $^{*}$ or $A B$ randomi?ed control ${ }^{\star}$ trial $^{*}$

S52 AB ( singl* or doubl* or trebl* or tripl*) and AB ( blind* or mask ${ }^{\star}$ )

S51 TI ( singl $l^{\star}$ or doubl* or trebl* or tripl ${ }^{\star}$ ) and TI ( blind ${ }^{\star}$ or mask ${ }^{\star}$ )

S50 II clinic $^{\star} \mathrm{N} 1$ trial $^{\star}$ or AB clinic ${ }^{\star} \mathrm{N} 1$ trial $^{\star}$

S49 PT Clinical trial

S48 MH "Clinical Trials+"

S47 S30 AND S46

S46 (S43 OR S44) AND (S42 AND S45)

S45 S43 OR S44

S44 TX ((open* or clos*) n5 wound $\left.{ }^{\star}\right)$

S43 TX (intent ${ }^{\star}$ or second ${ }^{\star}$ or heal* or complic $^{\star}$ )

S42 S31 OR S32 OR S33 OR S34 OR S35 OR S36 OR S37 OR S38 OR S39 OR S40 OR S41

S41 TX wound complication*

S40 TX (wound n5 disrupt*)

S39 TX (wound* $n 5$ infect ${ }^{\star}$ )

S38 TX (wound* $n 5$ dehisc*)

S37 TX (surg* n5 dehisc*)

S36 TX (surg* n5 incision $\left.{ }^{\star}\right)$

S35 TX (surg* n5 site*)

S34 TX (surg* $n 5$ wound $\left.{ }^{\star}\right)$

S33 TX (surg* $n 5$ infect*)

S32 (MH "Surgical Wound Dehiscence")

S31 (MH "Surgical Wound Infection")

S30 S1 OR S2 OR S3 OR S4 OR S5 OR S6 OR S7 OR S8 OR S9 OR S10 OR S11 OR S12 OR S13 OR S14 OR S15 OR S16 OR S17 OR S18 OR S19

OR S20 OR S 21 OR S22 OR S23 OR S24 OR S25 OR S26 OR S27 OR S28 OR S29

S29 TX (soap* or iodophor* or povidone or iodine or chlorhexidine or betadine or alcohol* or disinfectant* or hydrogen peroxide or benzoyl peroxide or gentian violet or hypochlorit* or eusol or dakin* or hexachlorophene or benzalkonium or potassium permanganate or silver sulfadiazine or silver sulphadiazine or honey*)

S28 (MH "Honey")

S27 (MH "Silver Sulfadiazine")

S26 (MH "Silver")

S25 (MH "Hexachlorophene")

S24 (MH "Hypochlorous Acid+")

S23 (MH "Gentian Violet")

S22 (MH "Peroxides+")

S21 (MH "Hydrogen Peroxide") 
S20 (MH "Alcohols+")

S19 (MH "Chlorhexidine")

S18 (MH "lodophors+")

S17 (MH "Soaps")

S16 TX antiseptic*

S15 (MH "Antiinfective Agents, Local+")

S14 TX (antibiotic ${ }^{\star}$ or antimicrobial* or antibacterial* or penicillin* or cephalosporin* or aminoglycoside* or quinolone* or clindamycin or metronidazole or trimethoprim or mupirocin or pseudomonic acid or neomycin or fusidic acid or framycetin or polymyxin* or chlortetracycline)

S13 (MH "Chlorthalidone")

S12 (MH "Polymyxins+")

S11 (MH "Fusidic Acid")

S10 (MH "Neomycin")

S9 (MH "Mupirocin")

S8 (MH "Trimethoprim+")

S7 (MH "Metronidazole")

S6 (MH "Clindamycin")

S5 (MH "Antiinfective Agents, Quinolone+")

S4 (MH "Aminoglycosides+")

S3 (MH "Cephalosporins+")

S2 (MH "Penicillins+")

S1 (MH "Antiinfective Agents+")

\section{Appendix 2. 'Risk of bias' assessment (cluster randomised controlled trials)}

In cluster randomised trials, particular biases to consider include: (i) recruitment bias; (ii) baseline imbalance; (iii) loss of clusters; (iv) incorrect analysis; and (v) comparability with individually randomised trials.

(i) Recruitment bias can occur when individuals are recruited to the trial after the clusters have been randomised, as the knowledge of whether each cluster is an 'intervention' or 'control' cluster could affect the types of participants recruited.

(ii) Cluster randomised trials often randomise all clusters at once, so lack of concealment of an allocation sequence should not usually be an issue. However, because small numbers of clusters are randomised, there is a possibility of chance baseline imbalance between the randomised groups, in terms of either the clusters or the individuals. Although not a form of bias as such, the risk of baseline differences can be reduced by using stratified or pair-matched randomisation of clusters. Reporting of the baseline comparability of clusters, or statistical adjustment for baseline characteristics, can help reduce concern about the effects of baseline imbalance.

(iii) Occasionally complete clusters are lost from a trial, and have to be omitted from the analysis. Just as for missing outcome data in individually randomised trials, this may lead to bias. In addition, missing outcomes for individuals within clusters may also lead to a risk of bias in cluster randomised trials.

(iv) Many cluster randomised trials are analysed by incorrect statistical methods, not taking the clustering into account. Such analyses create a 'unit of analysis error' and produce over-precise results (the standard error of the estimated intervention effect is too small) and $P$ values that are too small. They do not lead to biased estimates of effect. However, if they remain uncorrected, they will receive too much weight in a meta-analysis.

(v) In a meta-analysis including both cluster and individually randomised trials, or including cluster randomised trials with different types of clusters, possible differences between the intervention effects being estimated need to be considered. For example, in a vaccine trial of infectious diseases, a vaccine applied to all individuals in a community would be expected to be more effective than if the vaccine was applied to only half of the people. Another example is provided by discussion of a Cochrane review of hip protectors (Hahn 2005). The cluster trials showed large positive effect whereas individually randomised trials did not show any clear benefit. One possibility is that there was a 'herd effect' in the cluster randomised trials (which were often performed in nursing homes, where compliance with using the protectors may have been enhanced). In general, such 'contamination' would lead to underestimates of effect. Thus, if an intervention effect is still demonstrated despite contamination in those trials that were not cluster randomised, a confident conclusion about the presence of an effect can be drawn. However, the size of the effect is likely to be underestimated. Contamination and 'herd effects' may be different for different types of cluster.

\section{Appendix 3. 'Risk of bias' assessment (individually randomised controlled trials)}

1. Was the allocation sequence randomly generated?

Low risk of bias:

The investigators describe a random component in the sequence generation process, such as referring to a random number table; using a computer random number generator; tossing a coin; shuffling cards or envelopes; throwing dice; drawing lots. 
High risk of bias:

The investigators describe a non-random component in the sequence generation process. Usually, the description would involve some systematic, non-random approach, for example, sequence generated by odd or even date of birth; sequence generated by some rule based on date (or day) of admission; sequence generated by some rule based on hospital or clinic record number.

Unclear:

Insufficient information about the sequence generation process to permit judgement of low or high risk of bias.

2. Was the treatment allocation adequately concealed?

Low risk of bias:

Participants and investigators enrolling participants could not foresee assignment because one of the following, or an equivalent method, was used to conceal allocation: central allocation (including telephone, web-based and pharmacy-controlled randomisation); sequentially numbered drug containers of identical appearance; sequentially numbered, opaque, sealed envelopes.

High risk of bias:

Participants or investigators enrolling participants could possibly foresee assignments and thus introduce selection bias, such as allocation based on using an open random allocation schedule (e.g. a list of random numbers); assignment envelopes used without appropriate safeguards (e.g. if envelopes were unsealed or non-opaque or were not sequentially numbered); alternation or rotation; date of birth; case record number; any other explicitly unconcealed procedure.

Unclear:

Insufficient information to permit judgement of low or high risk of bias. This is usually the case if the method of concealment is not described or is not described in sufficient detail to allow a definitive judgement, for example, if the use of assignment envelopes is described, but it remains unclear whether envelopes were sequentially numbered, opaque and sealed.

3. Blinding (participants, personnel and outcome assessors) - was knowledge of the allocated interventions adequately prevented during the study?

Low risk of bias:

Any one of the following:

- No blinding, but the review authors judge that the outcome and the outcome measurement are not likely to be influenced by lack of blinding.

- Blinding of participants and key study personnel ensured, and unlikely that the blinding could have been broken.

- Either participants or some key study personnel were not blinded, but outcome assessment was blinded and the non-blinding of others is unlikely to introduce bias.

High risk of bias:

Any one of the following:

- No blinding or incomplete blinding, and the outcome or outcome measurement is likely to be influenced by lack of blinding.

- Blinding of key study participants and personnel attempted, but likely that the blinding could have been broken.

- Either participants or some key study personnel were not blinded, and the non-blinding of others is likely to introduce bias.

Unclear:

Any one of the following:

- Insufficient information to permit judgement of low or high risk of bias.

- The study did not address this outcome.

4. Were incomplete outcome data adequately addressed?

Low risk of bias:

Any one of the following:

- No missing outcome data.

- Reasons for missing outcome data unlikely to be related to true outcome (for survival data, censoring unlikely to be introducing bias).

- Missing outcome data balanced in numbers across intervention groups, with similar reasons for missing data across groups.

- For dichotomous outcome data, the proportion of missing outcomes compared with observed event risk not enough to have a clinically relevant impact on the intervention effect estimate.

- For continuous outcome data, plausible effect size (difference in means or standardised difference in means) among missing outcomes not enough to have a clinically relevant impact on observed effect size. 
- Missing data have been imputed using appropriate methods.

High risk of bias:

Any one of the following:

- Reason for missing outcome data likely to be related to true outcome, with imbalance in numbers or reasons for missing data across intervention groups.

- For dichotomous outcome data, the proportion of missing outcomes compared with observed event risk enough to induce clinically relevant bias in intervention effect estimate.

- For continuous outcome data, plausible effect size (difference in means or standardised difference in means) among missing outcomes enough to induce clinically relevant bias in observed effect size.

- 'As-treated' analysis done with substantial departure of the intervention received from that assigned at randomisation.

- Potentially inappropriate application of simple imputation.

Unclear:

Any one of the following:

- Insufficient reporting of attrition/exclusions to permit judgement of low or high risk of bias (e.g. number randomised not stated, no reasons for missing data provided).

- The study did not address this outcome.

5. Are reports of the study free of the suggestion of selective outcome reporting?

Low risk of bias:

Any one of the following:

- The study protocol is available and all of the study's prespecified (primary and secondary) outcomes that are of interest in the review have been reported in the prespecified way.

- The study protocol is not available but it is clear that the published reports include all expected outcomes, including those that were prespecified (convincing text of this nature may be uncommon).

High risk of bias:

Any one of the following:

- Not all of the study's prespecified primary outcomes have been reported.

- One or more primary outcomes are reported using measurements, analysis methods or subsets of the data (e.g. subscales) that were not prespecified.

- One or more reported primary outcomes were not prespecified (unless clear justification for their reporting is provided, such as an unexpected adverse effect).

- One or more outcomes of interest in the review are reported incompletely so that they cannot be entered in a meta-analysis.

- The study report fails to include results for a key outcome that would be expected to have been reported for such a study.

Unclear:

Insufficient information to permit judgement of low or high risk of bias. It is likely that the majority of studies will fall into this category.

6. Other sources of potential bias

Low risk of bias:

The study appears to be free of other sources of bias.

High risk of bias:

There is at least one important risk of bias. For example, the study:

- had a potential source of bias related to the specific study design used; or

- has been claimed to have been fraudulent; or

- had some other problem.

Unclear:

There may be a risk of bias, but there is either:

- insufficient information to assess whether an important risk of bias exists; or

- insufficient rationale or evidence that an identified problem will introduce bias.

Antibiotics and antiseptics for surgical wounds healing by secondary intention (Review) 
WHAT'S NEW

\begin{tabular}{lll}
\hline Date & Event & Description \\
\hline 21 April 2022 & Amended & Minor amendment made to Table 1 - Study outcomes. \\
\hline
\end{tabular}

\section{HISTORY}

Protocol first published: Issue 6, 2015

Review first published: Issue 3, 2016

\section{CONTRIBUTIONS OFAUTHORS}

Gill Norman: conceived and designed the review; checked the quality of data extraction; undertook and checked quality assessment; performed part of data analysis or interpretation; performed statistical analysis; completed the first draft of the review; approved the final version prior to submission.

Jo Dumville: conceived, designed and coordinated the review; extracted data; checked the quality of data extraction; analysed or interpreted data; undertook and checked quality assessment; performed statistical analysis; completed the first draft of the review; approved the final version prior to submission; secured funding; wrote to study authors / experts / companies; and is a guarantor of the review.

Devi Prasad Mohapatra: made an intellectual contribution to the review, advised on the review, and approved the final version of the review prior to submission.

Gemma Owens: extracted data; checked the quality of data extraction; undertook quality assessment; performed part of writing and editing the review; approved the final version prior to submission; advised on the review and wrote to study authors / experts / companies.

Emma Crosbie: checked the quality of statistical analysis; performed part of writing and editing the review; approved the final version prior to submission; and advised on the review.

\section{Contributions of editorial base:}

Julie Bruce: edited the review, advised on methodology, interpretation and content. Approved the final review prior to submission.

Sally Bell-Syer and Gill Rizzello: coordinated the editorial process. Advised on interpretation and content. Edited the review.

Rocio Rodriguez-Lopez: designed the search strategy. Reetu Child edited the search methods section and ran the searches.

\section{DECLARATIONS OF INTEREST}

Gill Norman: my employment at the University of Manchester is funded by NIHR and focuses on high priority Cochrane reviews in the prevention and treatment of wounds.

Jo Dumville: nothing to declare.

Devi Prasad Mohapatra: nothing to declare.

Gemma Owens: is a recipient of an MCRC Clinical Research Training Fellowship and previously received a Wellbeing of Women Entry Level Scholarship.

Emma Crosbie: is a Scientific Editor for BJOG, has received funding from an NIHR Clinician Scientist Award, the HTA, Wellbeing of Women/ the Wellcome Trust and Central Manchester University Hospitals NHS Foundation Trust. She is an employee of the University of Manchester.

\section{SOURCES OF SUPPORT}

\section{Internal sources}

- School of Nursing, Midwifery and Social Work, University of Manchester, UK 


\section{External sources}

- This project was supported by the National Institute for Health Research, via Cochrane Infrastructure and Cochrane Programme Grant funding (NIHR Cochrane Programme Grant 13/89/08 - High Priority Cochrane Reviews in Wound Prevention and Treatment) to Cochrane Wounds. The views and opinions expressed therein are those of the authors and do not necessarily reflect those of the Systematic Reviews Programme, NIHR, NHS or the Department of Health, UK

\section{DIFFERENCES BETWEEN PROTOCOLANDREVIEW}

We have amended the 'Summary of findings' section in the methods. The changes we made included the use of optimal information size (OIS) to inform the GRADE assessment of imprecision.

\section{INDEX TERMS}

\section{Medical Subject Headings (MeSH)}

Anti-Bacterial Agents [ ${ }^{*}$ therapeutic use]; Anti-Infective Agents, Local [ ${ }^{\star}$ therapeutic use]; lodine [therapeutic use]; Randomized Controlled Trials as Topic; Sucralfate [therapeutic use]; Surgical Mesh; ${ }^{\star}$ Surgical Procedures, Operative; Surgical Wound Infection [drug therapy]; Trimethoprim, Sulfamethoxazole Drug Combination [therapeutic use]; Wound Healing [ ${ }^{\star}$ drug effects]; Zinc Oxide [therapeutic use]

\section{MeSH check words}

Humans 